

\title{
2008 Wind Technologies Market Report
}

\author{
Primary authors \\ Ryan Wiser, Lawrence Berkeley National Laboratory \\ Mark Bolinger, Lawrence Berkeley National Laboratory \\ With contributions from
}

Galen Barbose, Andrew Mills, and Anna Rosa (Berkeley Lab); Kevin Porter and Sari Fink (Exeter Associates); Suzanne Tegen, Walt Musial, Frank Oteri, Donna Heimiller, and Billy Roberts (NREL); Kathy Belyeu and Ron Stimmel (AWEA)

\section{Table of Contents}

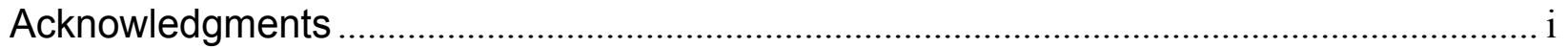

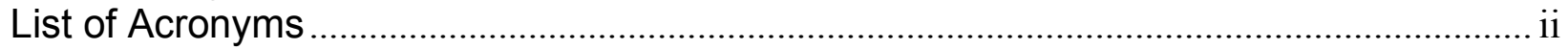

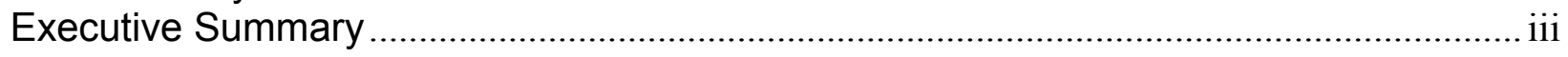

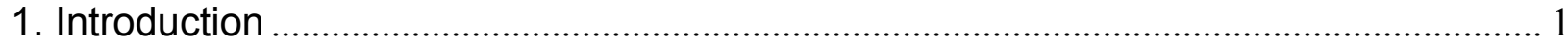

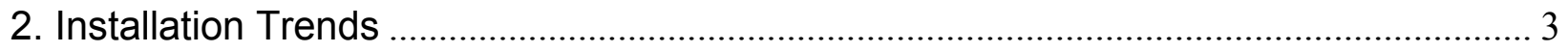

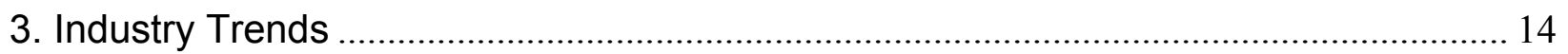

4. Price, Cost, and Performance Trends ..................................................................... 25

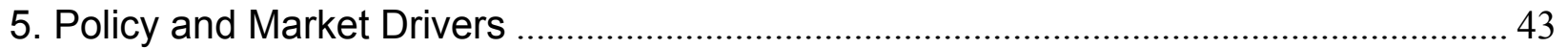

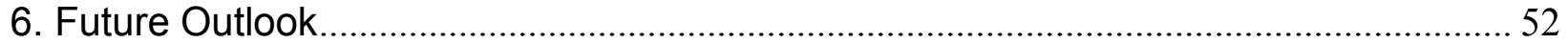

Appendix: Sources of Data Presented in this Report................................................. 55

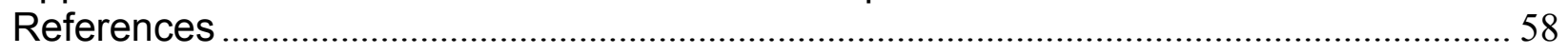

\section{Acknowledgments}

For their support of this project, the authors thank Megan McCluer, Jim Ahlgrimm, and Patrick Gilman of the U.S. DOE's Wind \& Hydropower Technologies Program. For reviewing elements of this paper, we thank: Lynn Coles and Erik Ela (NREL); Ed DeMeo (Renewable Energy Consulting Services); David Drescher and Matt Gredvig (John Deere Renewables); Michael Goggin (AWEA); Doug Larson (Western Interstate Energy Board); Megan McCluer, Jim Ahlgrimm, and Patrick Gilman (U.S. DOE); Chris Namovicz (EIA); Mike O'Sullivan (NextEra Energy Resources); Ryan Pletka and Ric O'Connell (Black \& Veatch); Charlie Smith (UWIG); Jim Walker (enXco); and Larry Willey (General Electric). Special thanks to the American Wind Energy Association for the use of their database of wind power projects, and for providing other data as discussed in the Appendix. Berkeley Lab's contributions to this report were funded by the Wind \& Hydropower Technologies Program, Office of Energy Efficiency and Renewable Energy of the U.S. Department of Energy under Contract No. DE-AC02-05CH11231. The authors are solely responsible for any omissions or errors contained herein. 


\section{List of Acronyms}

ARRA The American Recovery and Reinvestment Act of 2009

AWEA American Wind Energy Association

BPA Bonneville Power Administration

COD commercial operation date

CREB clean renewable energy bond

CREZ competitive renewable energy zone

DOE U.S. Department of Energy

EESA Emergency Economic Stabilization Act of 2008

EIA Energy Information Administration

ERCOT Electric Reliability Council of Texas

FERC Federal Energy Regulatory Commission

IOU investor-owned utility

IPP independent power producer

IRS internal revenue service

ISO independent system operator

IPO initial public offering

ITC investment tax credit

LBNL Lawrence Berkeley National Laboratory

MISO Midwest Independent System Operator

NERC North American Electric Reliability Corporation

NREL National Renewable Energy Laboratory

O\&M operations and maintenance

POU publicly owned utility

PPA power purchase agreement

PTC Production Tax Credit

R\&D research and development

REC renewable energy certificate

REPI renewable energy production incentive

RETI California's Renewable Energy Transmission Initiative

RPS renewables portfolio standard

RTO regional transmission organization

SPP Southwest Power Pool

USDA United States Department of Agriculture

WAPA Western Area Power Administration 


\section{Executive Summary}

The U.S. wind industry experienced a banner year in 2008, once again surpassing even optimistic growth projections from years past. At the same time, the past year has been one of upheaval, with the global financial crisis impacting near-term growth prospects for the wind industry, and with significant federal policy changes enacted to push the industry towards continued aggressive expansion. Key findings from this year's "Wind Technologies Market Report" include:

- U.S. Wind Power Additions Shattered Old Records in 2008, with 8,558 MW of New Capacity and \$16.4 Billion Invested. The pace of utility-scale wind development in 2008 was more than $60 \%$ higher than the previous U.S. record of 5,249 MW, set in 2007. To date, all wind power installations in the U.S. have been onshore, though there are now 11 "advanced-stage" offshore wind project proposals totaling more than 2,000 MW in various phases of development in U.S. waters.

- Wind Power Contributed 42\% of All New U.S. Electric Generating Capacity in 2008. This contribution is up from $35 \%$ in $2007,18 \%$ in $2006,12 \%$ in 2005 , and less than $4 \%$ from 2000 through 2004. For the fourth consecutive year, wind power was the second-largest new resource added to the U.S. electrical grid in terms of nameplate capacity, behind natural gas plants, but ahead of new coal.

- The U.S. Continued to Lead the World in Annual Capacity Growth, and Overtook Germany to Take the Lead in Cumulative Wind Capacity. For the fourth straight year, the United States led the world in wind capacity additions, capturing roughly $30 \%$ of the worldwide market. At the end of 2008, cumulative wind power capacity in the U.S. stood at 25,369 MW, ahead of Germany's 23,933 MW. Several countries are beginning to achieve relatively high levels of wind power penetration in their electricity grids: end-of-2008 installed wind is projected to supply roughly $20 \%$ of Denmark's electricity demand, $13 \%$ of Spain's, $12 \%$ of Portugal's, 9\% of Ireland's, and $8 \%$ of Germany's. In the United States, on the other hand, the cumulative wind capacity installed at the end of 2008 would, in an average year, be able to supply roughly $1.9 \%$ of the nation's electricity consumption.

- Texas Easily Exceeded Other States in Annual Capacity Growth. With 2,671 MW installed in 2008 alone, Texas dominated the 26 other states in which new large-scale wind turbines were installed in 2008 (the next highest being Iowa with 1,600 MW and Minnesota with $456 \mathrm{MW})$. In terms of wind penetration, however, Texas is less-notable, with end-of2008 wind capacity supplying an estimated $5.3 \%$ of in-state generation, well below frontrunners Iowa (13.3\%) and Minnesota (10.4\%). Some individual utilities are seeing even higher penetrations, with six utilities having in excess of $10 \%$ wind on their systems.

- Data from Interconnection Queues Demonstrate that an Enormous Amount of Wind Capacity Is Under Development. At the end of 2008, even after reforms to reduce the number of speculative projects in their queues, there were nearly $300 \mathrm{GW}$ of wind power capacity within the twelve transmission interconnection queues reviewed for this report more than 11 times the installed wind capacity in the U.S. at the end of 2008. This wind capacity represented more than half of all generating capacity within these queues at that time, and was more than twice as much capacity as the next-largest resource in these queues (natural gas). Though clearly not all of this capacity will ultimately be built as planned, it nevertheless demonstrates the high level of developer interest in wind power. 
- GE Wind Remained the Top Turbine Manufacturer in the U.S. Market, but a Growing Number of Other Manufacturers Are Capturing Market Share. GE captured 43\% of U.S. market share (by capacity) in 2008, followed by Vestas (13\%), Siemens (9\%), Suzlon (9\%), Gamesa (7\%), Clipper (7\%), and Mitsubishi (6\%). A number of international turbine manufacturers entered the U.S. market for the first time with installations in 2008, including Acciona (5\%), Repower (1\%), and Fuhrlander, CTC/DeWind, and AWE ( $<1 \%$ combined).

- Soaring Demand for Wind Spurred Expansion of U.S. Wind Turbine Manufacturing. The number of utility-scale wind turbine manufacturers assembling nacelles in the U.S. increased from just one in 2004 (GE) to five in 2008 (GE, Gamesa, Clipper, Acciona, CTC/DeWind), with five additional manufacturers publicly announcing the location of future assembly plants. In addition, a considerable number of new component manufacturing facilities in the U.S. were either opened or announced in 2008. As a result of this continued expansion, AWEA estimates that the share of domestically manufactured wind turbine components has grown from less than $30 \%$ in 2005 to roughly $50 \%$ in 2008 . This scale-up is also creating a number of new jobs; AWEA estimates that roughly 8,400 new domestic manufacturing jobs were added in the wind sector in 2008.

- Despite a Slight Increase in Average Turbine Size, the Average Size of Wind Projects Decreased in 2008. The average size of wind turbines installed in the United States in 2008 was roughly 1.67 MW, up slightly from 1.65 MW in 2007 and $1.60 \mathrm{MW}$ in 2006. Wind projects installed in 2008 averaged nearly $83 \mathrm{MW}$, which is below the $120 \mathrm{MW}$ average size for projects built in 2007, but is otherwise larger than in any previous period.

- Developer Consolidation Slowed in 2008. At least five significant acquisition or investment transactions involving roughly $19 \mathrm{GW}$ of in-development wind projects were announced in 2008, well below the 11 transactions and $37 \mathrm{GW}$ in 2007, and the 12 transactions and $34 \mathrm{GW}$ in 2006. The slowdown in consolidation in 2008 may be a reflection of the financial crisis, as well as the simple fact that many of the prime targets for investment and/or acquisition had already been acquired in earlier years.

- The Global Credit Crisis Caught Up With the Wind Sector in 2008. The unfolding financial crisis caused the outright demise of several prominent tax equity investors in wind projects (e.g., Lehman Brothers and Wachovia), and led to the general exodus of many others, such that only a handful of tax equity investors remained active (and on less-favorable terms) at the end of 2008. As a result, tax equity investment in the U.S. wind market actually declined in 2008, despite the record-shattering growth in installed capacity. Other sources of finance were also hit hard in 2008 - e.g., bank lending reportedly ground to a halt in late 2008. Spurred by a number of federal policy changes as well as a general thawing of credit, conditions appear to be improving somewhat as of mid-2009.

- Though IPP Project Ownership Remained Dominant, Utility Ownership Expanded. Private independent power producers (IPPs) own 79\% of all new wind capacity installed in the U.S. in 2008 , and $83 \%$ of cumulative capacity. In a continuation of the trend begun several years ago, however, 19\% of total wind additions in 2008 are owned by electric utilities, who now own $15 \%$ of cumulative wind capacity in the U.S.

- Though Long-Term Contracted Sales to Utilities Remained the Most Common OffTake Arrangement, Merchant Plants Were Popular in 2008. Investor-owned utilities continued to be significant purchasers of wind power, with $33 \%$ of new 2008 capacity and $47 \%$ of cumulative capacity selling power to these utilities under long-term contract. In what has been a growing trend, the owners of $43 \%$ of the wind power capacity added in 2008 
(primarily in Texas, New York, and several mid-Atlantic and Midwestern states) are accepting some merchant risk, bringing merchant/quasi-merchant ownership to $23 \%$ of total cumulative U.S. wind capacity. With wholesale power prices plummeting in late 2008 and through the first half of 2009, however, merchant activity is expected to diminish in the immediate future.

- Upward Pressure on Wind Power Prices Continued in 2008. Although many of the cost pressures facing the industry in recent years began to ease in the second half of 2008, it will take some time before these effects flow through the project development pipeline to impact wind power prices. As such, 2008 was another year of rising wind power prices. The capacity-weighted average 2008 sales price for power and renewable energy certificates from projects in the sample built in 2008 was roughly \$51.5/MWh (in 2008 dollars), up from an average of $\$ 43.2 / \mathrm{MWh}$ for the sample of projects built in 2007, and $\$ 20.6 / \mathrm{MWh}$ higher than the average of $\$ 30.9 / \mathrm{MWh}$ among projects built at the low point in 2002 and 2003. Among projects in the sample, those in Texas and the Heartland have the lowest prices on average, while those in the East and New England have the highest prices.

- Wind Remained Competitive in Wholesale Power Markets in 2008, but 2009 Is Likely To Be More Challenging. Despite moving higher in 2008, average wind power prices remained at or below the low end of the wholesale power price range. In other words, rising wholesale power prices through 2008 have, to a degree, mitigated the impact of rising wind power prices on wind's competitive position. With wholesale prices plummeting at the end of 2008 and into 2009, however, the economic position of wind in the near- to medium-term has become more challenging.

- Installed Project Costs Continued to Rise in 2008, After a Long Period of Decline. Among a sample of $72 \%$ of all wind capacity installed in 2008, reported installed costs had a capacity-weighted average of $\$ 1,915 / \mathrm{kW}$. This average is up $\$ 190 / \mathrm{kW}(11 \%)$ from the weighted-average cost of installed projects in 2007 , and is up $\$ 630 / \mathrm{kW}(49 \%)$ from the average cost of projects installed from 2001 through 2004. The average reported cost from a sample of more than 3,600 MW of projects likely to be built in 2009 is $\$ 2,120 / \mathrm{kW}$, or $\$ 205 / \mathrm{kW}$ higher than for projects completed in 2008 .

- After Increasing Dramatically in Recent Years, Turbine Prices Showed Signs of Easing in Late 2008. Since hitting a low point of roughly $\$ 700 / \mathrm{kW}$ in the $2000-2002$ period, turbine prices have increased by approximately $\$ 700 / \mathrm{kW}(100 \%)$, on average, through 2008 . Between 2007 and 2008, capacity-weighted average turbine prices increased by roughly $\$ 90 / \mathrm{kW}(7 \%)$, from $\$ 1,270 / \mathrm{kW}$ to $\$ 1,360 / \mathrm{kW}$. Increases in turbine prices over this period have been caused by several factors, including the declining value of the U.S. dollar relative to the Euro, increased materials and energy input prices, a general move by manufacturers to improve their profitability, shortages in certain turbine components, an up-scaling of turbine size (and hub height), and improved sophistication of turbine design (e.g., improved grid interactions). With a number of these drivers having experienced sharp trend reversals since mid-2008, evidence of softening turbine prices began to emerge in late 2008.

- Wind Project Performance Has Improved Over Time, But Has Leveled Off in Recent Years. The capacity-weighted average 2008 capacity factor among a sizable sample of installed wind projects increased from $22 \%$ for those projects installed before 1998 to roughly 30\%-33\% for projects installed from 1998-2003, and to roughly 35\%-37\% for projects installed from 2004-2007. Despite this general improvement among more recently built projects, the capacity-weighted-average 2008 capacity factor for projects installed in 
2007 (35.0\%) was down slightly from that for projects installed in 2006 (35.2\%), which in turn was somewhat lower than for projects built in 2004-2005 (36.9\%).

- Operations and Maintenance Costs Are Affected by the Age and Size of the Project, Among Other Factors. Despite limited data availability, it appears that projects installed more recently have, on average, incurred lower O\&M costs than older projects. Likewise, larger projects appear to experience lower O\&M costs than do smaller projects, and O\&M costs increase as projects age.

- The Policy Landscape Is Now More Favorable to Wind Than At Any Other Time in the Past Decade. At the federal level, The American Recovery and Reinvestment Act of 2009 (ARRA 2009) extended the Production Tax Credit (PTC) for wind through 2012. ARRA 2009 also implemented a number of other important policy changes, most notably an option to elect a 30\% Investment Tax Credit (ITC) or cash grant in lieu of the PTC, and the expansion and enhancement of a federal loan guarantee program managed by the DOE. At the state level, three new states established mandatory RPS programs in 2008 (Michigan, Missouri, and Ohio), and Kansas did so in May 2009, bringing the total to 29 states and Washington D.C.

- Despite Progress on Overcoming Transmission Barriers, Constraints Remain. At the federal level, the U.S. Congress is considering transferring additional transmission siting authority from states to FERC, and FERC itself has continued to press for modifications to interconnection queuing procedures. States, grid operators, and regional entities also continue to take proactive steps to encourage transmission investment to access remote renewable resources. Most notable among these is a growing list of entities engaged in identifying "renewable energy zones" to which transmission could be built. Progress was also made in 2008 on nearly twenty large transmission projects in the central and western U.S. that are designed, in part, to support wind power.

- Integrating Wind into Power Systems Is Manageable, but Not Costless, and Market Operators Are Developing Methods to Accommodate Increased Penetration. Recent wind integration studies continue to show that wind integration costs rise with higher levels of wind penetration, but are below $\$ 10 / \mathrm{MWh}$ - and often below $\$ 5 / \mathrm{MWh}$ - for wind capacity penetrations of as much as $30 \%$ of the peak load of the system in which the wind power is delivered. Moreover, a number of strategies that can help to ease the integration of increasing amounts of wind - including the use of larger balancing areas, the use of regional wind power forecasts to inform operational decisions, and intra-hour scheduling - are being implemented by grid operators across the U.S.

In conclusion, 2008 continued a string of record-breaking years for the U.S. wind industry, which has put the U.S. ahead of schedule vis-à-vis the deployment path laid out by the U.S. Department of Energy (2008) to reach $20 \%$ wind penetration by 2030 . Looking ahead, expectations are for a slower year in 2009, in large part due to the impact of the global recession. Projections among industry prognosticators range from 4,400 MW to 6,800 MW of wind likely to be installed in the U.S. in 2009 (AWEA has already reported that more than 2,800 MW came online in the first quarter of 2009). After a slower 2009, most predictions show market resurgence in 2010 and continuing for the immediate future, as the ARRA 2009 policy changes come into full swing, and as financing constraints are relieved. If realized, these near-term projections would maintain the nation's early progress towards meeting $20 \%$ of its electricity demand with wind power by 2030 . 


\section{Introduction}

The U.S. wind industry experienced a banner year in 2008, again surpassing even optimistic growth projections from years past. At the same time, the last year has been one of upheaval, with the global financial crisis impacting near-term growth prospects for the wind industry, and with federal policy changes enacted to push the industry towards continued aggressive expansion. This rapid pace of development has made it difficult to keep up with trends in the marketplace. Yet, the need for timely, objective information on the industry and its progress has never been greater. This report - the third of an ongoing annual series - attempts to meet this need by providing a detailed overview of developments and trends in the U.S. wind power market, with a particular focus on 2008 .

As with previous editions, this report begins with an overview of key wind power installationrelated trends: trends in wind capacity growth in the U.S., how that growth compares to other countries and generation sources, the amount and percentage of wind in individual states and serving specific utilities, and the quantity of proposed wind capacity in various interconnection queues in the United States. Next, the report covers an array of wind industry trends, including developments in turbine manufacturer market share, manufacturing and supply-chain investments, wind turbine and wind project size, project financing developments, and trends among wind power developers, project owners, and power purchasers. The report then turns to a discussion of wind project price, cost, and performance trends. In so doing, it reviews the price of wind power in the United States, and how those prices compare to the cost of fossil-fueled generation, as represented by wholesale power prices. It also describes trends in installed wind project costs, wind turbine transaction prices, project performance, and operations and maintenance expenses. Next, the report examines other policy and market factors impacting the domestic wind power market, including federal and state policy drivers, transmission issues, and grid integration. Finally, the report concludes with a preview of possible near- to medium-term market developments.

This version of the Annual Report updates data presented in the previous editions, while highlighting key trends and important new developments from 2008. New to this edition is an executive summary of the report and an expanded final section on near- to medium-term market development. The report concentrates on larger-scale wind applications, defined here as individual turbines or projects that exceed $50 \mathrm{~kW}$ in size. The U.S. wind power sector is multifaceted, however, and also includes smaller, customer-sited wind turbines used to power the needs of residences, farms, and businesses. Data on these applications are not the focus of this report, though a brief discussion on Distributed Wind Power is provided on page 4.

Much of the data included in this report were compiled by Berkeley Lab, and come from a variety of sources, including the American Wind Energy Association (AWEA), the Energy Information Administration (EIA), and the Federal Energy Regulatory Commission (FERC). The Appendix provides a summary of the many data sources used in the report. Data on 2008 wind capacity additions in the United States are based on information provided by AWEA; some minor adjustments to those data may be expected. In other cases, the data shown here represent only a sample of actual wind projects installed in the United States; furthermore, the data vary in quality. As such, emphasis should be placed on overall trends, rather than on individual data 
points. Finally, each section of this document focuses on historical market information, with an emphasis on 2008; with the exception of the final section, the report does not seek to forecast future trends. 


\section{Installation Trends}

\section{U.S. Wind Power Additions Shattered Old Records in 2008, with 8,558 MW of New Capacity and \$16.4 Billion Invested}

The U.S. wind power market delivered a record-shattering year in 2008, with 8,558 MW (i.e., $8.558 \mathrm{GW}$ ) of new capacity added, bringing the cumulative total to $25,369 \mathrm{MW}$ (Figure 1). ${ }^{1}$ This growth translates into roughly $\$ 16.4$ billion (real 2008 dollars) invested in wind project installation in 2008 , for a cumulative total of nearly $\$ 45$ billion since the 1980 s. $^{2}$

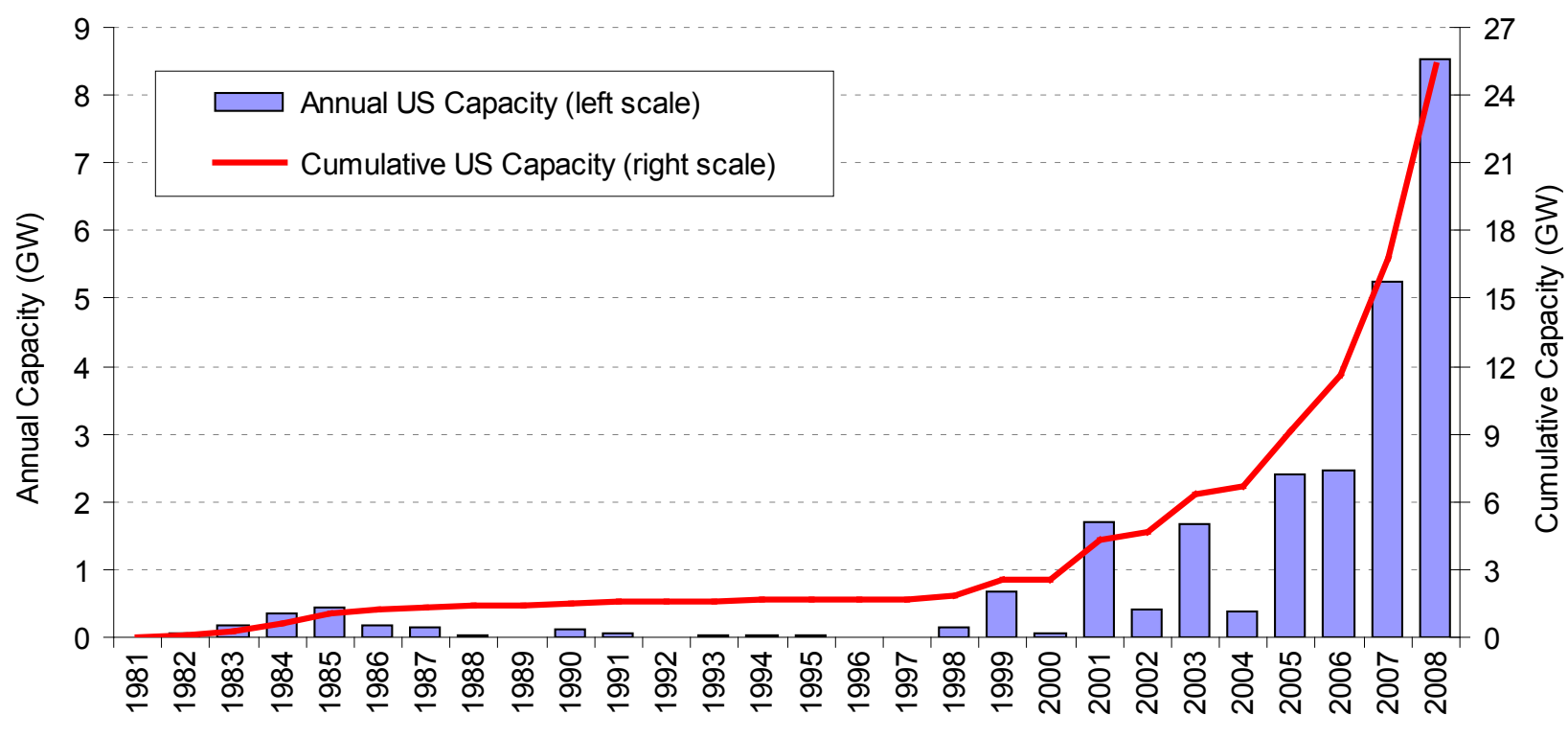

Source: AWEA

Figure 1. Annual and Cumulative Growth in U.S. Wind Power Capacity

Wind installations in 2008 were not only the largest on record in the U.S., but were more than $60 \%$ higher than the previous U.S. record, set in 2007. As in 2007, no country, in any single year, has added as much wind capacity as was added to the U.S. electrical grid in 2008. A thenscheduled expiration of the federal production tax credit at the end of 2008, state renewables portfolio standards (RPS), concerns about global climate change, and continued uncertainty about the future costs and liabilities of natural gas and coal facilities helped spur this intensified growth.

The yearly boom-and-bust cycle that characterized the U.S. wind market from 1999 through 2004 - caused by periodic, short-term extensions of the federal production tax credit (PTC) - has now been replaced by four consecutive years of sizable growth. With the PTC now extended through 2012, significant capacity additions and a semblance of medium-term market stability

\footnotetext{
${ }^{1}$ The net increase in wind capacity in 2008 was 8,545 MW, as some existing capacity was decommissioned. When reporting 2008 additions, this report focuses on gross capacity (i.e., 8,558 MW).

2 These investment figures are based on an extrapolation of the average project-level capital costs reported later in this report, and do not include investments in manufacturing facilities, R\&D expenditures, or O\&M costs.
} 
might be expected. At the same time, with the global financial crisis constraining the supply of available capital for project finance, most expect a slower pace of development in 2009, despite policy changes enacted in early 2009 intended to push the industry back towards aggressive expansion.

\section{Distributed Wind Power}

Wind turbines installed on the distribution side of the electric grid can provide power directly to homes, farms, schools, businesses, and industrial facilities; distributed wind turbines can also provide power to offgrid sites (see, e.g., Forsyth and Baring-Gould 2007). Distributed wind turbines are generally much smaller than the larger-scale turbines that are the focus of this report, ranging in size from a few hundred watts to up to $100 \mathrm{~kW}$ or more. Growth in this sector has been driven - at least in part - by a variety of state incentive programs.

The table below summarizes sales of distributed wind turbines from $300 \mathrm{~W}$ to $100 \mathrm{~kW}$ in size into the U.S. market in 2008. As shown, more than $17 \mathrm{MW}$ of distributed wind turbines were sold in the U.S. in 2008, with a majority (in capacity terms) used in grid-connected applications; most of this new capacity came from turbines manufactured by U.S. companies. These installation figures represent a $78 \%$ growth in annual sales - in capacity terms - relative to 2007 , yielding a cumulative installed capacity of distributed wind in the United States in this turbine size range of roughly 80 MW (AWEA 2009b).

\begin{tabular}{|l|c|c|c|}
\hline \multirow{2}{*}{ Application } & \multicolumn{3}{|c|}{ Distributed Wind Power, Annual Sales in 2008} \\
\hline Off-grid & Number of Turbines & Capacity Additions & Sales Revenue \\
\hline On-grid & 7,402 & $3.8 \mathrm{MW}$ & $\$ 15$ million \\
\hline TOTAL & 2,984 & $13.6 \mathrm{MW}$ & $\$ 62$ million \\
\hline
\end{tabular}

Source: AWEA

Of importance to the distributed wind segment, turbines under $100 \mathrm{~kW}$ in size are now eligible for an uncapped $30 \%$ investment tax credit (the $30 \%$ tax credit, with a dollar cap, was initially enacted in October 2008; the cap was removed in the economic stimulus bill passed in February 2009). As a result, expectations are for continued brisk growth in sales.

\section{Wind Power Contributed $42 \%$ of All New U.S. Electric Generating Capacity in 2008}

Wind power now represents one of the largest new sources of electric capacity additions in the United States. For the fourth consecutive year, wind power was the second-largest new resource added to the U.S. electrical grid in terms of aggregate capacity, behind the 9,700 MW of new natural gas plants added in 2008 , but ahead of the 1,400 MW of new coal. New wind plants contributed roughly $42 \%$ of the new nameplate capacity added to the U.S. electrical grid in 2008 , compared to $35 \%$ in $2007,18 \%$ in $2006,12 \%$ in 2005, and less than $4 \%$ from 2000 through 2004 (see Figure 2). ${ }^{3}$

\footnotetext{
${ }^{3}$ The same trend is even more apparent in Europe. In 2008, for example, more wind power was installed in the EU than any other generating technology, with $36 \%$ of all capacity additions coming from wind (EWEA 2009). From 2000 through $2008,32 \%$ of capacity additions in the EU came from wind, second only to natural gas.
} 


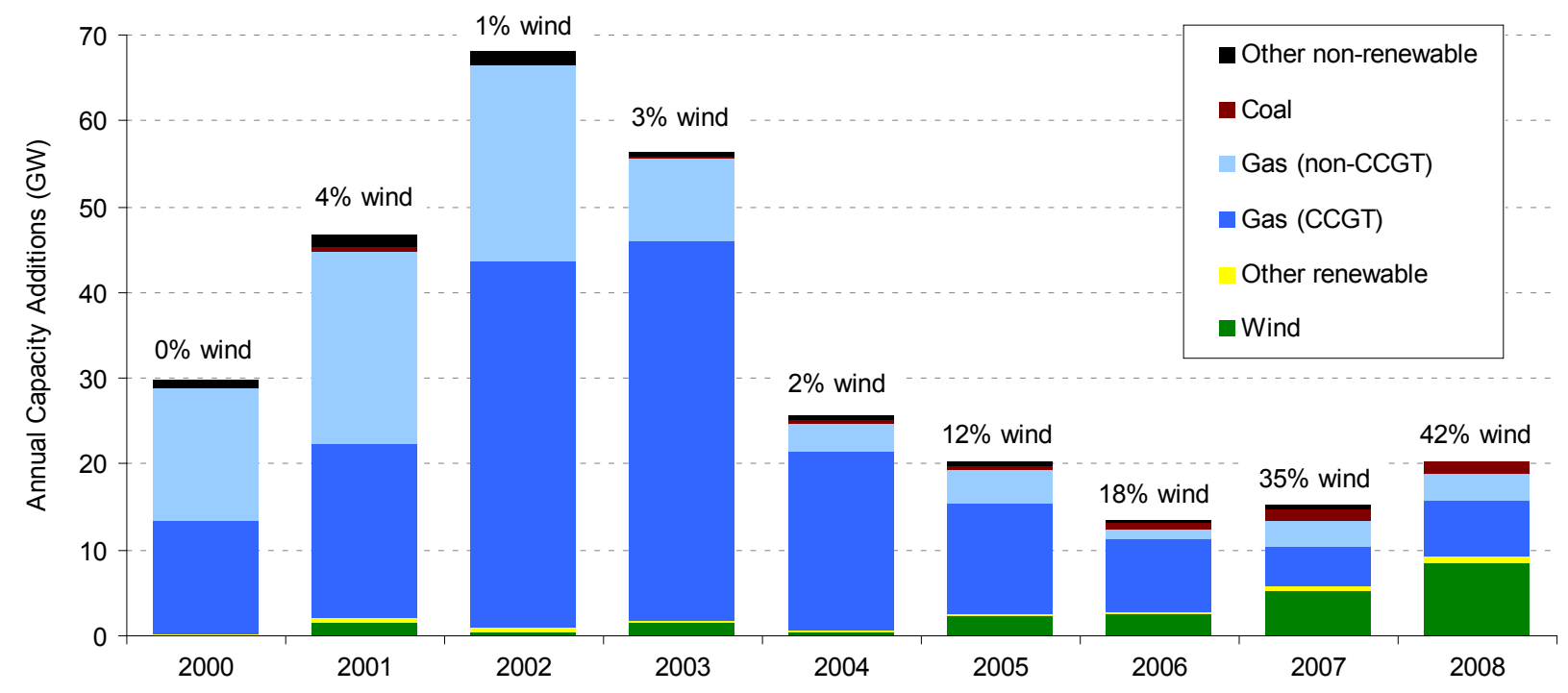

Source: EIA, Ventyx, AWEA, IREC, Berkeley Lab

Figure 2. Relative Contribution of Generation Types in Annual Capacity Additions

EIA (2009) projects that total U.S. electricity supply will need to increase at an average pace of roughly 44 TWh per year from 2009 to 2030 in order to meet demand growth. On an energy basis, the annual amount of electricity expected to be generated by the new wind capacity added in $2008(\sim 25 \mathrm{TWh})$ represents nearly $60 \%$ of this average annual projected growth in supply. ${ }^{4}$ By extension, if wind additions continued through 2030 at the same pace as set in 2008 , then almost $60 \%$ of the nation's projected increase in electricity generation from 2009 through 2030 would be met with wind electricity. Although future growth trends are hard to predict, it is clear that a significant portion of the country's new generation needs is already being met by wind.

\section{The U.S. Continued to Lead the World in Annual Capacity Growth, and Overtook Germany to Take the Lead in Cumulative Wind Capacity}

On a worldwide basis, roughly $28,000 \mathrm{MW}$ of wind capacity was added in 2008 , the highest volume achieved in a single year, and up from about 20,000 MW in 2007, bringing the cumulative total to approximately 122,000 MW. For the fourth straight year, the United States led the world in wind capacity additions (Table 1), capturing roughly $30 \%$ of the worldwide market, up from 27\% in 2007 and 16\% in 2006 (Figure 3). China, India, Spain, and Germany rounded out the top five countries in 2008 for annual wind capacity additions (Table 1). ${ }^{5}$

\footnotetext{
${ }^{4}$ Given the relatively low capacity factor of wind, one might initially expect that wind's percentage contribution on an energy basis would be much lower than on a capacity basis. This is not necessarily the case, as documented by a review of capacity and electricity production data from EIA, in part because even though combined-cycle gas plants can be operated as baseload facilities with high capacity factors, those facilities are often run as intermediate plants with capacity factors that are not dissimilar from that of wind. Combustion turbine facilities run at even lower capacity factors.

${ }^{5}$ Yearly and cumulative installed wind capacity in the United States are from AWEA, while global wind capacity in 2008 comes from BTM (2009), but updated with the most recent AWEA data for the United States. Global wind capacity in earlier years comes from the Earth Policy Institute. Some disagreement exists among these data sources and others, e.g., Windpower Monthly and the Global Wind Energy Council.
} 
Table 1. International Rankings of Wind Power Capacity

\begin{tabular}{|lrl|r|}
\multicolumn{1}{c}{$\begin{array}{c}\text { Annual Capacity } \\
\text { (2008, MW) }\end{array}$} & & \multicolumn{2}{c|}{$\begin{array}{c}\text { Cumulative Capacity } \\
\text { (end of 2008, MW) }\end{array}$} \\
\hline U.S. & $\mathbf{8 , 5 5 8}$ & U.S. & $\mathbf{2 5 , 3 6 9}$ \\
China & 6,246 & Germany & 23,933 \\
India & 1,810 & Spain & 16,453 \\
Spain & 1,739 & China & 12,121 \\
Germany & 1,665 & India & 9,655 \\
France & 1,200 & Italy & 3,731 \\
Italy & 1,010 & France & 3,671 \\
U.K. & 869 & U.K. & 3,263 \\
Portugal & 679 & Denmark & 3,159 \\
Australia & 615 & Portugal & 2,829 \\
Rest of World & 3,999 & Rest of World & 18,106 \\
TOTAL & $\mathbf{2 8 , 3 9 0}$ & TOTAL & $\mathbf{1 2 2 , 2 9 0}$ \\
\hline
\end{tabular}

Source: BTM Consult; AWEA for U.S. capacity

In terms of cumulative installed wind capacity, the United States ended the year with $21 \%$ of worldwide capacity, and for the first time in many years led the world by this metric, taking the mantle from long-time stalwart, Germany. So far this decade (i.e., over the past nine years), cumulative wind power capacity has grown an average of $29 \%$ per year in the United States, slightly higher than the $27 \%$ growth rate in worldwide capacity.

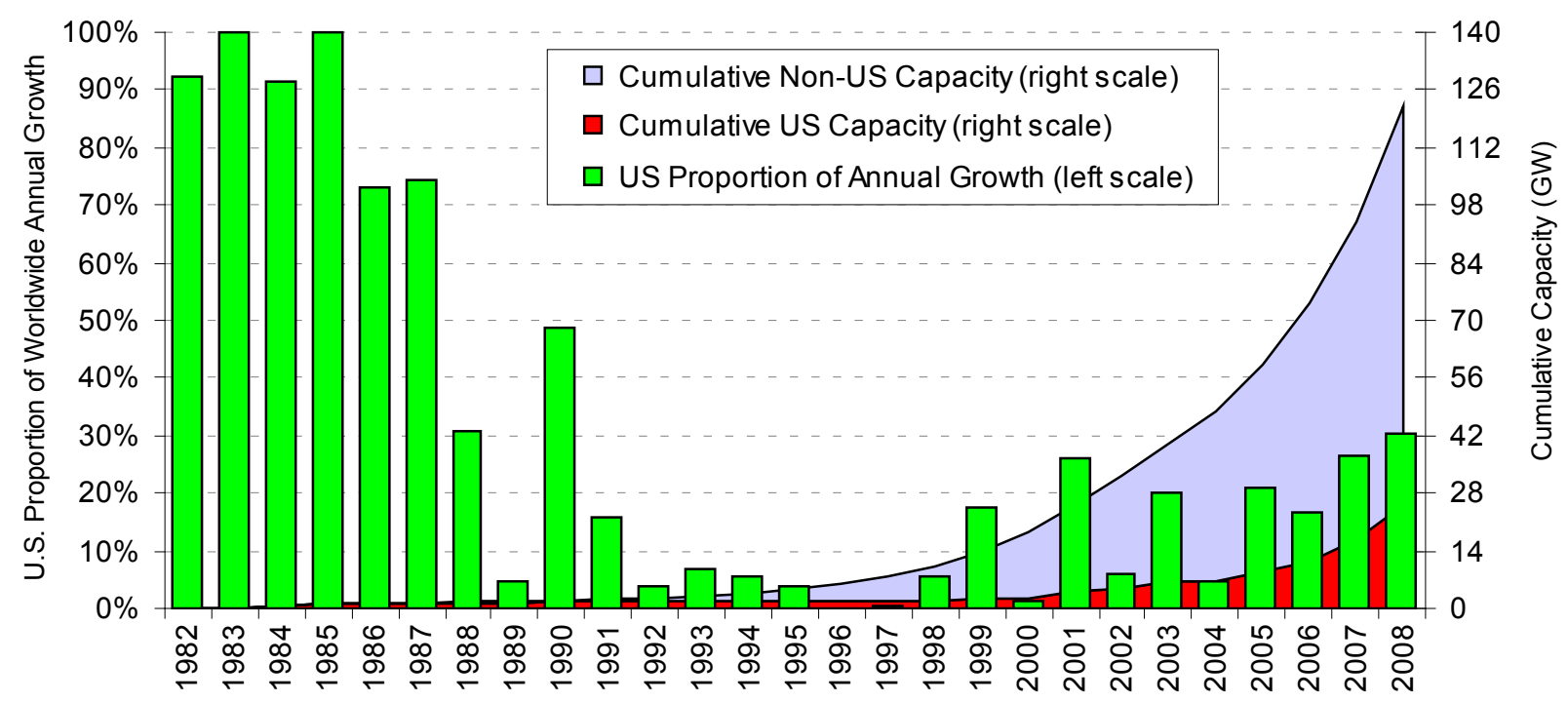

Source: Earth Policy Institute, BTM Consult, AWEA

Figure 3. The United States' Contribution to Global Wind Capacity 
Several countries are beginning to achieve relatively high levels of wind power penetration in their electricity grids. Figure 4 presents data on end-of-2008 (and end-of-2006/07) installed wind capacity, translated into projected annual electricity supply based on assumed countryspecific capacity factors, and divided by projected 2009 (and 2007/08) electricity consumption. Using this rough approximation for the contribution of wind to electricity consumption, and focusing only on the 20 countries with the greatest cumulative installed wind capacity, end-of2008 installed wind is projected to supply roughly $20 \%$ of Denmark's electricity demand, $13 \%$ of Spain's, $12 \%$ of Portugal's, 9\% of Ireland's, and 8\% of Germany's. In the United States, on the other hand, the cumulative wind capacity installed at the end of 2008 would, in an average year, be able to supply roughly $1.9 \%$ of the nation's electricity consumption (up from $1.3 \%$ at the end of 2007, and $0.9 \%$ at the end of 2006). ${ }^{6}$ On a global basis, wind's contribution at the end of 2008 is estimated to be $1.5 \%$.

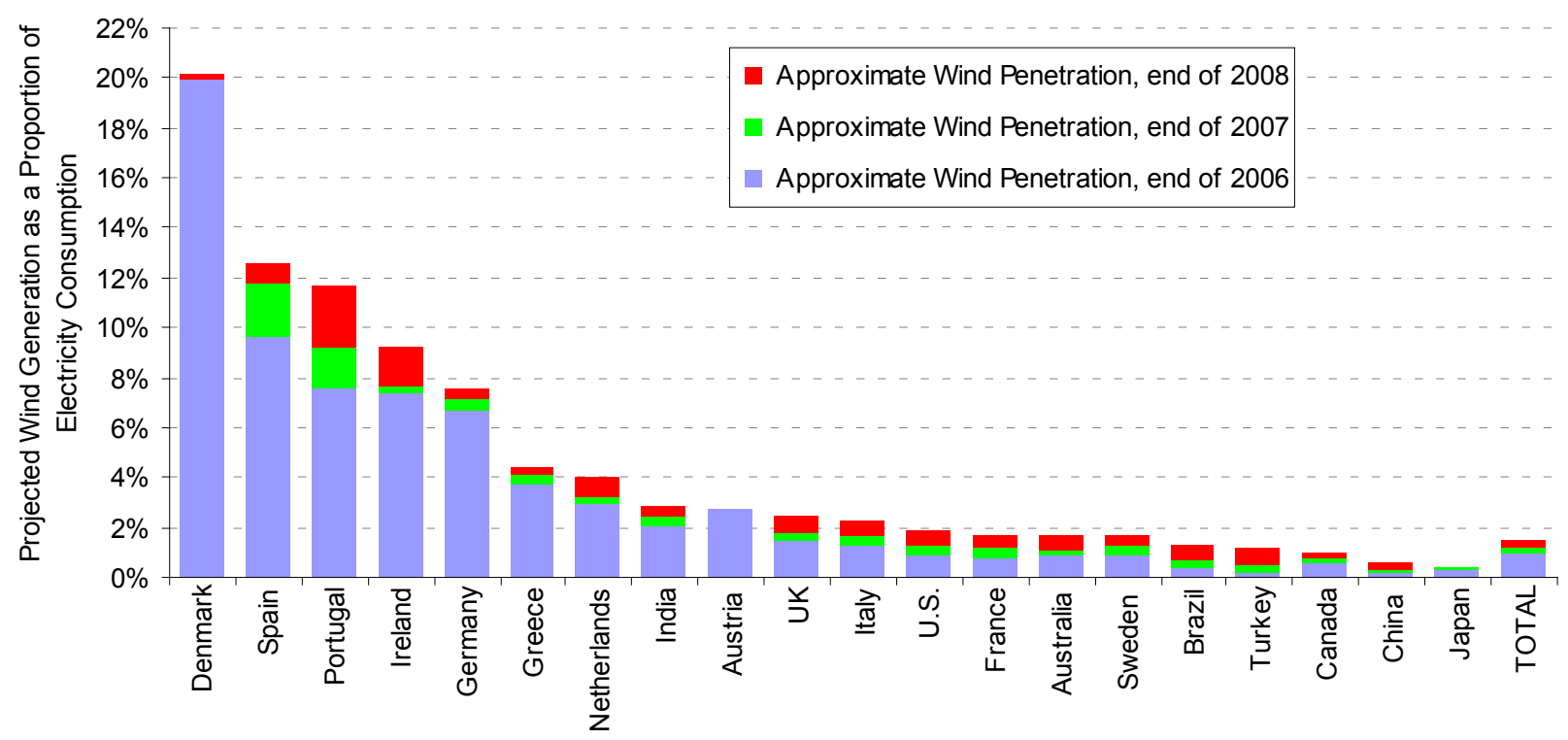

Source: Berkeley Lab estimates based on data from BTM Consult and elsewhere

Figure 4. Approximate Wind Power Penetration in the Twenty Countries with the Greatest Installed Wind Capacity

\section{Texas Easily Exceeded Other States in Annual Capacity Growth}

New large-scale ${ }^{7}$ wind turbines were installed in 27 states in 2008. Texas again dominated in terms of new capacity, with 2,671 MW installed in 2008 alone, up from 1,708 MW installed in 2007. As shown in Figure 5 and Table 2, other leading states in terms of new capacity include Iowa, Minnesota, Kansas, New York, Wyoming, and North Dakota. Eleven states added more than $200 \mathrm{MW}$ each in 2008.

\footnotetext{
${ }^{6}$ In terms of actual 2008 deliveries, wind represented $1.3 \%$ of net electricity generation and national electricity consumption in the United States. These figures are below the $1.9 \%$ figure provided above because $1.9 \%$ is a projection based on end-of-year 2008 wind capacity.

7 "Large-scale" turbines are defined consistently with the rest of this report - over $50 \mathrm{~kW}$.
} 
On a cumulative basis, Texas continued to build on its lead in 2008, with a total of 7,118 MW of wind capacity installed by the end of the year. In fact, Texas has more installed wind capacity than all but five countries worldwide. Following Texas are Iowa, California, Minnesota, and Washington. Thirteen states had more than $500 \mathrm{MW}$ of wind capacity as of the end of 2008, with seven topping 1,000 MW, and three topping 2,000 MW. Although all wind projects in the United States to date have been sited on land, offshore development activities continued in 2008 (see Offshore Wind Development Activities, page 11).

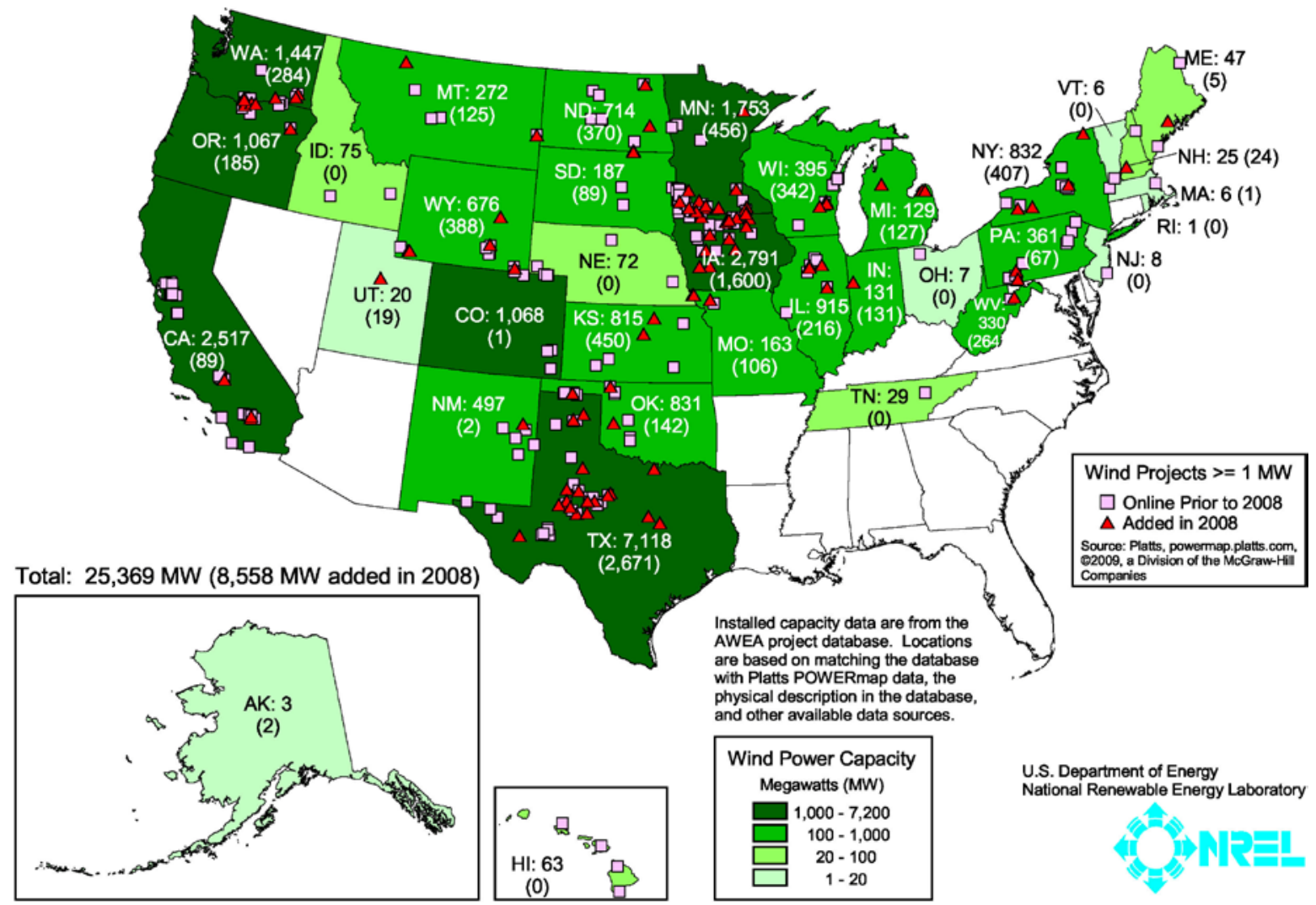

Note: Numbers within states represent cumulative installed wind capacity and, in parentheses, annual additions in 2008.

\section{Figure 5. Location of Wind Power Development in the United States}

Some states are beginning to realize relatively high levels of wind penetration. Table 2 lists the top-20 states based on an estimate of wind generation from end-of-2008 wind capacity, divided by total in-state generation in $2008 .^{8}$

\footnotetext{
${ }^{8}$ Wind power penetration can either be expressed as a percentage of in-state load or in-state generation. This report uses in-state generation, primarily because wind power is often sold across state lines, which tends to distort penetration levels expressed as a percentage of in-state load. To estimate these figures, end-of-2008 wind capacity is translated into estimated annual wind electricity production based on state-specific capacity factors that derive from the project performance data reported later in this report. The resulting state-specific wind production estimates are then divided by the latest data on total in-state electricity generation available from the EIA (i.e., 2008). The resulting wind penetration estimates shown in Table 2 differ from what AWEA provided in its Annual Wind Industry Report (AWEA 2009a). The most significant source of these differences is that AWEA uses preliminary data on actual 2008 wind generation from EIA, while this report estimates annual wind generation based on the amount of wind capacity installed at the end of 2008 .
} 
By this metric, two Midwestern states lead the list in terms of estimated wind power as a percentage of total in-state generation. Specifically, wind capacity installed as of the end of 2008 is estimated, in an average year, to generate approximately $13.3 \%$ and $10.4 \%$ of all in-state electricity generation in Iowa and Minnesota, respectively. Six additional states - South and North Dakota, Kansas, Colorado, Oregon, and Texas - surpass the 5\% mark by this metric, while fifteen states total exceed $2 \%$.

\section{Table 2. United States Wind Power Rankings: The Top 20 States}

Annual Capacity (2008, MW)

Texas
Iowa
Minnesota
Kansas
New York
Wyoming
North Dakota
Wisconsin
Washington
West Virginia
Illinois
Oregon
Oklahoma
Indiana
Michigan
Montana
Missouri
South Dakota
California
Pennsylvania
Rest of U.S.

TOTAL

\section{Cumulative Capacity} (end of 2008, MW)

\section{2,671}

1,600

456

450

407

388

370

342

284

264

216

185

142

131

127

125

106

89 Montana

89 South Dakota

67 Missouri

52 Rest of U.S.

8,558 TOTAL
7,118

2,791

2,517

1,753

1,447

1,068

1,067

915 Texas

832 New Mexico

831 Wyoming

815 Washington

714 Oklahoma

676 Montana

497 California

395 Hawaii

361 Idaho

330 New York

272 Illinois

187 Wisconsin

163 West Virginia

622 Rest of U.S.

25,369 TOTAL

$13.3 \%$

$10.4 \%$

$8.8 \%$

$7.1 \%$

$6.7 \%$

$6.6 \%$

$5.4 \%$

$5.3 \%$

$4.5 \%$

$4.1 \%$

$3.9 \%$

$3.7 \%$

$3.4 \%$

$3.1 \%$

$2.2 \%$

$1.6 \%$

$1.4 \%$

$1.4 \%$

$1.3 \%$

$0.9 \%$

$0.2 \%$

$1.8 \%$

Source: AWEA project database, EIA, Berkeley Lab estimates

Some utilities are achieving even higher levels of wind penetration into their individual electric systems. Table 3 lists the top- 20 utilities in terms of aggregate wind capacity on their systems at the end of 2008, based on data provided by AWEA (2009a). Included here are wind projects either owned by or under long-term contract with these utilities for use by their own customers; short-term renewable electricity and renewable energy certificate contracts are excluded.

The table also lists the top-20 utilities based on an estimate of the percentage of retail sales that wind generation represents, using end-of-2008 wind capacity and wind capacity factors that are consistent with the state or region in which these utilities operate, and EIA-provided aggregate 
retail electricity sales for each utility in $2007 .{ }^{9}$ As shown, two of the listed utility systems are estimated to have achieved in excess of $20 \%$ wind penetration based on this metric, while four others are estimated to have exceeded $10 \%$.

Table 3. Top-20 Utility Wind Power Rankings

\section{Total Wind Capacity \\ (end of 2008, MW)}

\begin{tabular}{|l|r|}
\hline Xcel Energy & 2,906 \\
\hline MidAmerican Energy & 2,363 \\
\hline Southern California Edison & 1,137 \\
\hline Pacific Gas \& Electric & 981 \\
\hline Luminant & 913 \\
\hline City Public Service of San Antonio & 502 \\
\hline American Electric Power & 468 \\
\hline Alliant Energy & 446 \\
\hline Austin Energy & 439 \\
\hline Puget Sound Energy & 435 \\
\hline Exelon Energy & 351 \\
\hline Great River Energy & 319 \\
\hline Empire District Electric Company & 255 \\
\hline First Energy & 244 \\
\hline San Diego Gas \& Electric & 239 \\
\hline Portland General Electric & 225 \\
\hline Public Service New Mexico & 204 \\
\hline MSR Public Power Agency & 200 \\
\hline Reliant Energy & 199 \\
\hline Minnkota Power Cooperative & 193 \\
\hline Source: AWEA, EIA, Berkeley Lab estimates & \\
\hline
\end{tabular}

\section{Estimated Percentage of Retail Sales (for utilities with $>100 \mathrm{MW}$ of wind)}

Minnkota Power Cooperative 22.6\%

Empire District Electric Company $\quad 20.7 \%$

Otter Tail Power $14.9 \%$

Southern Minn. Muni. Power Authority $\quad 13.0 \%$

Austin Energy $11.7 \%$

\begin{tabular}{l|l} 
Xcel Energy & $10.7 \%$
\end{tabular}

\begin{tabular}{l|r|} 
MSR Public Power Agency & $9.3 \%$
\end{tabular}

Great River Energy $\quad 9.1 \%$

\begin{tabular}{l|l} 
City Public Service of San Antonio & $8.2 \%$
\end{tabular}

MidAmerican Energy $\quad 8.1 \%$

\begin{tabular}{l|l} 
Public Service New Mexico & $6.2 \%$
\end{tabular}

\begin{tabular}{l|l}
\hline Luminant & $5.6 \%$
\end{tabular}

\begin{tabular}{l|l} 
Alliant Energy & $5.4 \%$
\end{tabular}

\begin{tabular}{l|l} 
Puget Sound Energy & $5.3 \%$ \\
\hline
\end{tabular}

\begin{tabular}{l|l} 
Seattle City Light & $5.3 \%$
\end{tabular}

\begin{tabular}{l|l} 
Northwestern Energy & $5.0 \%$ \\
\hline
\end{tabular}

\begin{tabular}{l|l} 
Minnesota Power & $4.6 \%$
\end{tabular}

\begin{tabular}{l|l}
\hline Aquila & $3.9 \%$
\end{tabular}

\begin{tabular}{l|l} 
Portland General Electric & $3.3 \%$
\end{tabular}

\begin{tabular}{l|l} 
Southern California Edison & $3.1 \%$ \\
\hline
\end{tabular}

\footnotetext{
${ }^{9}$ In calculating these figures, several issues deserve mention. First, the utility-specific capacity data that AWEA released in its Annual Wind Industry Report (AWEA 2009a) are used. Second, only utilities with more than 100 MW of wind capacity are included in the calculation of wind as a proportion of retail sales. Third, projected wind generation based on each utility's installed wind capacity at the end of 2008 is divided by the aggregate national retail sales of that utility in 2007 (which is the latest full year of utility-specific retail sales data provided by EIA). Fourth, in the case of generation and transmission (G\&T) cooperatives and power authorities that provide power to other cooperatives and municipal utilities (but do not directly serve retail load themselves), 2007 retail sales from the electric utilities served by those G\&T organizations and power authorities are used. In some cases, these individual utilities may be buying additional wind power directly from other projects, or may be served by other G\&T cooperatives or power authorities that supply wind. In these cases, the penetration percentages shown here may be somewhat misleading. As an example, the "MSR Public Power Agency" (MSR) is a joint powers agency created to procure power for municipal utilities in the California cities of Modesto, Santa Clara, and Redding. The $200 \mathrm{MW}$ of wind capacity associated with MSR in the first column of Table 3 (and the corresponding 9.3\% penetration rate shown in the second column) represents MSR's power purchase agreement with the Big Horn wind project in Washington state. However, two of the three municipal utilities participating in MSR purchase additional wind power from other wind projects. The result is that if one were to look at these three municipal utilities individually rather than as a group through MSR, their penetration rates would be considerably higher than the $9.3 \%$ shown in Table 3. Finally, some of the entities shown in Table 3 are wholesale power marketing companies that are affiliated with electric utilities. In these cases, estimated wind generation is divided by the retail sales of the power marketing company and any affiliated electric utilities.
} 


\section{Offshore Wind Development Activities}

In Europe, three offshore wind projects, totaling $344 \mathrm{MW}$, were installed in 2008, bringing total worldwide offshore wind capacity to 1,421 MW (BTM 2009). In contrast, all wind projects built in the United States to date have been sited on land. The availability of low-cost onshore wind resources, regulatory delays and uncertainty associated with offshore development, turbine supply shortages, high and uncertain offshore project costs, and public acceptance concerns have hampered progress in the offshore wind sector in the U.S.

Nonetheless, there is interest in offshore wind in several parts of the country due to the proximity of offshore wind resources to large population centers, advances in technology, and potentially superior capacity factors.

The table below shows the amount of proposed capacity from "advanced-stage" offshore wind project proposals in the United States, as of the end of 2008. Project proposals are considered to be in an "advanced stage" if they plan to use proven technology and recognized design standards, and have commenced with feasibility studies for a defined amount of capacity at a specific site. Eleven such projects, totaling 2,075 MW, are included in the table, while another 11 projects, totaling 2,380 MW, have been identified as "early stage," and are not included. Note that even the "advanced-stage" proposals tallied in the table are in various stages of development, and a number of these projects may never be realized.

\begin{tabular}{|l|c|}
\hline State & $\begin{array}{c}\text { Proposed Offshore } \\
\text { Wind Capacity } \\
\text { (Advanced-Stage Only) }\end{array}$ \\
\hline Massachusetts & $783 \mathrm{MW}$ \\
\hline Rhode Island & $412 \mathrm{MW}$ \\
\hline Delaware & $350 \mathrm{MW}$ \\
\hline New Jersey & $350 \mathrm{MW}$ \\
\hline Texas & $150 \mathrm{MW}$ \\
\hline Ohio & $20 \mathrm{MW}$ \\
\hline Georgia & $10 \mathrm{MW}$ \\
\hline \multicolumn{1}{|c|}{ TOTAL } & $\mathbf{2 , 0 7 5}$ MW \\
\hline
\end{tabular}

Source: NREL

Several events in 2008 and early 2009 demonstrate that progress continues with offshore wind in the United States. Specifically, Bluewater Wind and Delmarva Power signed a power purchase agreement to bring 200 MW of offshore wind to Delaware; negotiations with other off-takers may allow the project to exceed this capacity rating. The state of Rhode Island, meanwhile, signed a joint development agreement with Deepwater Wind for a two-phase project of $20 \mathrm{MW}$ and $380 \mathrm{MW}$, respectively. In New Jersey, a joint venture between Public Service Enterprise Group and Deepwater Wind was selected by the New Jersey Board of Public Utilities to build a $350 \mathrm{MW}$ offshore wind farm, and shortly after this announcement, the Governor raised the state goal for offshore wind to $1000 \mathrm{MW}$ by 2010 and opened the field to other bidders. In New York, the Long Island Power Authority and Consolidated Edison are collaborating on a possible offshore wind project, while the New York Power Authority issued a request for expressions of interest in offshore projects in the New York waters of Lake Erie and Lake Ontario. On the regulatory front, in April 2009 the U.S. Minerals Management Service (MMS) finalized the rules governing offshore wind development leases, easements, and royalties, clearing a major hurdle to development. Additionally, Cape Wind continued its permitting efforts in Massachusetts, with MMS' final environmental impact statement completed in January 2009, and with a vote of the Massachusetts Energy Facilities Siting Board in May 2009 granting Cape Wind a 'Certificate of Environmental Impact and Public Interest.' 


\section{Data from Interconnection Queues Demonstrate that an Enormous Amount of Wind Capacity Is Under Development}

One visible testament to the increased interest in wind is the amount of wind power capacity currently working its way through the major transmission interconnection queues across the country. Figure 6 provides this information, for wind and other resources, aggregated across 12 wind-relevant independent system operators (ISOs), regional transmission organizations (RTOs), and utilities. ${ }^{10}$ These data should be interpreted with caution: though placing a project in the interconnection queue is a necessary step in project development, being in the queue does not guarantee that a project will actually get built. In fact, there is a growing recognition that many of the projects currently in interconnection queues are very early in the development process. As a result, efforts have been and are being taken by the Federal Energy Regulatory Commission (FERC), ISOs, RTOs, and utilities to reduce the number of speculative projects that have - in recent years - clogged these queues (Porter et al. 2009).

Even with this important caveat, though, the amount of wind capacity in the nation's interconnection queues still provides at least some indication of the number and capacity of projects that are in the planning phase. At the end of 2008, even after reforms by a number of ISOs, RTOs, and utilities to reduce the number of projects in their queues, there were nearly 300 $\mathrm{GW}$ of wind power capacity within the twelve interconnection queues reviewed for this report more than 11 times the installed wind capacity in the U.S. at the end of 2008. ${ }^{11}$ This wind capacity represented more than half of all generating capacity within these queues at that time, and was more than twice as much capacity as the next-largest resource in these queues (natural gas). ${ }^{12}$

Much of this wind capacity is planned for the Midwest, Texas, Southwest, and PJM regions: wind in the interconnection queues of MISO (64 GW), ERCOT (52 GW), SPP (48 GW), and PJM (43 GW) account for over $70 \%$ of the aggregate $292 \mathrm{GW}$ of wind in all twelve queues. At the other end of the spectrum, the Northeast exhibits the least amount of wind capacity in the pipeline, with the New York ISO $(8 \mathrm{GW})$ and ISO-New England $(6 \mathrm{GW})$ together accounting for about $5 \%$ of the aggregate $292 \mathrm{GW}$. The remaining five queues include WAPA (14 GW), BPA $(14 \mathrm{GW})$, California ISO $(13 \mathrm{GW})$, Tri-State $(11 \mathrm{GW})$, Xcel's Colorado service area $(10 \mathrm{GW})$, and PacifiCorp $(10 \mathrm{GW})$. Among all regions, the SPP experienced the greatest amount of wind $(31 \mathrm{GW})$ entering its queue in 2008. Again, though, some or even many of the projects in these queues may never be built.

\footnotetext{
${ }^{10}$ The queues surveyed include PJM Interconnection, Midwest Independent System Operator (MISO), New York ISO, ISO-New England, California ISO, Electricity Reliability Council of Texas (ERCOT), Southwest Power Pool (SPP), Western Area Power Administration (WAPA), Bonneville Power Administration (BPA), PacifiCorp, Xcel Energy (Colorado), and Tri-State. To provide a sense of sample size and coverage, roughly $60 \%$ of the total installed generating capacity (both wind and non-wind) in the United States is located within these ISOs, RTOs, and utility service territories. Figure 6 only includes projects that were active in the queue at the end of 2008 but that had not yet been built; suspended projects are not included.

${ }^{11}$ As a rough benchmark, $300 \mathrm{GW}$ of wind is also the approximate amount of capacity required to reach $20 \%$ wind penetration in the U.S., as estimated in U.S. DOE (2008).

${ }^{12}$ It is important to keep in mind that most of the twelve ISOs, RTOs, and utilities in our queue sample cover geographic areas of significant wind power development, and that on a comprehensive, nationwide basis, wind would likely not dominate the queues as much as it does within this sample.
} 


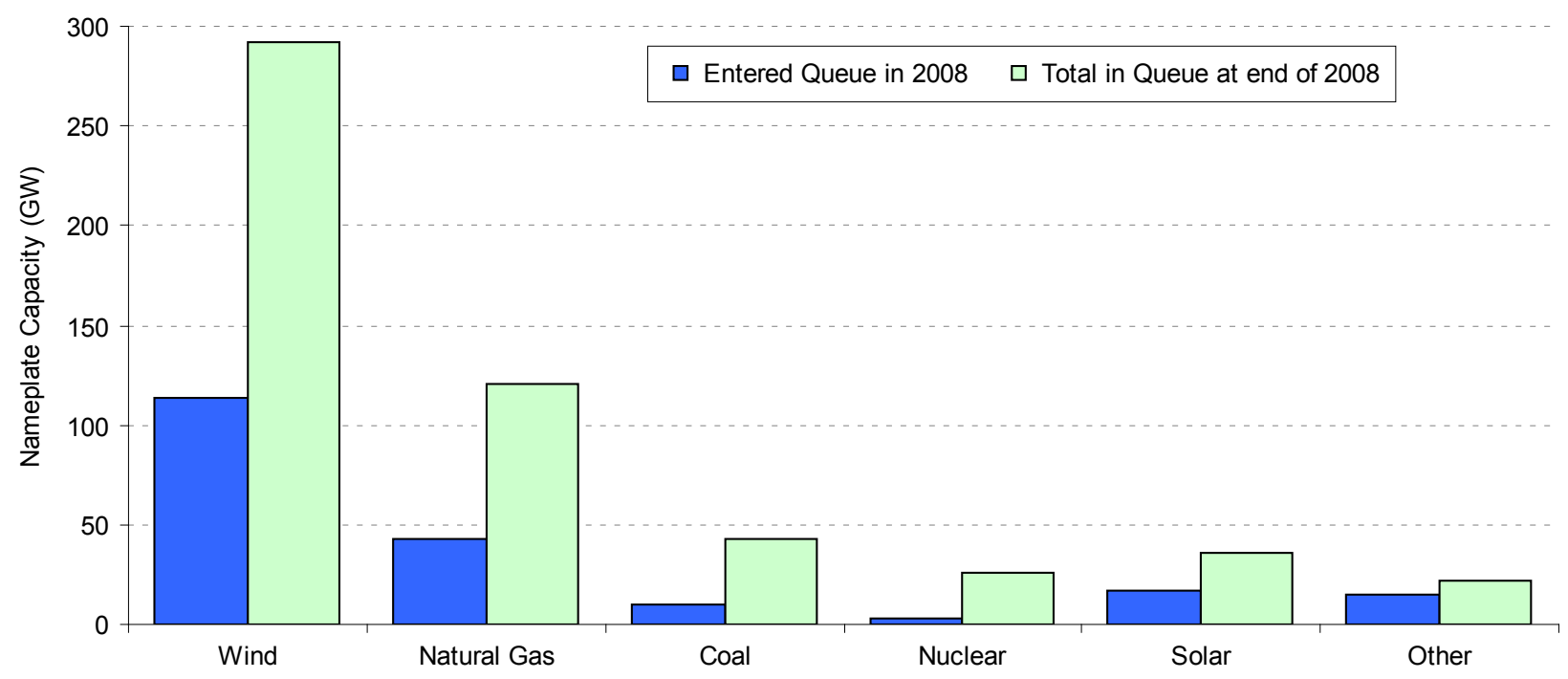

Source: Exeter Associates review of interconnection queues

Figure 6. Nameplate Resource Capacity in Twelve Major Interconnection Queues

As another data point, one with tighter screens on project viability, the North American Electric Reliability Corporation (NERC) finds that $145 \mathrm{GW}$ of new wind capacity is planned or proposed for construction over the next ten years (NERC 2008). Once again, though, it is unlikely that all of these planned projects will ultimately come to fruition within this time frame. 


\section{Industry Trends}

\section{GE Wind Remained the Top Turbine Manufacturer in the U.S. Market, but a Growing Number of Other Manufacturers Are Capturing Market Share}

GE Wind remained the number one manufacturer of wind turbines supplying the U.S. market in 2008 , with $43 \%$ of domestic turbine installations (down slightly from $45 \%$ in 2007 and $47 \%$ in 2006). ${ }^{13}$ Following GE were Vestas (13\%), Siemens (9\%), Suzlon (9\%), Gamesa (7\%), Clipper (7\%), Mitsubishi (6\%), Acciona (5\%), and REpower (1\%).

Noteworthy developments in 2008 include the growth in market share for Clipper, Suzlon, and Acciona, while Siemens and Vestas experienced the most significant drops in market share, in percentage terms. Perhaps more significantly, however, is the growing number of turbine vendors active in the U.S. market. International turbine manufacturers entering the U.S. market for the first time in 2008 include Acciona (3 projects, $410 \mathrm{MW}$ ), REpower (2 projects, $102 \mathrm{MW}$ ), Fuhrlander (1 project, $5 \mathrm{MW}$ ), CTC/DeWind (2 projects, $4 \mathrm{MW}$ ), and AWE (2 projects, 1.8 MW).

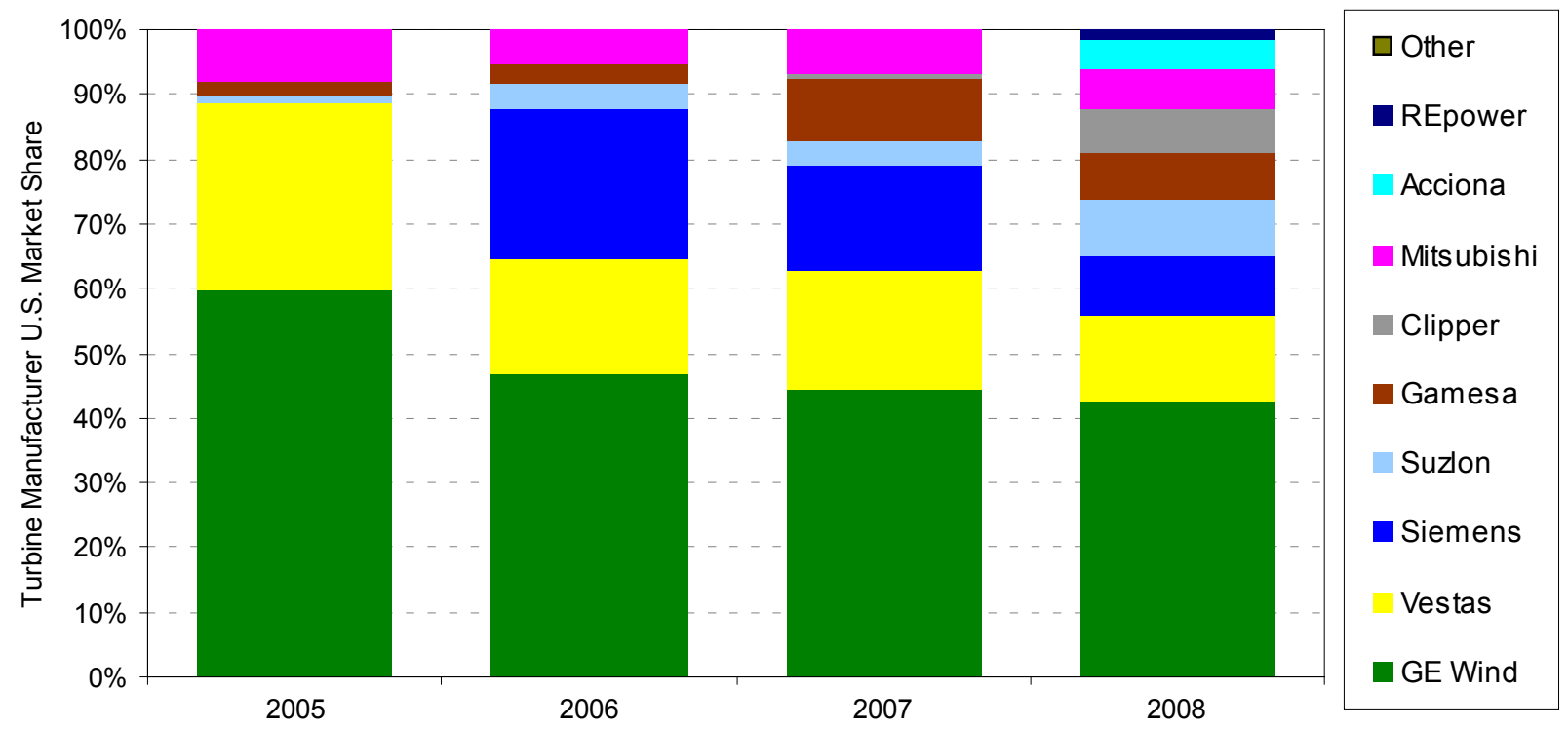

Source: AWEA project database

Figure 7. Annual U.S. Market Share of Wind Manufacturers by MW, 2005-2008

Notwithstanding these changes in market share in percentage terms, virtually every manufacturer active in the U.S. market saw installations of their turbines grow between 2007 and 2008, in many cases dramatically. As shown in Table 4, the most significant growth was experienced by GE (1,316 MW), Clipper (548 MW), and Suzlon (541 MW); only Siemens witnessed a decline in sales, by this metric.

\footnotetext{
${ }^{13}$ Market share reported here is in MW terms, and is based on project installations in the year in question, not turbine shipments or orders.
} 
Table 4. Annual U.S. Turbine Installation Capacity, by Manufacturer

\begin{tabular}{|l|c|c|c|c|}
\hline Manufacturer & \multicolumn{4}{|c|}{ Turbine Installations (MW) } \\
\hline GE Wind & $\mathbf{2 0 0 5}$ & $\mathbf{2 0 0 6}$ & $\mathbf{2 0 0 7}$ & $\mathbf{2 0 0 8}$ \\
\hline Vestas & 1,433 & 1,146 & 2,342 & 3,657 \\
\hline Siemens & 700 & 439 & 948 & 1,120 \\
\hline Suzlon & 0 & 573 & 863 & 791 \\
\hline Gamesa & 25 & 92 & 197 & 738 \\
\hline Clipper & 50 & 74 & 494 & 616 \\
\hline Mitsubishi & 2.5 & 0 & 47.5 & 595 \\
\hline Acciona & 190 & 128 & 356 & 516 \\
\hline REpower & 0 & 0 & 0 & 410 \\
\hline Other & 0 & 0 & 0 & 102 \\
\hline TOTAL & 2 & 2 & 3 & 13 \\
\hline Source: AWEA project database & $\mathbf{2 , 4 0 2}$ & $\mathbf{2 , 4 5 4}$ & $\mathbf{5 , 3 2 9}$ & $\mathbf{8 , 5 5 8}$ \\
\hline
\end{tabular}

\section{Soaring Demand for Wind Spurred Expansion of U.S. Wind Turbine Manufacturing}

As wind power deployment has increased in the U.S., a growing number of foreign turbine and component manufacturers have either begun or continued to localize operations in the United States, and manufacturing by U.S.-based companies has also expanded.

Figure 8 presents a (non-exhaustive) list of 11 wind turbine and component manufacturing and assembly facilities that opened in 2008, and identifies their location. The map also shows the location of 24 new manufacturing facilities announced (but not yet built) in 2008, identifies 7 existing firms that expanded into the wind sector in 2008, and plots 87 existing turbine and component manufacturing facilities that opened prior to 2008 .

Of the 35 new or announced facilities captured in Figure 8, nine are owned by major international wind turbine manufacturers: Vestas (nacelles, blades, and towers in Pueblo, Brighton, and Windsor, Colorado), Acciona (turbines in West Branch, Iowa), General Electric (parts in Memphis, Tennessee, and Schenectady, New York), Siemens (gear drives in Elgin, Illinois), and Nordex (nacelles and blades in Jonesboro, Arkansas). Siemens also expanded its blade plant in Fort Madison, Iowa, and plans to open a research facility in Boulder, Colorado, while Vestas announced two new research centers, in Boston and Houston (research and development facilities are not included in Figure 8).

Several smaller turbine manufacturers also either opened or announced new U.S. factories in 2008. Fuhrlander announced its decision to build a turbine assembly plant in Butte, Montana, while Nordic Windpower announced that it would open a turbine manufacturing and assembly facility in Pocatello, Idaho. CTC/DeWind began manufacturing turbines in Round Rock, Texas, and by the end of 2008 had commissioned two of its 2 MW D8.2 turbines in the United States. Emergya Wind Technologies - the owner of the Dutch Lagerwey turbine technology - is behind 
two new manufacturing facilities in Little Rock, Arkansas, with turbine assembly expected to start by the end of 2009. Northern Power Systems, the maker of a $100 \mathrm{~kW}$ direct-drive turbine, re-organized its business in 2008 and is planning a $2.2 \mathrm{MW}$ direct-drive turbine.

As a result of this activity, the number of utility-scale wind turbine manufacturers assembling nacelles in the U.S. increased from just one in 2004 (GE) to five in 2008 (GE, Gamesa, Clipper, Acciona, CTC/DeWind), with five additional manufacturers publicly announcing the location of future assembly plants (Vestas, Nordex, Nordic, Fuhrlander, and Emergya).

Figure 8 also shows a considerable number of new component manufacturing facilities announced or opened in 2008, from both foreign and domestic firms. Moreover, a number of domestic manufacturers that were not previously active in the wind sector either branched out to or transitioned into the wind industry in 2008. Figure 8 identifies seven such companies located in two states that have been hit hard by the economic downturn: Michigan and Ohio. In Watertown Township, Michigan, for example, E-T-M has shifted from making composite parts for the automotive industry to creating composites used in wind turbines. Similarly, for more than 100 years, family-run Minster Machine Company in Minster, Ohio, has been manufacturing equipment for the auto, medical, and food industries; its new division, Minster Wind, manufactures wind turbine hubs, and hopes to manufacture other turbine components.

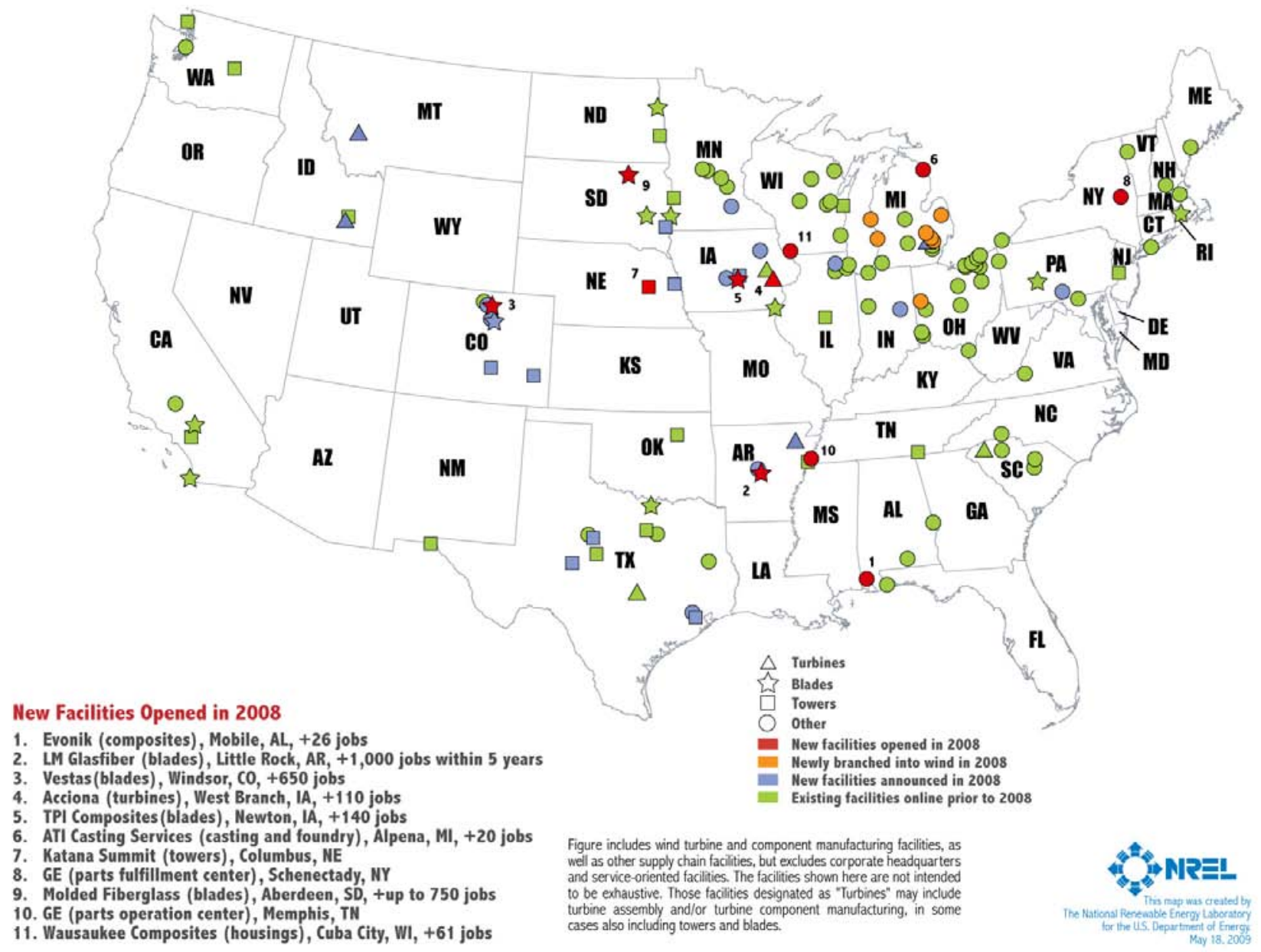

Figure 8. Location of Existing and New Wind Manufacturing Facilities 
Some of the states that have experienced the greatest growth in installed wind capacity in recent years are also seeing significant new manufacturing activity: in 2008, four manufacturing facilities were announced in Texas, six were opened or announced in Colorado, and five were opened or announced in Iowa. Even states with little installed wind capacity, however, are reaping job and economic benefits from new wind-related manufacturing facilities, particularly if those states are strategically positioned geographically. For example, 2008 saw four new manufacturing facilities either opened or announced in Arkansas, and eight facilities - either new, announced, or newly branched into wind - in Michigan.

As a result of the continued expansion of U.S.-based wind turbine and component manufacturing, AWEA estimates that the share of domestically manufactured wind turbine components grew from less than 30\% in 2005 to roughly 50\% in 2008 (AWEA 2009a). This scale-up has also created a number of new jobs; AWEA estimates that roughly 8,400 new domestic manufacturing jobs were added in the wind sector in $2008 .^{14}$ This represents a significant portion of the estimated 35,000 total wind-related jobs created in the U.S. in 2008, bringing total U.S.-based employment in the wind industry to an estimated 85,000 at the end of 2008 (AWEA 2009a). In addition to manufacturing, these jobs span project development, construction and turbine installation, operations and maintenance, legal services, and marketing.

Notwithstanding the generally positive outlook for the turbine manufacturing sector in the U.S., the industry is facing economic headwinds. Most notably, the global financial crisis and recession have slowed project development and reduced the near-term demand for turbines. As a result, some manufacturers have delayed their plans to expand into the U.S., while others - even those that had only recently begun to scale up their U.S. presence - have had to scale back their efforts and even lay off workers. With financial conditions showing signs of stabilizing as of mid-2009, however, some manufacturers have already begun the process of rehiring workers and resuming their expansion plans. As the domestic industry continues to expand, a new challenge has become more acute: workforce training and development. A variety of programs at the local and national levels are beginning to target these needs, but workforce development remains a near-term challenge for the industry's scale-up.

\section{Average Turbine Size Inched Higher in 2008}

The average size of wind turbines installed in the United States in 2008 increased to roughly 1.67 MW (Figure 9), up slightly from 1.65 MW in 2007 and 1.60 MW in 2006. Since 1998-99, average turbine size has increased by $133 \%$, but growth in average turbine size has slowed in recent years. ${ }^{15}$

\footnotetext{
${ }^{14}$ This estimate is larger than the summed total of jobs at new facilities presented in Figure 8, in part because the AWEA (2009a) estimate for new manufacturing jobs also includes jobs at existing and expanded manufacturing facilities.

${ }^{15}$ Except for 2006, 2007, and 2008, Figure 9 (as well as a number of the other figures and tables included in this report) combines data into two-year periods in order to avoid distortions related to small sample size in the PTC lapse years of 2000, 2002, and 2004. Though not a PTC lapse year, 1998 is grouped with 1999 due to the small sample of 1998 projects.
} 


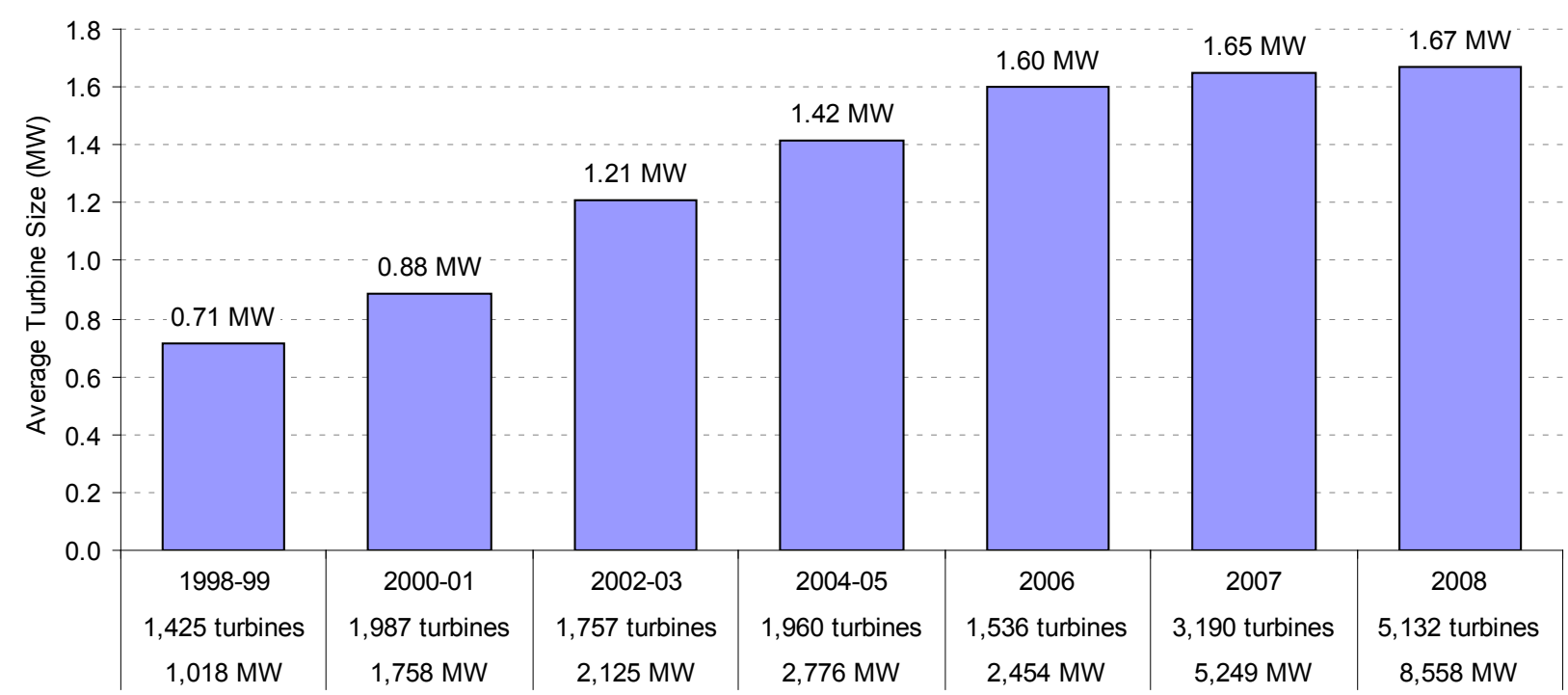

Source: AWEA project database

\section{Figure 9. Average Turbine Size Installed During Period}

Table 5 shows how the distribution of turbine size has shifted over time; $19.9 \%$ of all turbines installed in 2008 had a nameplate capacity larger than $2.0 \mathrm{MW}$, compared to $16.5 \%$ in 2007 , $16.2 \%$ in 2006 , and just $0.1 \%$ in 2004-2005 and 2002-2003. GE's $1.5 \mathrm{MW}$ wind turbine remained by far the nation's most-popular turbine in 2008, with 2,438 units installed.

Table 5. Size Distribution of Number of Turbines Over Time

\begin{tabular}{|c|c|c|c|c|c|c|c|c|}
\hline & $\begin{array}{r}\text { Years: } \\
\text { \# MW: } \\
\text { \# turbines: }\end{array}$ & $\begin{array}{c}\mathbf{1 9 9 8 - 9 9} \\
1,018 \\
1,425\end{array}$ & $\begin{array}{c}\mathbf{2 0 0 0 - 0 1} \\
1,758 \\
1,987\end{array}$ & $\begin{array}{c}\mathbf{2 0 0 2 - 0 3} \\
2,125 \\
1,757\end{array}$ & $\begin{array}{c}\mathbf{2 0 0 4 - 0 5} \\
2,776 \\
1,960\end{array}$ & $\begin{array}{l}\mathbf{2 0 0 6} \\
2,454 \\
1,536\end{array}$ & $\begin{array}{l}\mathbf{2 0 0 7} \\
5,249 \\
3,190 \\
\end{array}$ & $\begin{array}{c}\mathbf{2 0 0 8} \\
8,558 \\
5,132\end{array}$ \\
\hline \multirow{6}{*}{ 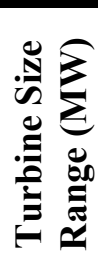 } & $0.00-0.5$ & $1.3 \%$ & $0.4 \%$ & $0.5 \%$ & $1.8 \%$ & $0.7 \%$ & $0.0 \%$ & $0.5 \%$ \\
\hline & $0.51-1.0$ & $98.5 \%$ & $73.9 \%$ & $43.4 \%$ & $18.5 \%$ & $10.7 \%$ & $11.2 \%$ & $10.1 \%$ \\
\hline & 1.01-1.5 & $0.0 \%$ & $25.4 \%$ & $43.5 \%$ & $56.0 \%$ & $54.0 \%$ & $49.2 \%$ & $53.4 \%$ \\
\hline & $1.51-2.0$ & $0.3 \%$ & $0.4 \%$ & $12.5 \%$ & $23.6 \%$ & $18.4 \%$ & $23.1 \%$ & $16.1 \%$ \\
\hline & 2.01-2.5 & $0.0 \%$ & $0.0 \%$ & $0.0 \%$ & $0.1 \%$ & $16.2 \%$ & $15.2 \%$ & $17.5 \%$ \\
\hline & 2.51-3.0 & $0.0 \%$ & $0.0 \%$ & $0.1 \%$ & $0.0 \%$ & $0.0 \%$ & $1.3 \%$ & $2.4 \%$ \\
\hline
\end{tabular}

Source: AWEA project database

\section{The Average Size of Wind Projects Decreased in 2008, but the Longer-Term Trend Has Been Towards Larger Projects}

As the wind industry has grown, so too has the average size of installed wind projects. Projects installed in 2008 averaged nearly $83 \mathrm{MW}$, which is below the $120 \mathrm{MW}$ average size of projects built in $2007,{ }^{16}$ but is otherwise larger than in any other period (Figure 10).

\footnotetext{
${ }^{16}$ Reasons for the decline in average project size in 2008 are unclear, but potential causes might include: either 2008 or 2007 simply being an outlier within the longer-term trend; the impact of the financial crisis making smaller, less-capital-intensive projects easier to finance and build in 2008; difficulty in securing sufficient turbines to build out larger projects in 2008; and an increasing number of transmission constraints favoring smaller projects.
} 
The long-term increase in average project size may reflect a number of interrelated trends highlighted elsewhere in this report: growing demand for wind; the upward march in turbine size; the large turbine orders that had become standard practice up until the recent credit crisis; consolidation among wind project developers to support those orders; and increasing turbine and project costs, which may require taking full advantage of any and all economies of scale.

Whatever the specific cause, larger project sizes reflect an increasingly mature energy source that is beginning to penetrate into the domestic electricity market in a significant way.

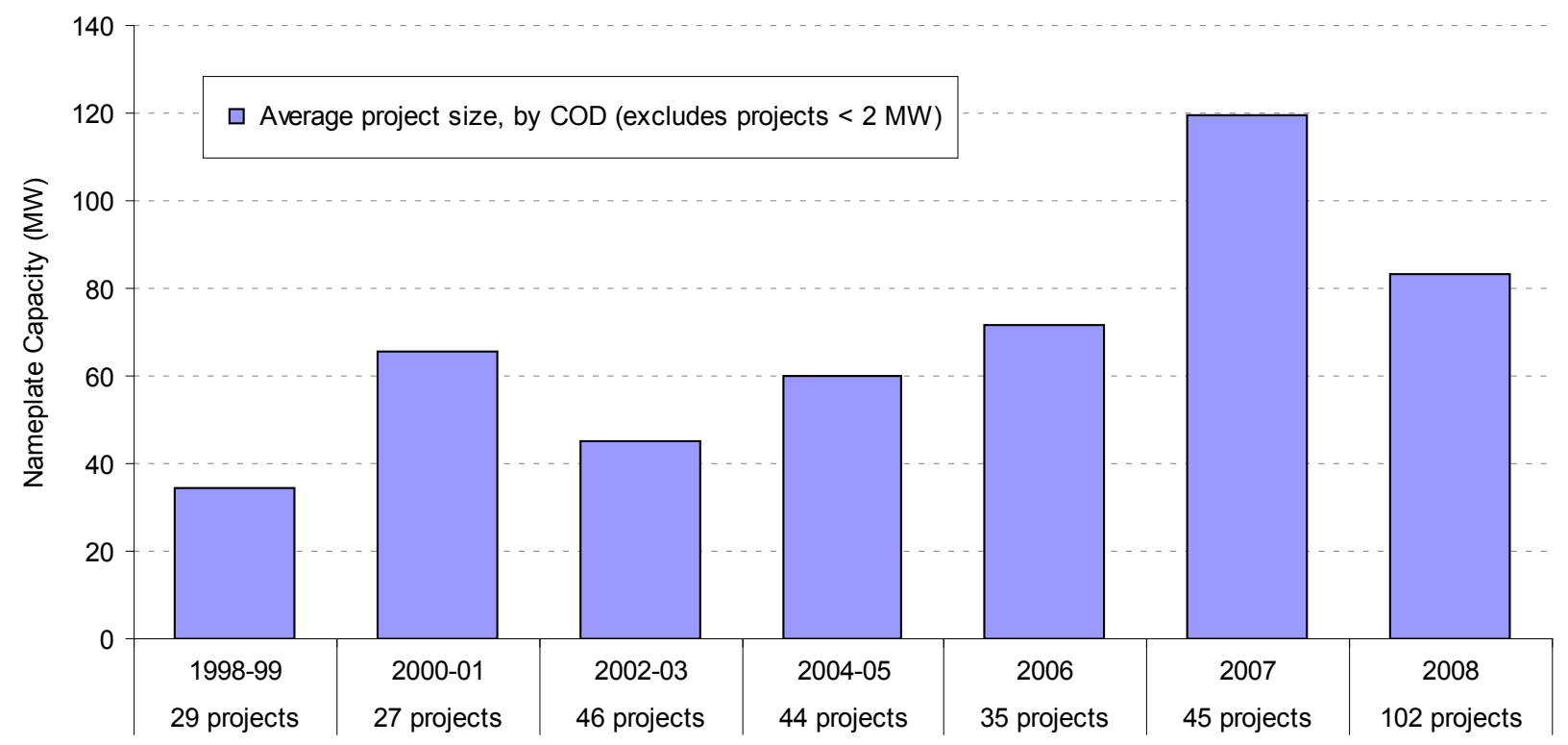

Source: Berkeley Lab analysis of AWEA project database

Figure 10. Average Project Size, by Commercial Operation Date (COD) ${ }^{17}$

\section{Developer Consolidation Slowed in 2008}

Consolidation on the development end of the wind business slowed in 2008, perhaps a reflection of the financial crisis, as well as the simple fact that many of the prime targets for investment and/or acquisition had already been acquired in earlier years. Table 6 provides a listing of major acquisition and investment activity among U.S. wind developers from 2002 through $2008 .{ }^{18}$

\footnotetext{
${ }^{17}$ Projects less than 2 MW in size are excluded from Figure 10 so that a large number of single-turbine "projects" (that, in practice, may have been developed as part of a larger, aggregated project) do not end up skewing the average. For projects defined in phases, each phase is considered to be a separate project. Projects that are partially constructed in two different years are counted as coming online in the year in which a clear majority of the capacity was completed. If roughly equal amounts of capacity are built in each year, then the full project is counted as coming online in the later year.

${ }^{18}$ Only transactions that are known to involve $500 \mathrm{MW}$ or more of in-development U.S. wind projects are included. Not included are transactions in which one developer purchases a subset of another developer's pipeline.
} 
Table 6. Acquisition and Investment Activity Among Wind Developers*

\begin{tabular}{|c|c|c|c|}
\hline Investor & $\begin{array}{c}\text { Transaction } \\
\text { Type }\end{array}$ & Developer & $\begin{array}{c}\text { Announcement } \\
\text { Date }\end{array}$ \\
\hline EDF (SIIF Energies) & Acquisition & enXco & May-02 \\
\hline Gamesa & Investment & Navitas & Oct-02 \\
\hline AES & Investment & US Wind Force & Sep-04 \\
\hline PPM (Scottish Power) & Acquisition & Atlantic Renewable Energy Corp. & Dec-04 \\
\hline AES & Acquisition & SeaWest & Jan-05 \\
\hline Goldman Sachs & Acquisition & Zilkha (Horizon) & Mar-05 \\
\hline JP Morgan Partners & Investment & Noble Power & Mar-05 \\
\hline Arclight Capital & Investment & CPV Wind & Jul-05 \\
\hline Diamond Castle & Acquisition & Catamount & Oct-05 \\
\hline Pacific Hydro & Investment & Western Wind Energy & Oct-05 \\
\hline EIF U.S. Power Fund II & Investment & Tierra Energy, LLC & Dec-05 \\
\hline Airtricity & Acquisition & Renewable Generation Inc. & Dec-05 \\
\hline Babcock \& Brown & Acquisition & G3 Energy LLC & Jan-06 \\
\hline Iberdrola & Acquisition & Community Energy Inc. & Apr-06 \\
\hline Shaw/Madison Dearborn & Investment & UPC Wind & May-06 \\
\hline NRG & Acquisition & Padoma & Jun-06 \\
\hline CPV Wind & Acquisition & Disgen & Jul-06 \\
\hline BP & Investment & Clipper & Jul-06 \\
\hline $\mathrm{BP}$ & Acquisition & Greenlight & Aug-06 \\
\hline Babcock \& Brown & Acquisition & Superior & Aug-06 \\
\hline Enel & Investment & TradeWind & Sep-06 \\
\hline Iberdrola & Acquisition & Midwest Renewable Energy Corp. & Oct-06 \\
\hline Iberdrola & Acquisition & PPM (Scottish Power) & Dec-06 \\
\hline BP & Acquisition & Orion Energy & Dec-06 \\
\hline Naturener & Acquisition & Great Plains Wind \& Energy, LLC & Feb-07 \\
\hline HSH Nordbank & Investment & Ridgeline Energy & Feb-07 \\
\hline Energias de Portugal & Acquisition & Horizon & Mar-07 \\
\hline Iberdrola & Acquisition & CPV Wind & Apr-07 \\
\hline Duke Energy & Acquisition & Tierra Energy, LLC & May-07 \\
\hline Acciona & Acquisition & EcoEnergy, LLC & Jun-07 \\
\hline Babcock \& Brown & Acquisition & Bluewater Wind & Sep-07 \\
\hline Good Energies & Investment & EverPower & Sep-07 \\
\hline E.ON AG & Acquisition & Airtricity North America & Oct-07 \\
\hline Wind Energy America & Acquisition & Boreal & Oct-07 \\
\hline Marubeni & Investment & Oak Creek Energy Systems & Dec-07 \\
\hline NTR & Investment & Wind Capital Group & Apr-08 \\
\hline Canadian Pension Plan & Investment & Noble Power & Apr-08 \\
\hline ArcLight and Terra-Gen & Acquisition & Allco Wind Energy & Jun-08 \\
\hline Duke Energy & Acquisition & Catamount & Jun-08 \\
\hline Veolia & Acquisition & Ridgeline Energy & Oct-08 \\
\hline
\end{tabular}


At least five significant transactions involving roughly $19 \mathrm{GW}$ of in-development wind projects (also called the development "pipeline") were announced in 2008, well below the 11 transactions and $37 \mathrm{GW}$ in 2007, and the 12 transactions and $34 \mathrm{GW}$ in 2006. In 2005, eight transactions totaling nearly $12 \mathrm{GW}$ were announced, while only four transactions totaling less than $4 \mathrm{GW}$ were completed from 2002 through 2004.

A number of large companies have entered the U.S. wind development business in recent years, some through acquisitions, and others through their own development activity or through joint development agreements with others. Particularly striking in recent years has been the entrance of large European energy companies into the U.S. market. Following similar activity in Europe in recent years, 2008 also marked the first significant steps by U.S.-based wind project developers - specifically, First Wind and Noble Environmental Power - to pursue initial public offerings (IPOs) to fund their growth (both companies subsequently delayed their IPOs due to market turmoil, and Noble has since canceled its offering).

\section{The Global Credit Crisis Caught Up With the Wind Sector in 2008}

After having spent the previous few years gaining comfort with and refining complicated tax equity structures to finance a growing proportion of U.S. wind projects, ${ }^{19}$ the industry received an unwelcome reminder in 2008 of the perils of using the tax code to stimulate investment in renewable energy projects. Specifically, when economic times are tough, taxable income declines and, as a result, third-party tax equity is harder to come by.

The tax equity squeeze was particularly acute in late 2008 due to the severity of the credit crisis, which caused the outright demise of several prominent tax equity investors (e.g., Lehman Brothers and Wachovia), and led to the general exodus of many others. As a result, by the end of 2008 , only a handful of tax equity investors - out of a previously growing stable that had numbered in the teens - remained in the market. ${ }^{20}$ Moreover, those investors left in the market were able to charge considerably higher yields - reportedly about 200 basis points higher (Chadbourne \& Parke 2009, 2008) - for the use of their tax base.

As the supply of tax equity dwindled, demand for tax equity increased markedly, not only from the wind sector, but also from other renewable energy sectors - namely solar and, to a lesser extent, geothermal. As a result of this increasing competition for a scarce resource, as well as the global credit crisis, tax equity investment in the U.S. wind market actually declined in 2008, despite the record-shattering growth in installed wind capacity. Specifically, JPMorgan Capital estimates that roughly 3,385 MW of wind (out of 8,545 MW total) installed in 2008 were financed by third-party tax equity - down from 3,616 MW (out of 5,249 MW total) in 2007 (Eber 2009).

\footnotetext{
19 JPMorgan Capital Corporation estimates that roughly $70 \%$ of the wind capacity installed in the U.S. in 2007 (i.e., 3,616 MW out of 5,249 MW) was financed using tax equity from third-party investors. This is up from more than $1,000 \mathrm{MW}$, accounting for $45 \%-50 \%$ of total installed capacity, in each of the two previous years (Eber 2009).

${ }^{20}$ The list of tax investors that remained in the market at the end of 2008 included (but was not limited to) JPMorgan, Union Bank of California, Bank of America, Wells Fargo, and New York Life.
} 
Other sources of finance were also hit hard in 2008. Bank lending reportedly ground to a halt in late 2008, as banks were not only concerned about preserving their own capital base, but also found it impossible to price loans amidst the unprecedented volatility in financial markets. The equity market was similarly troubled, causing two of the larger wind developers in the U.S. Noble Environmental Power and First Wind - to delay their plans for initial public stock offerings as a means of raising cash (and in June 2009, Noble withdrew its offering altogether).

In the wake of the wave of bad news that swept through the fourth quarter of 2008 in particular, however, the first half of 2009 has brought a number of indications that conditions are improving. First, the sharp increase in tax equity yields has reportedly attracted the interest of non-traditional (in the sense that they are not within the financial sector) tax equity investors, thereby suggesting that yields may have reached their peak. In addition, a few of the traditional tax investors that had exited the market in the fourth quarter of 2008 are now reportedly back in the market looking to invest; GE Energy Financial Services is perhaps the most notable example. Banks are also once again willing to lend, albeit on significantly more-conservative terms. Finally, one major foreign-owned developer/owner of wind projects in the U.S. - Iberdrola - has taken steps to reduce its dependency on third-party tax investors by purchasing Energy East, a utility holding company in the Northeastern United States. This acquisition will generate U.S. income tax liability that will better enable Iberdrola to use the tax credits and depreciation deductions generated by its U.S. wind project portfolio.

A number of policy changes in 2009 also promise to facilitate wind project finance going forward. In particular, the American Recovery and Reinvestment Act of 2009 (ARRA 2009) not only extended the PTC for qualifying wind projects through 2012, but also provides developers with the flexibility to choose either a 30\% investment tax credit (ITC) or, for a more limited time period, a 30\% cash grant in lieu of the PTC. The cash grant election in particular is projected to be quite popular, as it will reduce the amount of tax equity required to finance a project. Tax investors are already responding to the ARRA 2009 provisions by adapting existing financing structures to work in conjunction with the new incentives (Eber 2009). ARRA 2009 also significantly expanded and enhanced an existing DOE loan guarantee program that could lead to a resurgence in the use of project-level debt, and at very low cost.

\section{Though IPP Project Ownership Remained Dominant, Utility Ownership Expanded}

Private independent power producers (IPPs) continued to dominate the wind industry in 2008, owning $79 \%$ of all new capacity (Figure 11). In a continuation of the trend begun several years ago, however, $19 \%$ of total wind additions in 2008 are owned by local electric utilities, with investor-owned utilities (IOUs) owning 1,620 MW and publicly owned utilities (POUs) owning another $35 \mathrm{MW}$. Community wind power projects - defined here as projects using turbines over $50 \mathrm{~kW}$ in size and completely or partly owned by towns, schools, commercial customers, or farmers, but excluding publicly owned utilities - constitute the remaining $2 \%$ of 2008 projects. Of the cumulative 25,369 MW of installed wind capacity at the end of 2008, IPPs owned 83\% (20,989 MW), with utilities contributing 15\% (3,339 MW for IOUs and $561 \mathrm{MW}$ for POUs), and community ownership just 2\% (479 MW). The community wind sector, in particular, has found 
it difficult to make much headway in the last couple of years, in part due to the difficulty of securing smaller wind turbine orders amidst the rapid U.S. wind market expansion. The recent slowdown in the overall U.S. wind market, however, coupled with federal policy changes that could benefit community wind, ${ }^{21}$ may help boost the community wind numbers in future years.

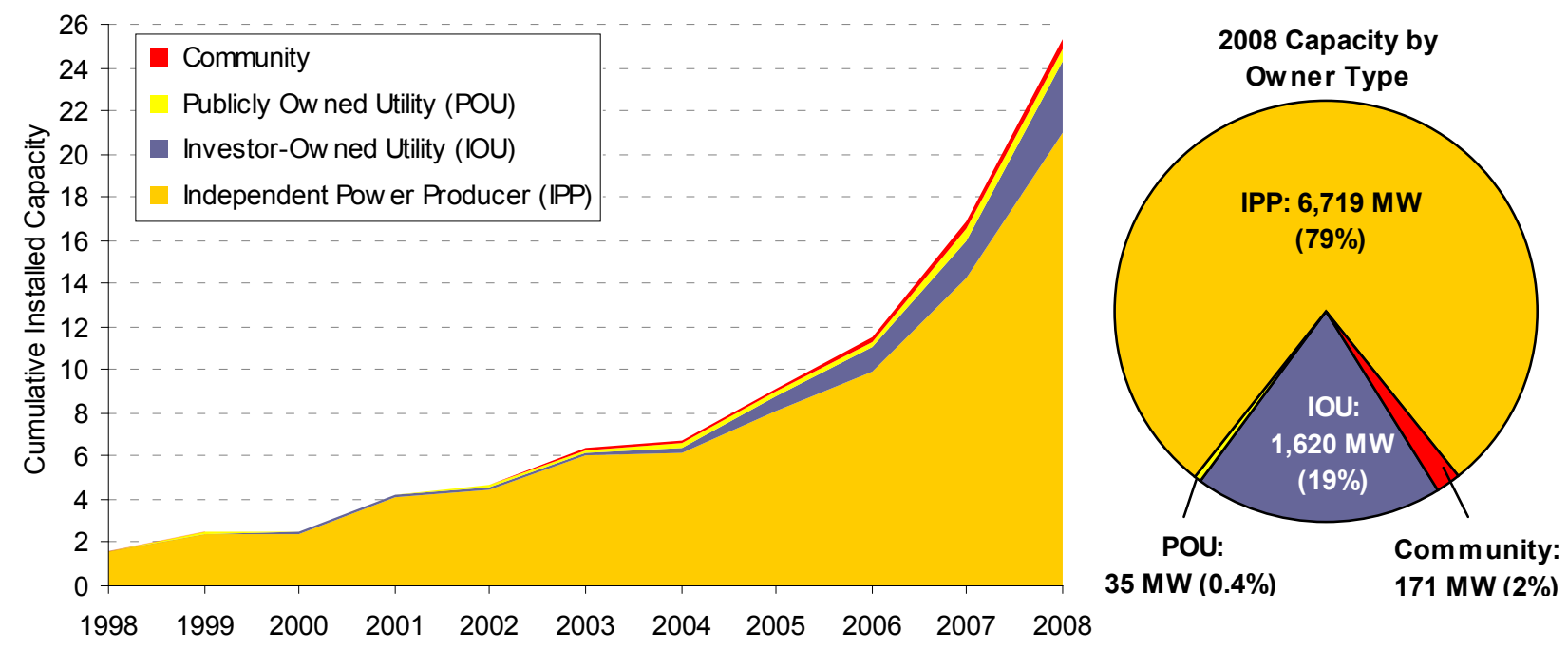

Source: Berkeley Lab estimates based on AWEA project database

Figure 11. Cumulative and 2008 Wind Capacity Categorized by Owner Type

\section{Though Long-Term Contracted Sales to Utilities Remained the Most Common Off-Take Arrangement, Merchant Plants Were Popular in 2008}

Investor-owned utilities continued to be the dominant purchasers of wind power, with $33 \%$ of new 2008 capacity and $47 \%$ of cumulative capacity selling power to IOUs under long-term contract (see Figure 12). Publicly owned utilities have also taken an active role, purchasing the output of $17 \%$ of new 2008 capacity and 16\% of cumulative capacity. For both IOUs and POUs, power purchase agreement (PPA) terms for projects built in 2008 range from 10 to 25 years, with 20 years being the most common.

The role of power marketers - defined here as corporate intermediaries that purchase power under contract and then re-sell that power to others, sometimes taking some merchant risk ${ }^{22}-$ in the wind power market has waned somewhat in recent years. In 2008, power marketers purchased the output of $7 \%$ of the new wind power capacity, with $14 \%$ of cumulative capacity

\footnotetext{
${ }^{21}$ For example, in lieu of the PTC, ARRA 2009 enables qualifying wind projects to elect, for a limited time, a federal cash grant equal to $30 \%$ of eligible project costs. This temporary policy change (described in more detail later) may, depending on how the implementing regulations are written, be favorable for some types of community wind projects, many of which have difficulty using the PTC and other tax credits.

${ }^{22}$ Power marketers are defined here to include not only traditional marketers such as PPM Energy (now part of Iberdrola), but also the wholesale power marketing affiliates of large investor-owned utilities (e.g., PPL Energy Plus or FirstEnergy Solutions), which may buy wind power on behalf of their load-serving affiliates.
} 
selling to power marketers. Among projects built in 2008, PPAs with power marketers range from 5 to 18 years in length, somewhat shorter than the range of utility PPAs.

Increasingly over time, owners of wind projects have taken on some merchant risk, meaning that a portion of their electricity sales revenue is tied to short-term contracted and/or spot market prices (with the resulting price risk commonly hedged over a 5- to 10-year period via financial transactions $)^{23}$ rather than being locked in through a long-term PPA. The owners of $43 \%$ of the wind power capacity added in 2008, for example, are accepting some merchant risk, bringing merchant/quasi-merchant ownership to $23 \%$ of total cumulative U.S. wind capacity. The majority of this activity exists in Texas, New York, and several mid-Atlantic and Midwestern states - i.e., states in which wholesale spot markets exist, where wind power has for the last several years been able to compete with these spot prices, and where significant additional revenue may be possible from the sale of renewable energy certificates (RECs). With wholesale power prices plummeting in late 2008 and through the first half of 2009, however, merchant activity is expected to diminish in the immediate future.
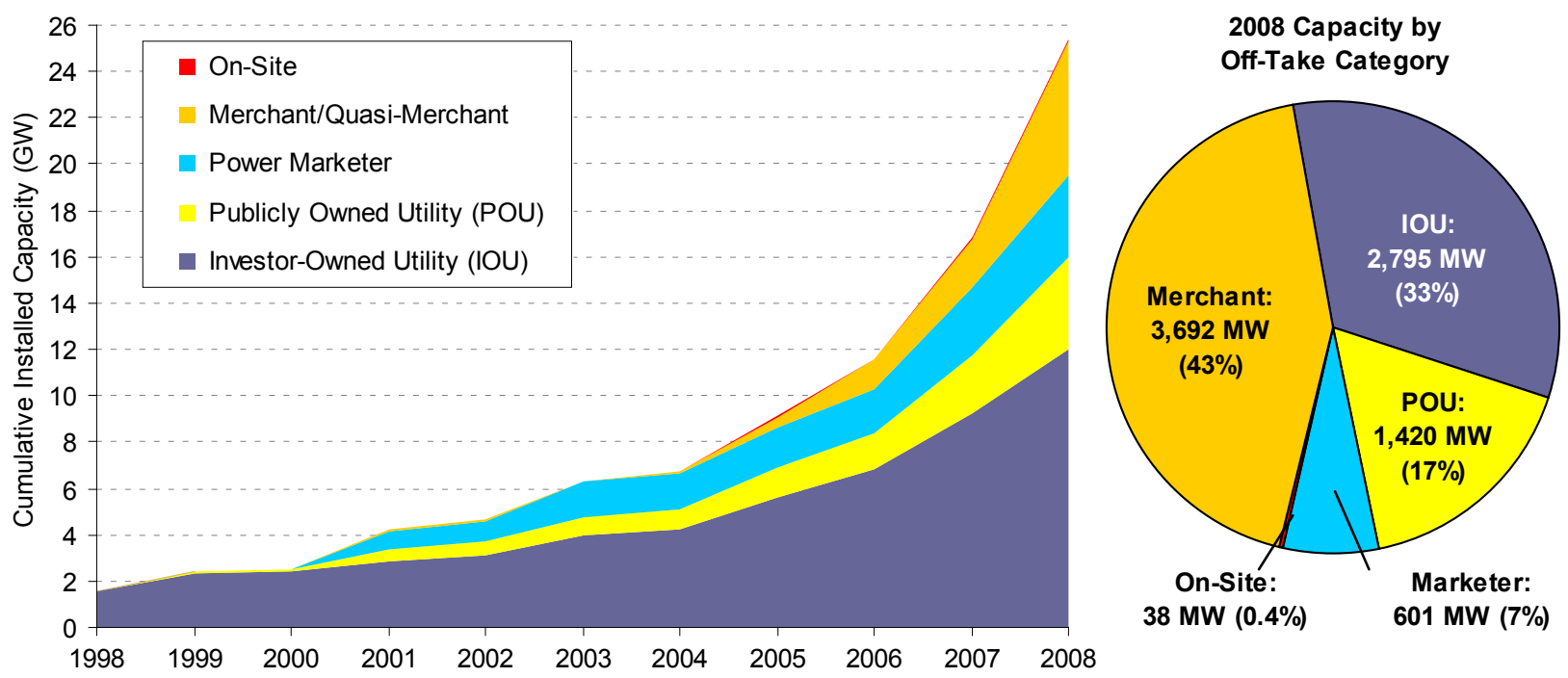

Source: Berkeley Lab estimates based on AWEA project database

Figure 12. Cumulative and 2008 Wind Capacity Categorized by Power Off-Take Arrangement

\footnotetext{
${ }^{23}$ Hedge providers working with 2008 wind projects include (but are not limited to) Fortis, Credit Suisse, Morgan Stanley, and Coral Energy Holding (a division of Shell). These hedges are often structured as a "fixed-for-floating" power price swap - a purely financial arrangement whereby the wind project swaps the "floating" revenue stream that it earns from spot power sales for a "fixed" revenue stream based on an agreed-upon strike price. For at least one project in Texas (where natural gas is virtually always the marginal supply unit), the hedge has been structured in the natural gas market rather than the power market, in order to take advantage of the greater liquidity and longer terms available in the forward gas market.
} 


\section{Price, Cost, and Performance Trends}

\section{Upward Pressure on Wind Power Prices Continued in 2008}

Although many of the cost pressures facing the industry in recent years (e.g., rising materials costs, the weak dollar, turbine and component shortages) began to ease in the second half of 2008, it will take some time before these effects flow through the project development pipeline to impact wind power prices. As such, 2008 was another year of rising wind power prices.

Berkeley Lab maintains a database of wind power sales prices, which currently contains price data for 145 wind projects installed between 1998 and the end of 2008. These projects total $9,873 \mathrm{MW}$, or $42 \%$ of the wind capacity brought on line in the U.S. over the 1998-2008 period. ${ }^{24}$ The dataset excludes merchant plants and projects that sell renewable energy certificates (RECs) separately. As such, the prices in this database reflect the bundled price of electricity and RECs as sold by the project owner under a power purchase agreement. Because these prices are artificially suppressed by the receipt of available state and federal incentives (e.g., the prices reported here would be at least $\$ 20 / \mathrm{MWh}$ higher without the PTC), they do not represent wind energy generation costs.

Based on this database, the capacity-weighted average power sales price from the sample of post-1997 wind projects remains low by historical standards. Figure 13 shows the cumulative capacity-weighted average wind power price (along with the range of individual project prices falling between the $25^{\text {th }}$ and $75^{\text {th }}$ percentiles) in each calendar year from 1999 through 2008. Based on the limited sample of 7 projects built in 1998 or 1999 and totaling $450 \mathrm{MW}$, the weighted-average price of wind in 1999 was more than \$64/MWh (expressed in 2008 dollars). By 2008, in contrast, the cumulative sample of projects built from 1998 through 2008 had grown to 145 projects totaling $9,873 \mathrm{MW}$, with an average price of just over $\$ 40 / \mathrm{MWh}$ (with $50 \%$ of individual project prices falling between $\$ 33 / \mathrm{MWh}$ and $\$ 51.5 / \mathrm{MWh}){ }^{25}$ Although Figure 13 does show a modest increase in the weighted-average wind power price over the past three years, reflecting rising prices from new projects, the cumulative nature of the graphic mutes the degree of increase.

\footnotetext{
${ }^{24}$ Three factors significantly restrict the size of this sample: (1) projects located within ERCOT (in Texas) fall outside of FERC's jurisdiction, and are therefore not required to report prices (reduces sample by about 6,500 MW); (2) the increasing number of utility-owned projects are not included, since these projects do not sell their power on the wholesale market (reduces sample by about 3,900 MW); (3) the increasing number of merchant (or quasimerchant) projects that sell power and RECs separately are not included in the sample, because the power price reported by these projects only represents a portion of total revenue received (reduces sample by about 1,200 MW). ${ }^{25}$ All wind power pricing data presented in this report exclude the few projects located in Hawaii. Such projects are considered outliers in that they are significantly more expensive to build than projects in the continental United States, and receive a power sales price that is significantly higher-than-normal, in part because it is linked to the price of oil. For example, the three major wind projects located in Hawaii (totaling $62 \mathrm{MW}$ ) earned revenue in 2008 that ranged from $\$ 130 / \mathrm{MWh}$ to $\$ 230 / \mathrm{MWh}$ on average, which is considerably higher than the price received by most wind projects built on the mainland.
} 


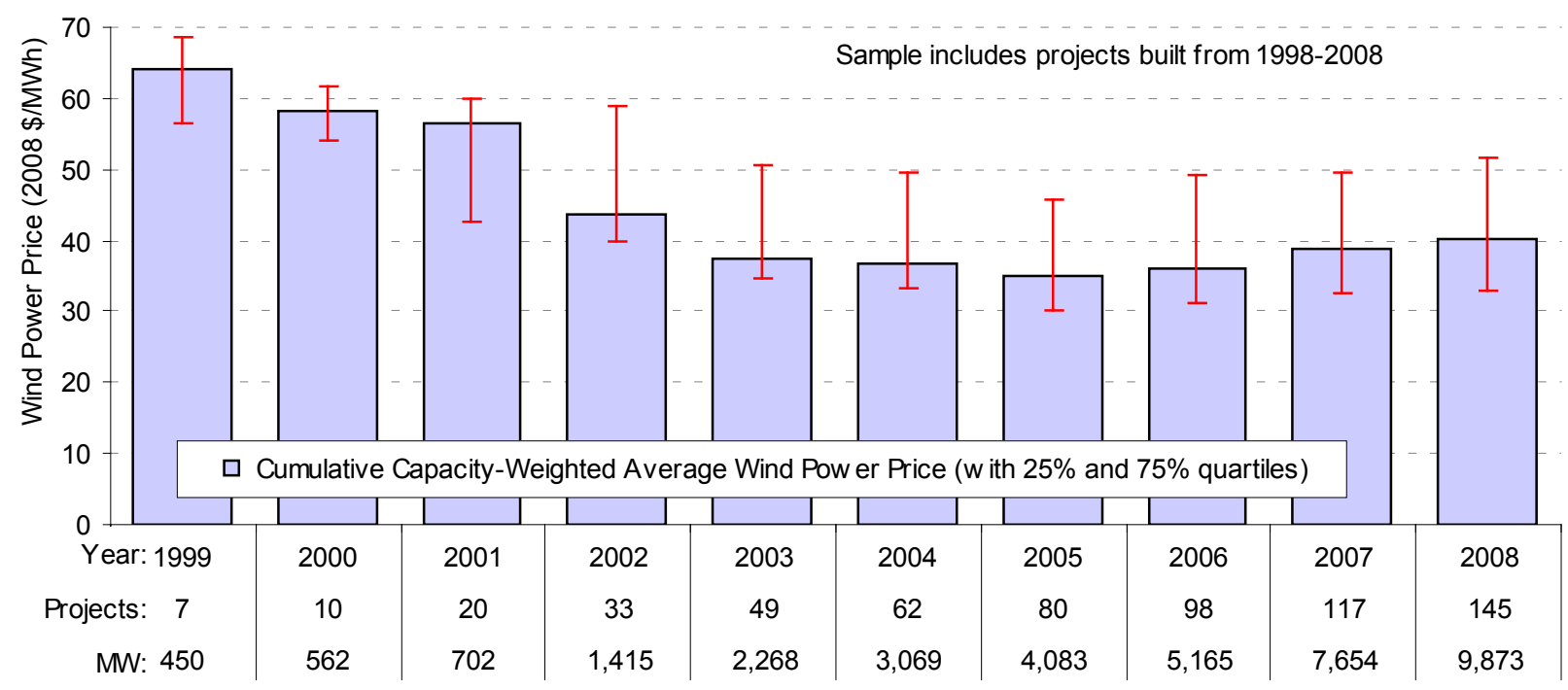

Source: Berkeley Lab database

Figure 13. Cumulative Capacity-Weighted Average Wind Power Prices Over Time

To better illustrate changes in the price of power from newly built wind projects, Figure 14 shows average wind power sales prices in 2008, grouped by project vintage (i.e., by each project's initial commercial operation date) ${ }^{26}$ Although the limited project sample and the considerable variability in prices across projects installed in a given time period complicate analysis of national price trends (with averages subject to regional and other factors), the general trend exhibited by the capacity-weighted-average prices (i.e., the blue columns) nevertheless suggests that, following a general decline since 1998, prices bottomed out for projects built in 2002 and 2003, and have since risen significantly. ${ }^{27}$ Specifically, the capacity-weighted average 2008 sales price for projects in the sample built in 2008 was roughly $\$ 51.5 / \mathrm{MWh}$, up from an average of \$43.2/MWh for the sample of projects built in 2007, and \$20.6/MWh higher than the average of $\$ 30.9 / \mathrm{MWh}$ among projects built at the low point in 2002 and 2003.

\footnotetext{
${ }^{26}$ Prices from two individual projects built during the 2000-2001 period, and one project built in 2008, are not shown in Figure 14 (due to the scale of the y-axis), but are included in the capacity-weighted averages for those periods. The omitted prices are roughly $\$ 93 / \mathrm{MWh}$ and $\$ 150 / \mathrm{MWh}$ in the earlier period, and $\$ 126 / \mathrm{MWh}$ for the 2008 project.

${ }^{27}$ Although it may seem counterintuitive, the weighted-average price in 1999 for projects built in 1998 and 1999 (shown in Figure 13 to be about $\$ 64 / \mathrm{MWh}$ ) is significantly higher than the weighted-average price in 2008 for projects built in 1998 and 1999 (shown in Figure 14 to be about $\$ 34 / \mathrm{MWh}$ ) for three reasons: (1) the sample size is larger in Figure 14, due to the fact that 2008 prices are presented, rather than 1999 prices as in Figure 13 (i.e., we were unable to obtain early-year pricing for some of the projects built in 1998-1999); (2) two of the larger projects built in 1998 and 1999 (for which both 1999 and 2008 prices are available, meaning that these projects are represented within both figures) have nominal PPA prices that actually decline, rather than remaining flat or escalating, over time; and (3) inflating all prices to constant 2008 dollar terms impacts older (i.e., 1999) prices more than it does more-recent (i.e., 2008) prices.
} 


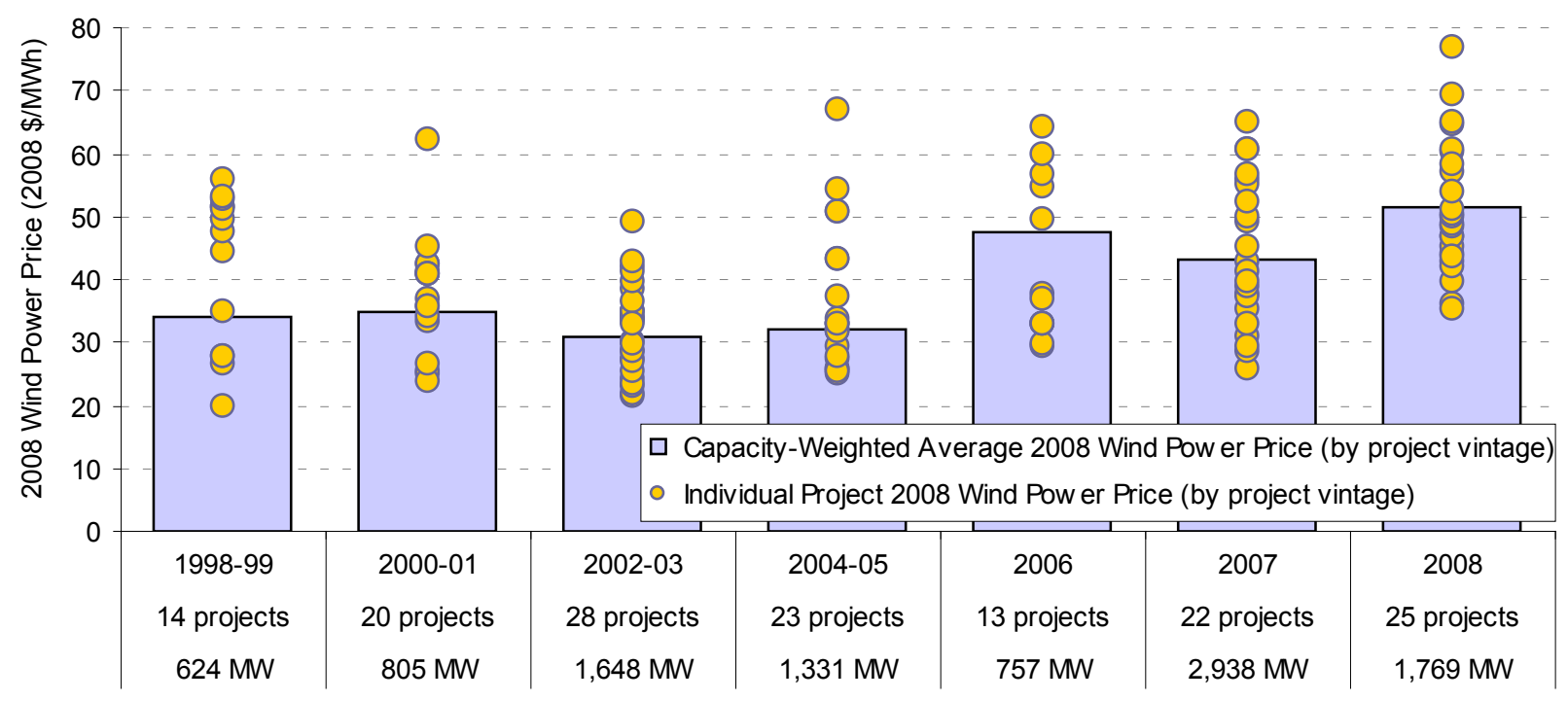

Source: Berkeley Lab database

\section{Figure 14. 2008 Wind Power Prices by Project Vintage}

The underlying variability in prices within a year is caused in part by regional factors, which may affect not only project capacity factors (depending on the strength of the wind resource in a given region), but also development and installation costs (depending on a region's physical geography, population density, or even regulatory processes). It is also possible that regions with higher wholesale power prices will, in general, yield higher wind contract prices due to arbitrage opportunities on the wholesale market.

Figure 15 shows individual project and average 2008 wind power prices by region for just those wind projects installed from 2006-2008 (a period of time in which pricing was reasonably stable, as shown in Figure 14), with regions as defined in Figure 16. Although sample size is quite small and therefore problematic in numerous regions, Texas and the Heartland region appear to be among the lowest price areas on average, while the East and New England are among the higher price regions. ${ }^{28}$

\footnotetext{
${ }^{28}$ One of the two New England projects in our sample over this period is not shown in Figure 15 because its price (\$126/MWh) exceeds the scale of the y-axis; however, this project's price is included in the capacity-weighted average for New England. Once again, sample size in Texas is so limited (despite the enormous growth of wind capacity in that state) because generators located within ERCOT are not required to file pricing information with FERC. As such, the pricing information for Texas provided in this report comes primarily from projects located in the Texas panhandle, which is within the Southwest Power Pool (SPP) rather than ERCOT.
} 


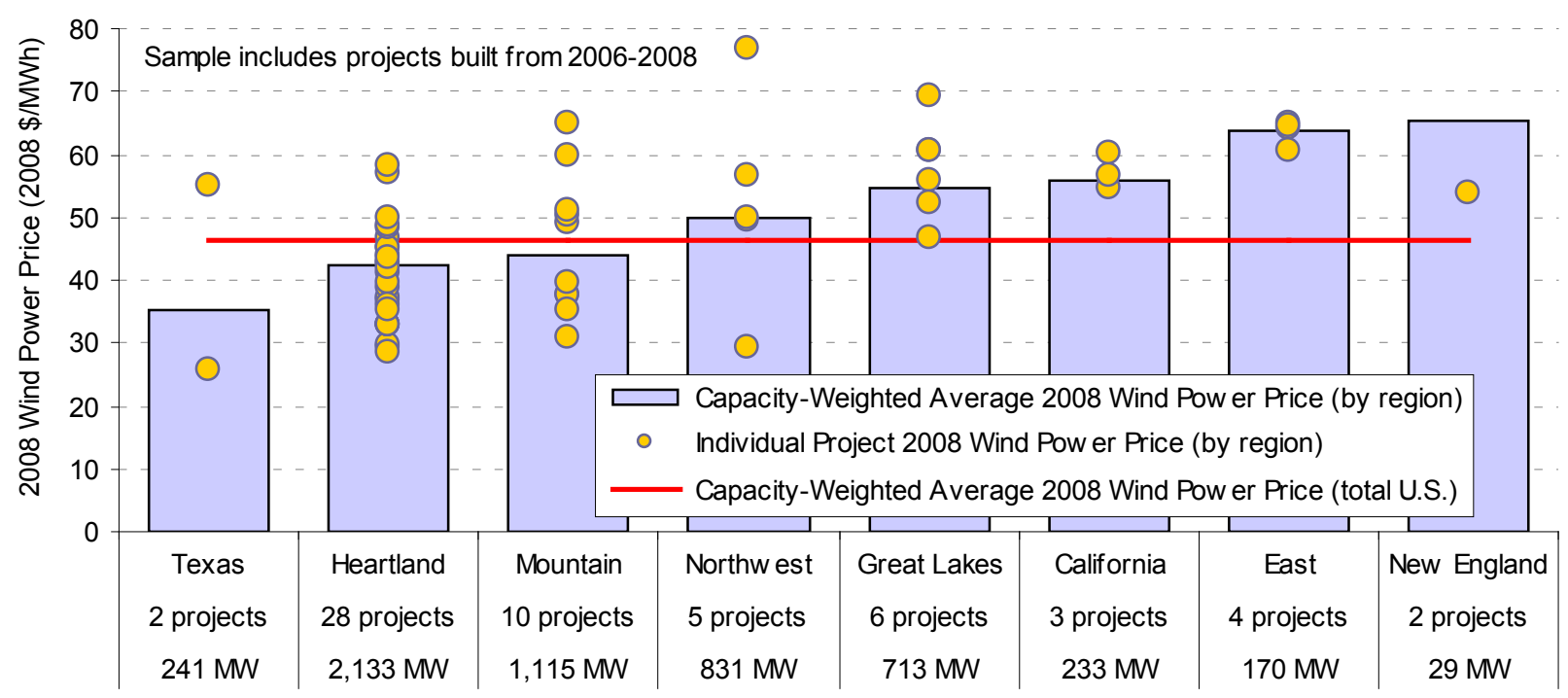

Source: Berkeley Lab database

\section{Figure 15. 2008 Wind Power Prices by Region: 2006-2008 Projects Only}

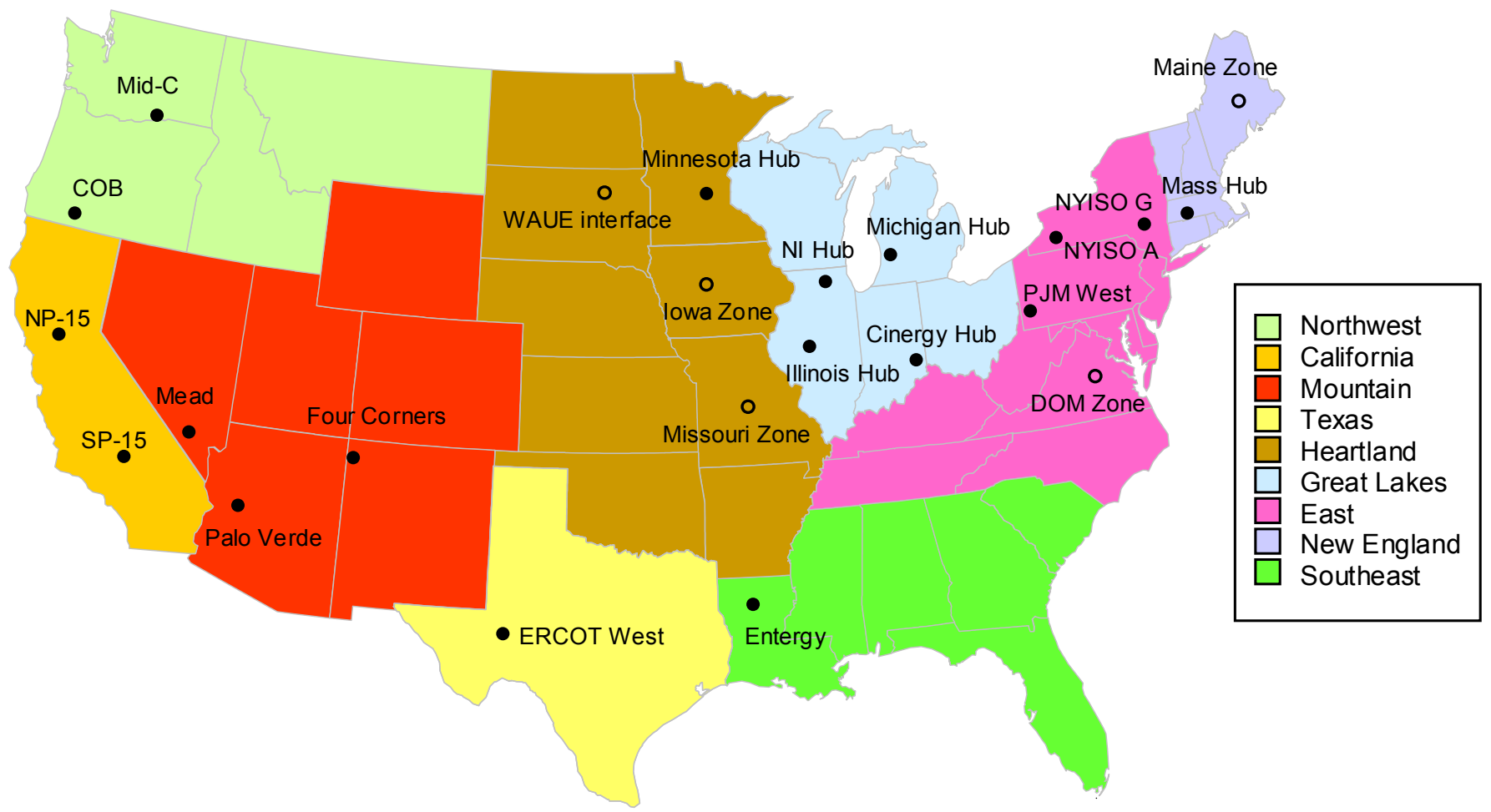

Figure 16. Map of Regions and Wholesale Price Hubs Used in Analysis 


\section{REC Markets Remain Fragmented, with a Wide Range of Pricing}

The wind power transactions identified in Figures 13 through 15 reflect only the bundled sale of both electricity and RECs; excluded from those figures are projects that sell RECs separately from electricity, thereby generating two sources of revenue. REC markets are highly fragmented in the United States, but consist of two distinct segments: compliance markets in which RECs are purchased to meet state RPS obligations, and green power markets in which RECs are purchased on a voluntary basis.

The figures below present indicative monthly data of spot-market REC prices in both compliance and voluntary markets; data for compliance markets focus on the "Class I" or "Main Tier" of the RPS policies. Clearly, spot REC prices have varied substantially, both among states and over time within individual states. Key trends in 2008 compliance markets include substantial declines in REC prices to serve RPS requirements in Connecticut, Massachusetts, and New Jersey. Prices remained relatively low in Texas, Maryland, Pennsylvania, and Washington D.C., due to a surplus of eligible renewable energy supply relative to RPS-driven demand in those markets. Despite low REC prices in Texas, the combination of relatively high wholesale power prices and the possibility of additional REC revenue increased merchant wind activity in that state in 2008. RECs offered in voluntary markets ranged from less than $\$ 5 / \mathrm{MWh}$ to approximately $\$ 10 / \mathrm{MWh}$ in 2008 , with a slight erosion of prices in the West relative to levels observed at the end of 2007.
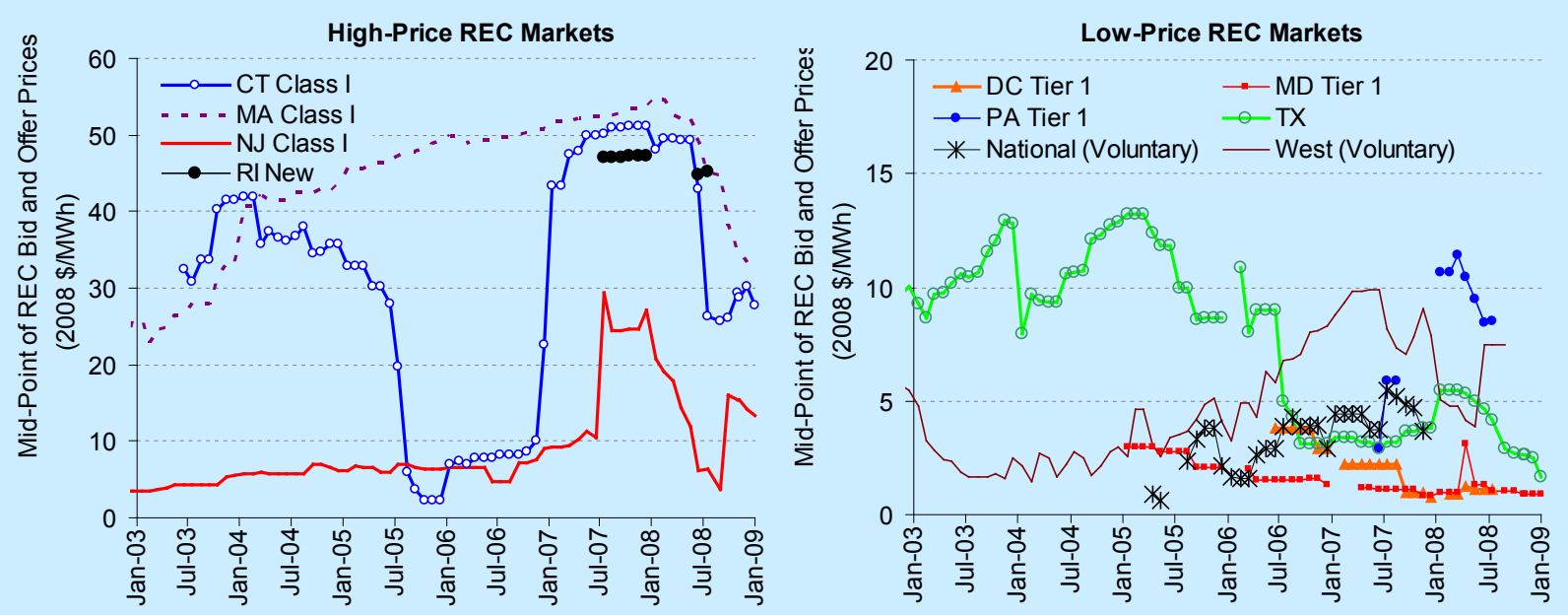

Source: Evolution Markets, Spectron

\section{Wind Remained Competitive in Wholesale Power Markets in 2008, but 2009 Is Likely To Be More Challenging}

A simple comparison of the wind prices presented in the previous section to recent wholesale power prices throughout the United States demonstrates that wind power prices have been competitive with wholesale power market prices over the past few years. Figure 17 shows the range (minimum and maximum) of average annual wholesale power prices for a flat block of power $^{29}$ going back to 2003, at twenty-three different pricing nodes located throughout the

${ }^{29}$ A flat block of power is defined as a constant amount of electricity generated and sold over a specified time period. Though wind projects do not provide a perfectly flat block of power, as a common point of comparison, a flat block is not an unreasonable starting point. In other words, the time-variability of wind generation is often such that its wholesale market value is not too dissimilar from that of a flat block of (non-firm) power. 
country (refer to Figure 16 for the names and approximate locations of the twenty-three pricing nodes represented by the blue-shaded area ${ }^{30}$ ). The red dots show the cumulative capacityweighted average price received by wind projects in each year among those projects in the sample with commercial operation dates of 1998 through 2008 (consistent with the data first presented in Figure 13). At least on a cumulative basis within the sample of projects reported here, average wind power prices have consistently been at or below the low end of the wholesale power price range.

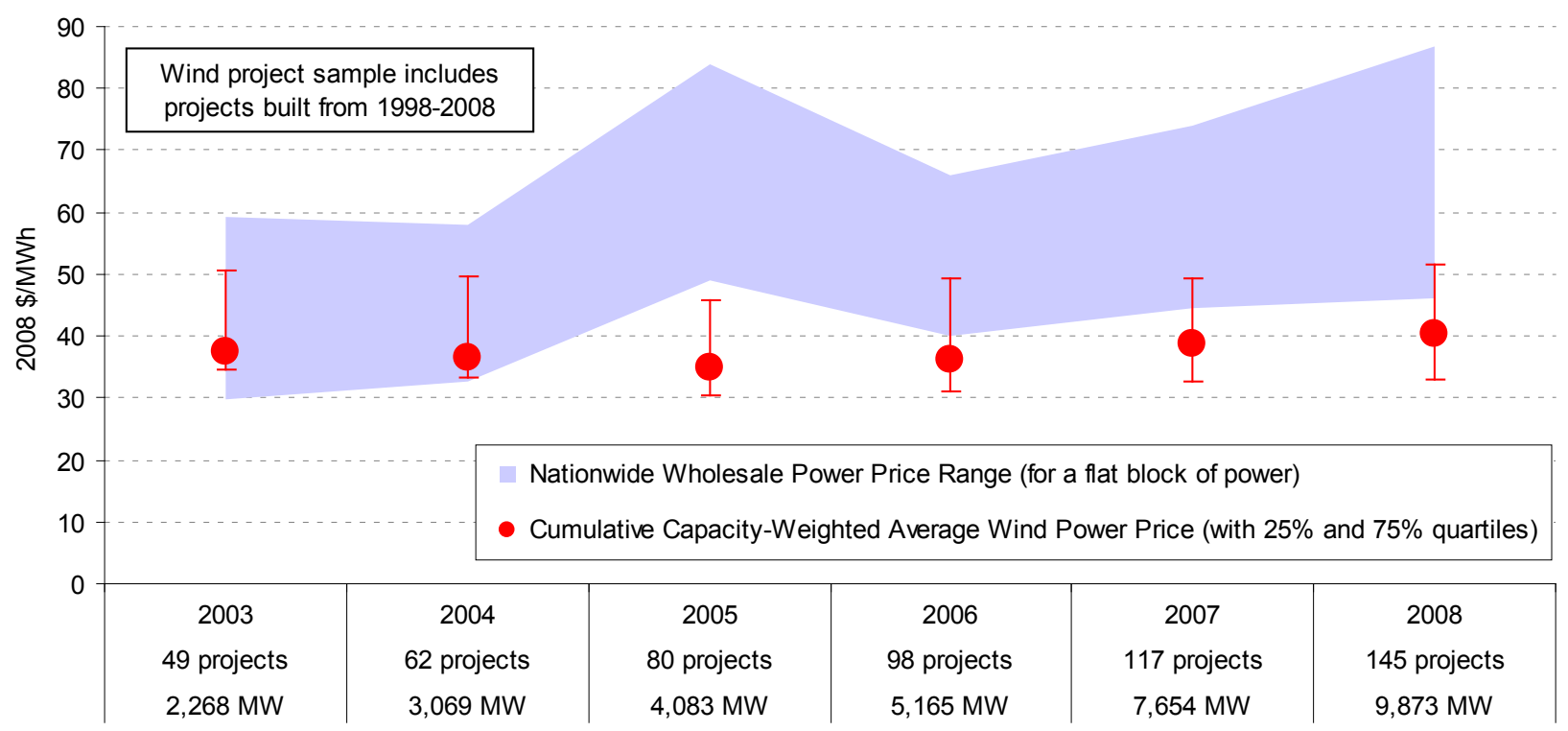

Source: Berkeley Lab database, FERC, Ventyx, ICE

\section{Figure 17. Average Cumulative Wind and Wholesale Power Prices Over Time}

Though Figure 17 shows that - on average - wind projects installed from 1998 through 2008 have, since 2003 at least, been priced at or below the low end of the wholesale power price range on a nationwide basis, there are clearly regional differences in wholesale power prices and in the average price of wind power. Moreover, as shown earlier in Figure 14, wind power prices have risen among more-recently built projects. Figure 18 accounts for both of these considerations by focusing on 2008 wind and wholesale power prices in the same regions as shown earlier, based only on the sample of wind projects installed from 2006 through 2008 (i.e., a recent period of relative pricing stability, as shown earlier in Figure 14). ${ }^{31}$ Although there is quite a bit of variability within some regions, and several also have limited sample size, in most regions the average wind power price - even among this recent sample of projects - was either within or below the range of average wholesale prices in 2008. In other words, rising wholesale power prices since earlier in the decade and through 2008 have, to a degree, mitigated the impact of rising wind power prices on wind's competitive position. Lower wholesale power prices so far in 2009, however, may reverse this trend in the coming years.

\footnotetext{
${ }^{30}$ The five pricing nodes represented in Figure 16 by an open, rather than closed, bullet do not have complete pricing history back through 2003. As such, the wholesale price range presented in Figure 17 does not, in every year, reflect data from the complete set of hubs.

${ }^{31}$ Although its price $(\$ 126 / \mathrm{MWh})$ is factored into the capacity-weighted average wind power price (depicted by the red dash), one New England project is not shown in Figure 18, due to scale limitations.
} 


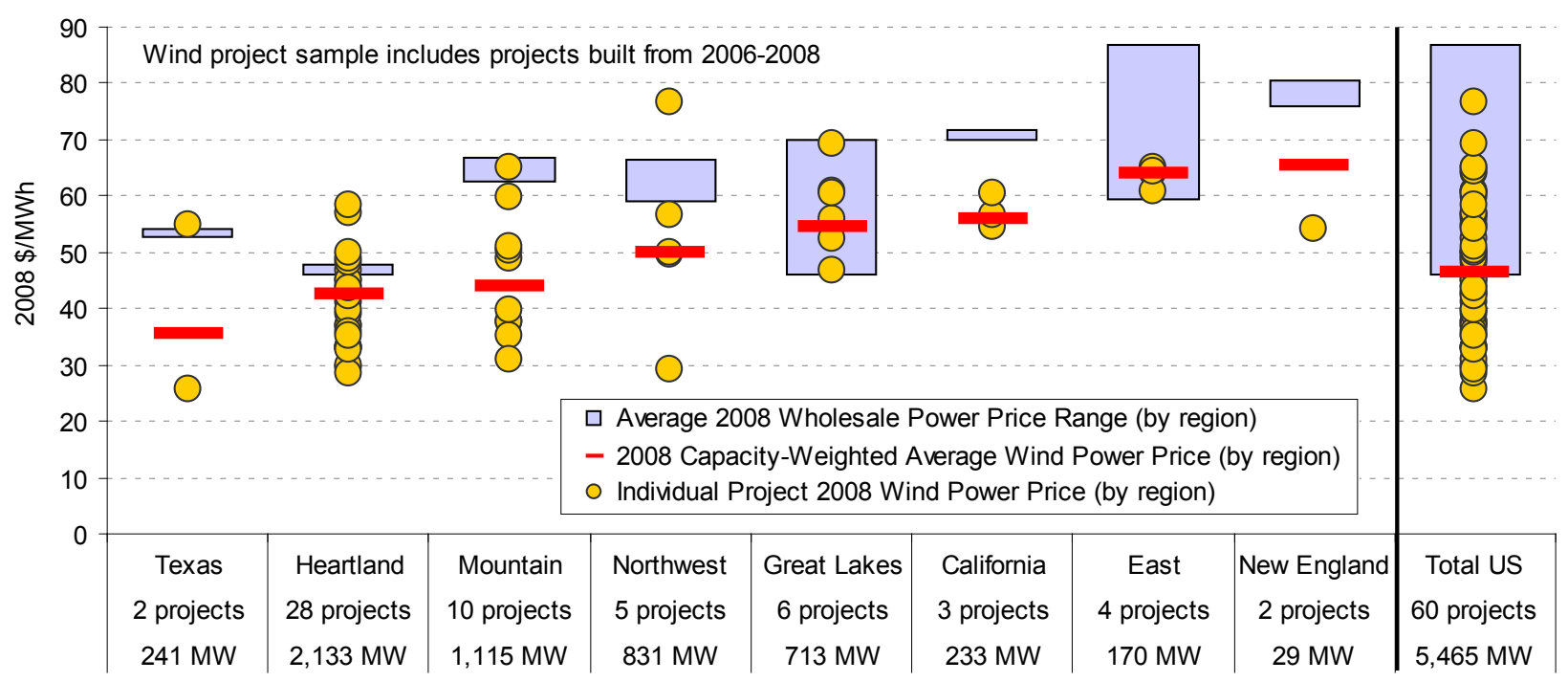

Source: Berkeley Lab database, Ventyx, ICE

Figure 18. Wind and Wholesale Power Prices by Region: 2006-2008 Projects Only

Notwithstanding the comparisons made in Figures 17 and 18, it should be recognized that neither the wind nor wholesale power prices presented in this section reflect the full social costs of power generation and delivery. Specifically, the wind power prices are suppressed by virtue of federal and, in some cases, state tax and financial incentives. Furthermore, these prices do not fully reflect integration, resource adequacy, or transmission costs. At the same time, wholesale power prices do not fully reflect transmission costs, may not fully reflect capital and fixed operating costs, and are suppressed by virtue of any financial incentives provided to fossil-fueled generation and by not fully accounting for the environmental and social costs of that generation. In addition, wind power prices - once established - are typically fixed and known (because wind is often sold through long-term, fixed-price power purchase agreements), whereas wholesale power prices are short-term and therefore subject to change over time. Finally, the location of the wholesale pricing nodes and the assumption of a flat-block of power are not perfectly consistent with the location and output profile of the sample of wind projects.

In short, comparing wind and wholesale power prices in this manner is not appropriate if one's goal is to fully account for the costs and benefits of wind relative to its competition. Another way to think of Figures 17 and 18, however, is as loosely representing the decision facing wholesale power purchasers - i.e., whether to contract long-term for wind power or buy a flat block of (non-firm) spot power on the wholesale market. In this sense, the costs represented in Figures 17 and 18 are reasonably comparable, in that they represent (to some degree, at least) what the power purchaser would actually pay. 


\section{Project Performance and Capital Costs Drive Wind Power Prices}

Wind power sales prices are affected by a number of factors, two of the most important of which are installed project costs and project performance. ${ }^{32}$ Figures 19 and 20 illustrate the importance of these two variables.

Figure 19 shows the relationship between project-level installed costs and power sales prices in 2008 for a sample of more than 7,800 MW of wind projects installed in the United States from 1998 through $2008 .^{33}$ Though the scatter is considerable, in general, projects with higher installed costs also have higher wind power prices.

Figure 20 illustrates the relationship between project-level capacity factors in 2008 and power sales prices in that same year for a sample of more than 7,800 MW of wind projects installed from 1998 through 2007. The inverse relationship shows that projects with higher capacity factors generally have lower wind power prices, though considerable scatter is again apparent.

The next few sections of this report explore trends in installed costs and project performance in more detail, as both factors can have significant effects on wind power prices.

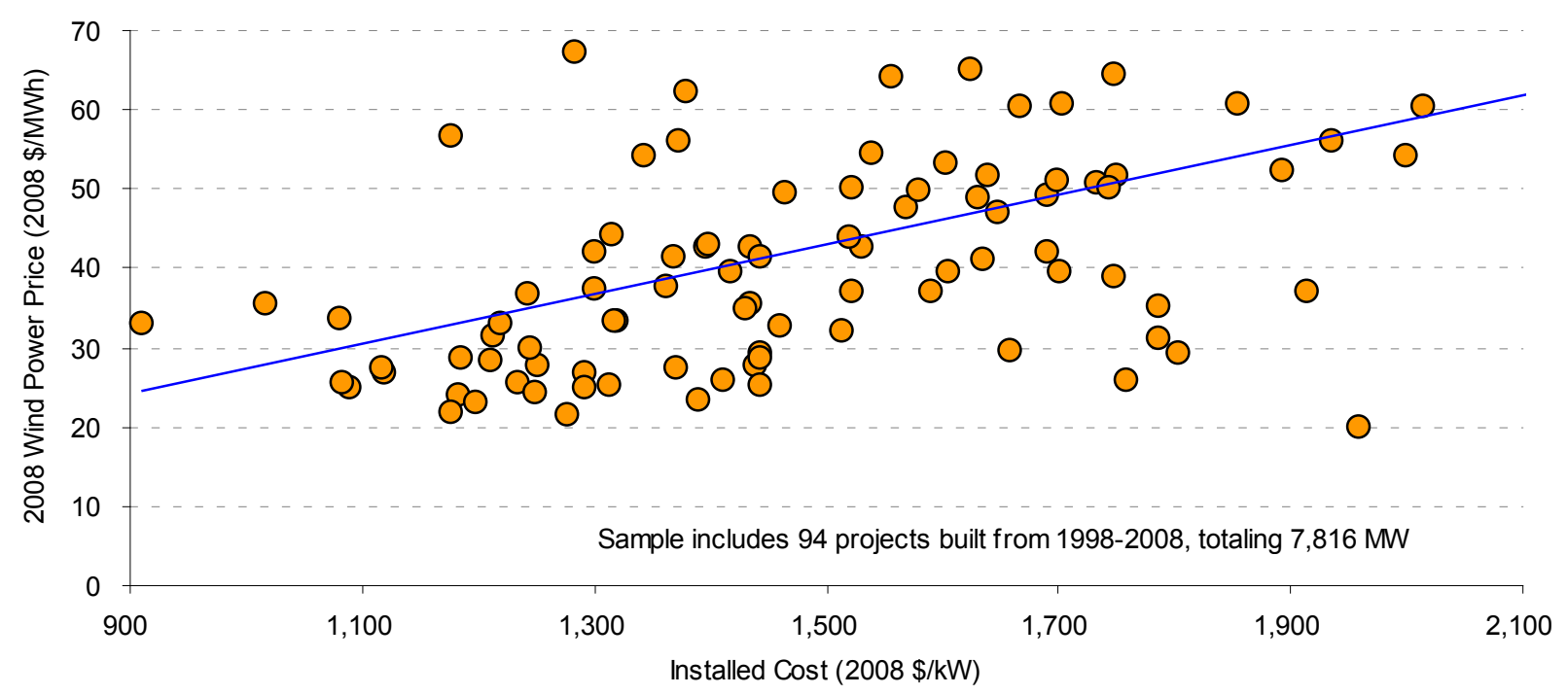

Source: Berkeley Lab database

Figure 19. 2008 Wind Power Price as a Function of Installed Project Costs

\footnotetext{
${ }^{32}$ Operations and maintenance (O\&M) costs are another important variable that affects wind power prices. A later section of this report covers trends in project-level O\&M costs.

${ }^{33}$ In Figure 19, three project outliers (the same three described earlier in footnote 26) are obscured by the compressed y-axis scale, yet still influence the trend line. In Figure 20, two of these three outliers are obscured by the compressed y-axis scale, yet still influence the trend line.
} 


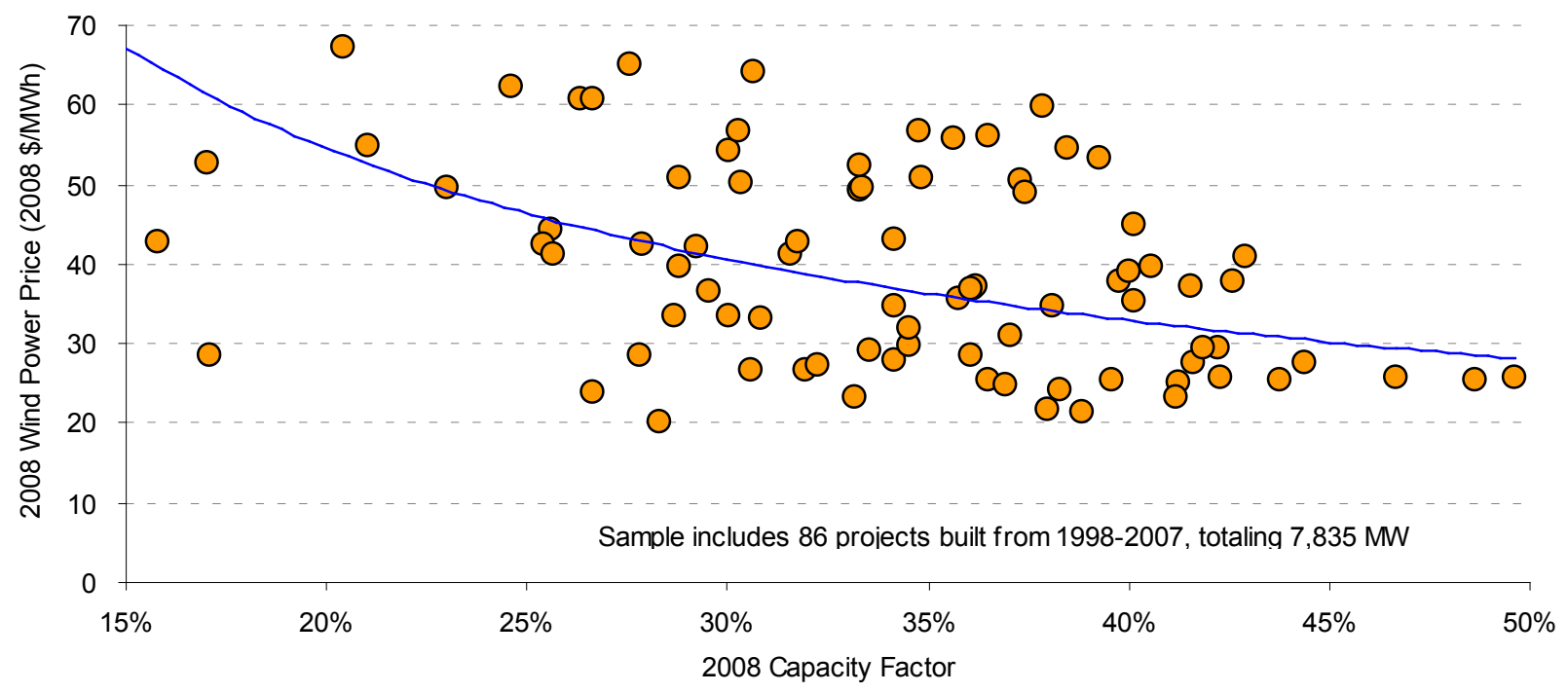

Source: Berkeley Lab database

Figure 20. 2008 Wind Power Price as a Function of 2008 Capacity Factor

\section{Installed Project Costs Continued to Rise in 2008, After a Long Period of Decline}

Berkeley Lab has compiled a sizable database of the installed costs of wind projects in the United States, including data on 61 projects completed in 2008 totaling $6,125 \mathrm{MW}$, or $72 \%$ of the wind power capacity installed in that year. In aggregate, the dataset includes 283 completed wind projects in the continental United States totaling 18,641 MW, and equaling roughly $73 \%$ of all wind capacity installed in the United States at the end of 2008. The dataset also includes cost projections for a sample of proposed projects. In general, reported project costs reflect turbine purchase and installation, balance of plant, and any substation and/or interconnection expenses. Data sources are diverse, however, and are not all of equal credibility, so emphasis should be placed on overall trends in the data, rather than on individual project-level estimates.

As shown in Figure 21, wind project installed costs declined dramatically from the beginning of the industry in California in the 1980s through the early 2000s (falling by roughly $\$ 2,700 / \mathrm{kW}$ over this period ${ }^{34}$ ), but have more recently increased. ${ }^{35}$ Among the sample of projects built in 2008 , for example, the capacity-weighted average installed cost rose to $\$ 1,915 / \mathrm{kW}$, up $\$ 190 / \mathrm{kW}$ (11\%) from the weighted-average cost of installed projects in $2007(\$ 1,725 / \mathrm{kW})$, and up

\footnotetext{
${ }^{34}$ Limited sample size early on - particularly in the 1980 s - makes it difficult to pin down this number with a high degree of confidence.

${ }^{35}$ Learning curves have been used extensively to understand past cost trends and to forecast future cost reductions for a variety of energy technologies, including wind. Learning curves start with the premise that increases in the cumulative production or installation of a given technology leads to a reduction in its costs. The principal parameter calculated by learning curve studies is the learning rate: for every doubling of cumulative production/installation, the learning rate specifies the associated percentage reduction in costs. Based on the installed cost data presented in Figure 21 and global cumulative wind installations, learning rates can be calculated as follows: $10.8 \%$ (using data from 1982 through 2008) or 14.4\% (using data only during the period of cost reduction, 1982-2004).
} 
$\$ 630 / \mathrm{kW}(49 \%)$ from the average cost of projects installed from 2001 through 2004. Project costs are clearly on the rise. ${ }^{36}$

Moreover, despite the recent softening in spot wind turbine prices (described later), installed project costs are likely to remain high in 2009 (and perhaps beyond), as developers continue to work their way through a backlog of turbines purchased in late 2007 and early 2008 at peak prices under long-term frame agreements. For example, though not shown in Figure 21, the weighted-average cost estimate for more than 3,600 MW of projects likely to be built in 2009 is $\$ 2,120 / \mathrm{kW}$, or $\$ 205 / \mathrm{kW}$ higher than for our sample of projects completed in 2008 .

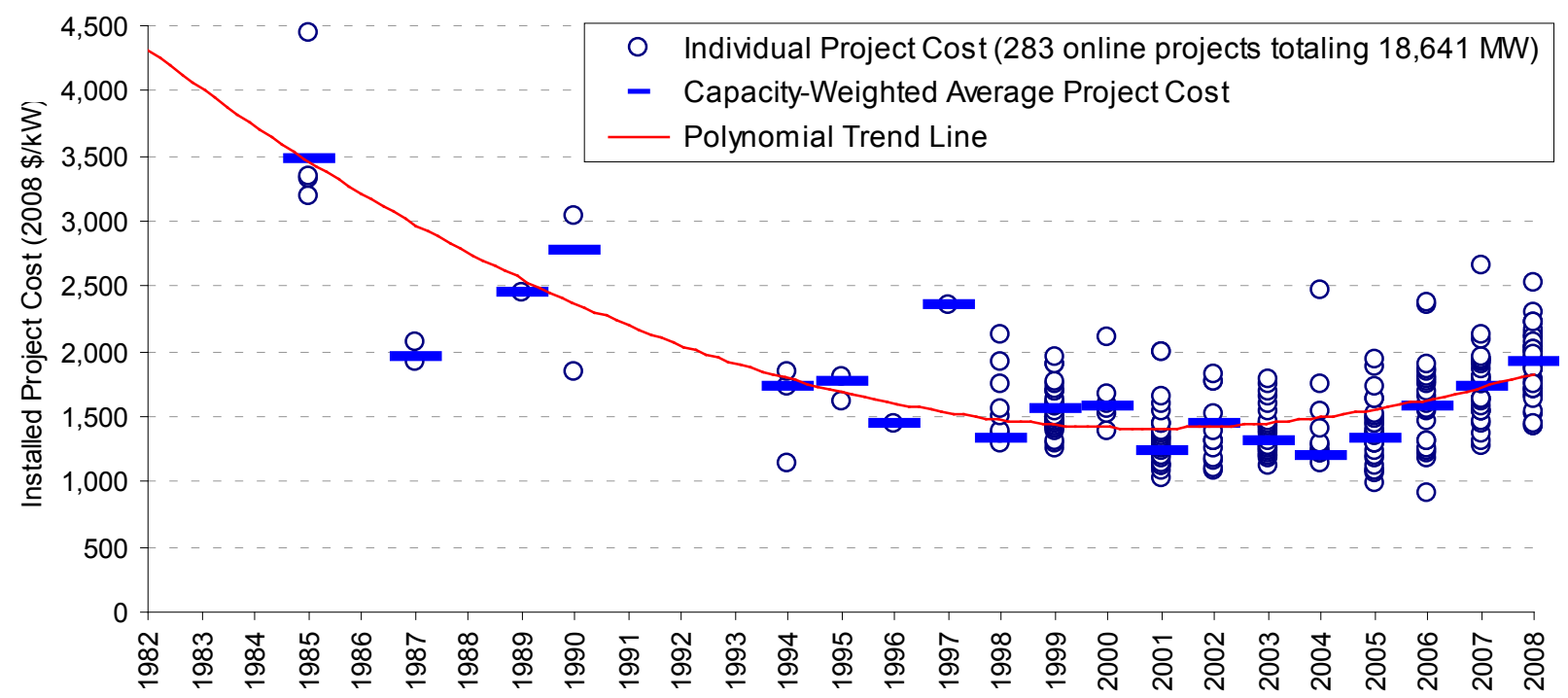

Source: Berkeley Lab database (some data points suppressed to protect confidentiality)

Figure 21. Installed Wind Project Costs Over Time

Regional differences in project costs may occur due to variations in development costs, transportation costs, siting and permitting requirements and timeframes, and balance-of-plant and construction expenditures. Considering projects in the sample that were installed in 2007 and 2008 , Figure 22 shows that the capacity-weighted average cost equaled $\$ 1,850 / \mathrm{kW}$ nationwide over this period, but varied somewhat by region. New England and the East were the highest cost regions, while the Mountain region and Texas were the lowest cost. ${ }^{37}$

\footnotetext{
${ }^{36}$ It is important to recognize that wind was not alone in seeing upward pressure on project costs - other types of power plants experienced similar increases in capital costs. In September 2007, for example, the Edison Foundation published a report showing increases in the installed cost of both natural gas and coal power plants that rival that seen in the wind industry (Chupka and Basheda 2007). Similarly, the IHS CERA Power Capital Cost Index (PCCI) of coal, gas, and wind power plants continued its escalation to 189 in the third quarter of 2008, indicating that the average cost of these power plants had increased by $89 \%$ since 2000 (IHS CERA 2008).

${ }^{37}$ California is excluded from Figure 22 because of insufficient sample size (only one data point during this period). Graphical presentation of the data in this way should be viewed with some caution, as numerous factors influence project costs (e.g., whether projects are repowered vs. "greenfield" development, etc.). Actual cost differences among some regions may therefore be more (or less) significant than they appear in Figure 22.
} 


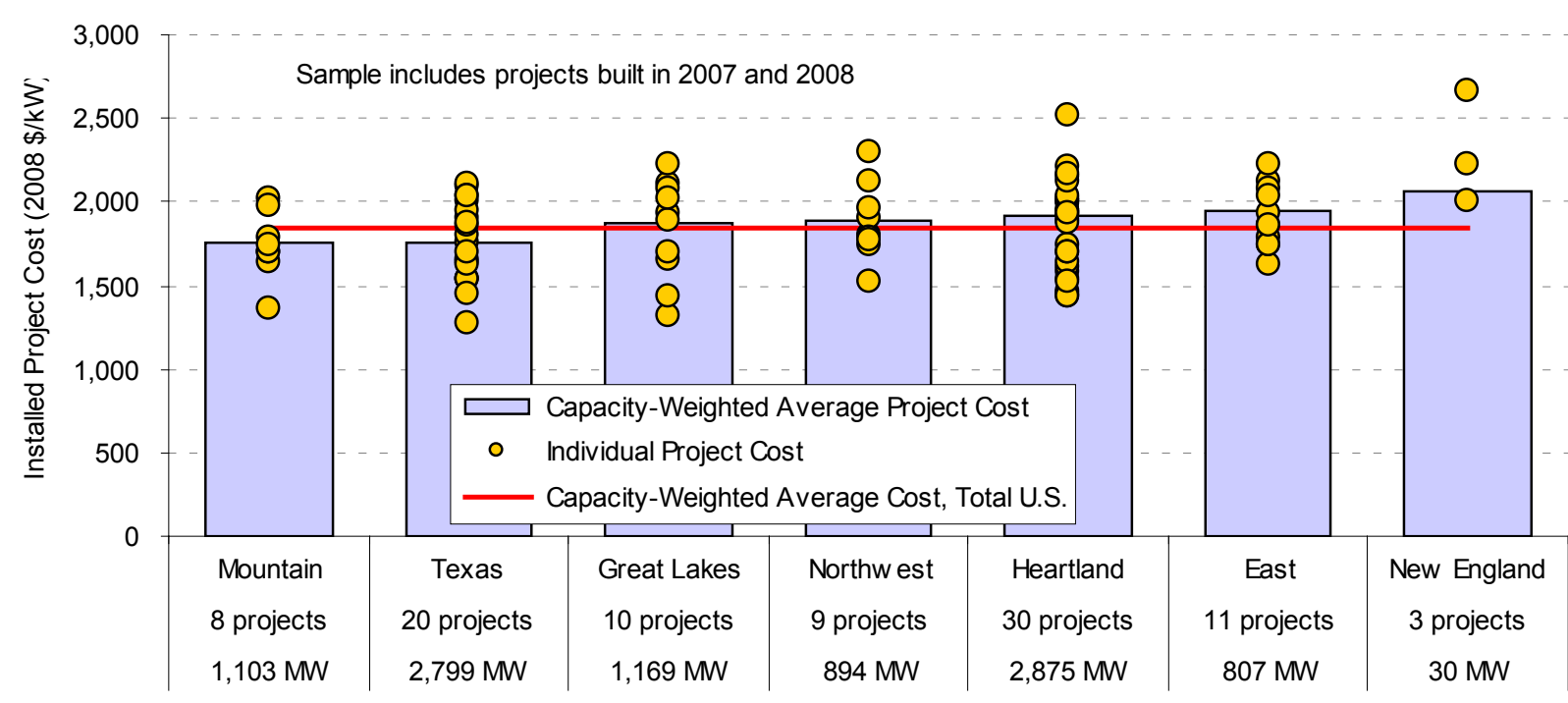

Source: Berkeley Lab database

Figure 22. Installed Wind Project Costs by Region: 2007-2008 Projects

\section{After Increasing Dramatically in Recent Years, Turbine Prices Showed Signs of Easing in Late 2008}

Increases in wind power prices and overall installed project costs mirror increases in the cost of wind turbines over the last several years. Berkeley Lab has gathered data on 59 U.S. wind turbine transactions totaling 21,100 MW, including 10 transactions summing to 4,500 MW in 2008 alone. Figure 23 depicts these reported wind turbine transaction prices.

Sources of transaction price data vary, but most derive from press releases and press reports. Wind turbine transactions differ in the services offered (e.g., whether towers and installation are provided, the length of the service agreement, etc.) and on the timing of future turbine delivery, driving some of the observed intra-year variability in transaction prices. Nonetheless, most of the transactions included in the Berkeley Lab dataset likely include turbines, towers, erection, and limited warranty and service agreements. ${ }^{38}$

Since hitting a low point of roughly $\$ 700 / \mathrm{kW}$ in the $2000-2002$ period, turbine prices appear to have increased by approximately $\$ 700 / \mathrm{kW}(100 \%)$, on average, through 2008. Between 2007 and 2008, capacity-weighted average turbine prices increased by roughly $\$ 90 / \mathrm{kW}(7 \%)$, from $\$ 1,270 / \mathrm{kW}$ to $\$ 1,360 / \mathrm{kW}$. Increases in turbine prices over this period have been caused by several factors, including the declining value of the U.S. dollar relative to the Euro, increased materials and energy input prices (e.g., steel and oil), a general move by manufacturers to improve their profitability, shortages in certain turbine components, an up-scaling of turbine size (and hub height), and improved sophistication of turbine design (e.g., improved grid interactions).

\footnotetext{
${ }^{38}$ Because of data limitations, the precise content of many of the individual transactions is not known.
} 
Figure 23 also suggests that larger turbine orders may have generally yielded somewhat lower pricing than smaller orders at any given point in time. This is reflected in the fact that the majority of the larger turbine orders shown in Figure 23 are located below the polynomial trend line, while the majority of the smaller orders are located above that line.

The trend of increasing turbine prices also suggests that most of the recent rise in installed project costs reported earlier $(\$ 630 / \mathrm{kW}$ from 2001-04 through 2008) has come from turbine price increases (recognizing that these prices reflect the cost of turbines, towers, and erection). In fact, because project-level installed costs have increased, on average, by roughly $\$ 630 / \mathrm{kW}$ through 2008 , while turbine prices appear to have increased by $\$ 700 / \mathrm{kW}$ over the same time span, further increases in project costs might be expected in the near future as the high turbine prices seen in 2008 flow through to project costs. As noted earlier, some evidence of these potentially higher total installed costs are documented by the expected installed cost of projects planned for installation in 2009.

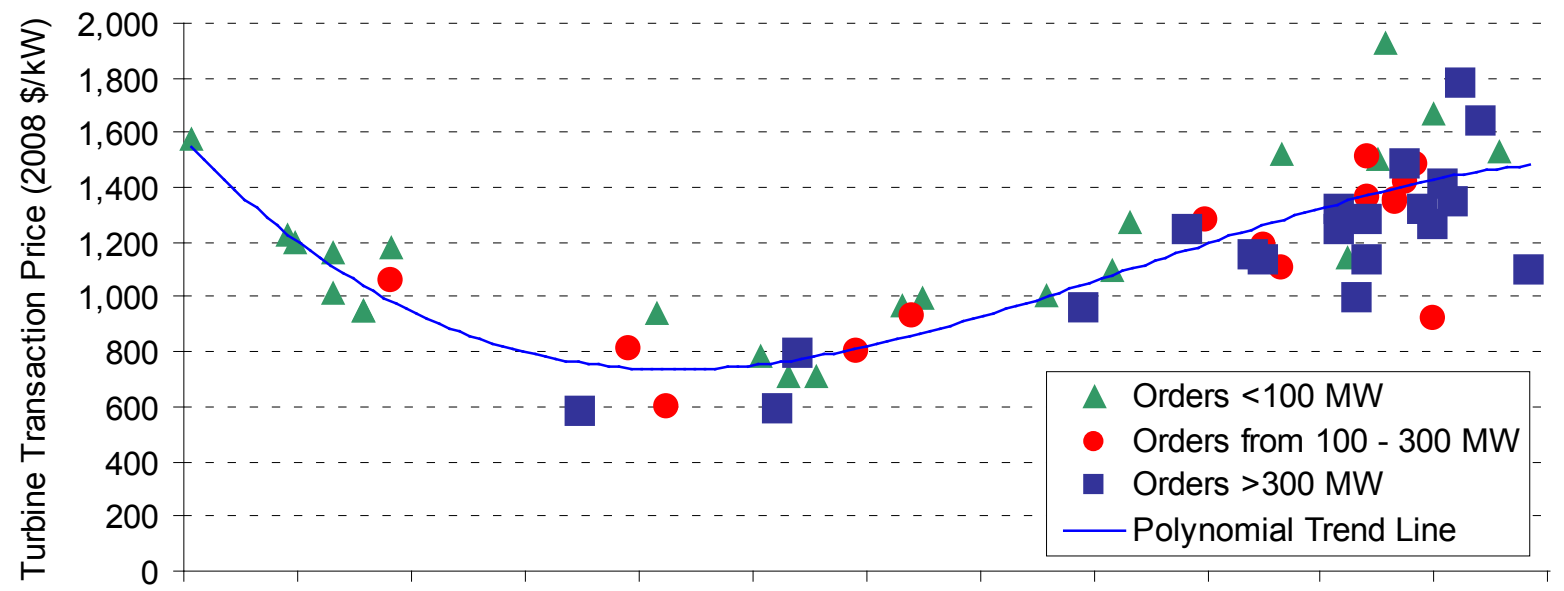

Jan-97 Jan-98 Jan-99 Jan-00 Jan-01 Jan-02 Jan-03 Jan-04 Jan-05 Jan-06 Jan-07 Jan-08 Jan-09

Announcement Date

Source: Berkeley Lab database

Figure 23. Reported U.S. Wind Turbine Transaction Prices Over Time

Though year-on-year turbine price increases have been the rule for the last several years, evidence is beginning to emerge that those days have ended, at least temporarily. Visibility of wind turbine transaction prices has declined in recent months, as the financial crisis has taken its toll and developers sit on turbine supply frame agreements that may exceed near-term project development plans. Energy and commodity prices have dropped substantially since mid-2008, however, and the supply-demand balance for turbines has resulted in a turn towards a buyer's market. As a result, rumors abound of price reductions in the 5-20\% range (NEF 2009), or even as high as $25 \%$ (Hays 2009), of increased availability of turbines in the "gray" (i.e., secondary) market (Goodwin 2009), and of more favorable terms for turbine purchasers. These price reductions and improved terms can be expected, over time, to put downward pressure on total project costs. 


\section{Wind Project Performance Has Improved Over Time, But Has Leveled Off in Recent Years}

Though recent turbine and installed project cost increases have driven wind power prices higher, improvements in wind project performance have mitigated these impacts to some degree. In particular, capacity factors have generally increased for projects installed more recently, driven by some combination of higher hub heights, improved siting, and technological advancements. These performance improvements appear to have leveled off in the most recent time period, however.

Figures 24 and 25, as well as Table 7, present excerpts from a Berkeley Lab compilation of wind project capacity-factor data. The sample consists of 183 projects built between 1983 and 2007 , and totaling $14,155 \mathrm{MW}$ (84\% of nationwide installed wind capacity at the end of 2007). ${ }^{39}$ Though capacity factors are not an ideal metric of project performance due to variations in the design and rating of wind turbines, absent rotor diameter data for each project, this report is unable to present the arguably more-relevant metric of electricity generation per square meter of swept rotor area. Both figures and the table summarize capacity factors in the year $2008 .{ }^{40}$

Figure 24 shows individual project as well as capacity-weighted average 2008 capacity factors broken out by each project's vintage (i.e., commercial operation date). The capacity-weighted average 2008 capacity factors in the Berkeley Lab sample increased from $22 \%$ for wind projects installed before 1998 to roughly 30\%-33\% for projects installed from 1998-2003, and to roughly $35 \%-37 \%$ for projects installed in 2004-2007.

Despite this general improvement among more-recently built projects, the capacity-weightedaverage 2008 capacity factor for projects installed in $2007(35.0 \%)$ is down slightly from that for projects installed in 2006 (35.2\%), which in turn is lower than for projects built in 2004-2005 $(36.9 \%)$. There are a number of potential reasons why projects installed in 2006 and 2007 have bucked the general trend of rising capacity factors among newer projects. These include the following:

- For projects completed in late 2007 , the initial break-in period during which operational kinks are worked out may have extended into 2008, negatively impacting 2008 capacity factors.

- Curtailment of wind project output due to transmission inadequacy and low wholesale market prices is reportedly a growing problem, primarily in Texas, but also in other markets. In the face of tightening transmission constraints, for example, recently built wind projects in West Texas have been forced by grid operators to curtail (i.e., reduce) their output (or have

\footnotetext{
${ }^{39}$ Though some performance data for wind projects installed in 2008 are available, those data do not span an entire year of operations. As such, for the purpose of this section, the focus is on project-level 2008 capacity factors for projects with commercial online dates in 2007 and earlier.

${ }^{40}$ Although focusing just on 2008 tends to limit the effects of inter-annual fluctuations in the nationwide wind resource, it also means that the absolute capacity factors shown in Figure 24 may not be representative if 2008 was not a representative year in terms of the strength of the wind resource. Note also that by including only 2008 capacity factors, variations in the quality of the wind resource year in 2008 across regions could skew the regional results presented in Figure 25 and Table 7.
} 
voluntarily chosen to do so in response to negative price signals in the wholesale power market).

- Related to the previous bullet, developers may be reacting to increasing transmission constraints (or even just regionally differentiated wholesale power prices) by focusing on those projects in their development pipeline that may not have the highest capacity factor, but that do have ready access to unconstrained transmission (or high-priced markets).

- Finally, some wind turbine manufacturers experienced blade and gearbox problems among their fleet of turbines installed in 2007 and 2008.

Though many of these issues appear to have impacted the lower end of the range of project-level capacity factors (dragging the average lower), the upper end of the range has continued to improve. In the best wind resource areas, for example, capacity factors in excess of $40 \%$ are increasingly common. Of the 91 projects in the sample installed prior to 2004 , only $5(5.5 \%)$ had capacity factors in excess of 40\% in 2008 (in capacity terms, $275 \mathrm{MW}$, or 5.7\%, exceeded 40\%). Of the 92 projects installed from 2004 through 2007, on the other hand, 24 (26.1\%) achieved capacity factors in excess of $40 \%$ in 2008 (in capacity terms, 2,585 MW, or $27.8 \%$, exceeded $40 \%$ ). Furthermore, two projects installed in 2007 realized capacity factors in excess of $50 \%$ in 2008 - a threshold not exceeded by any of the previously built projects.

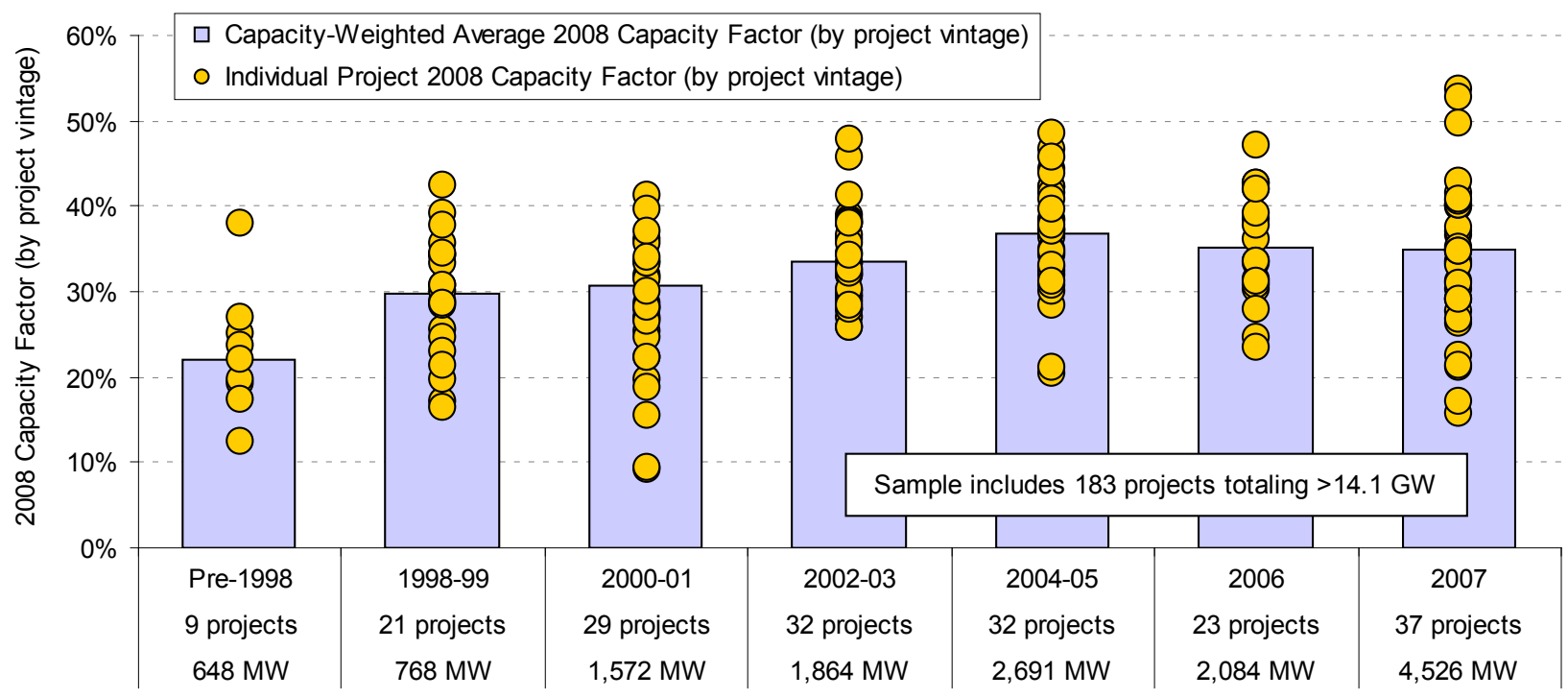

Source: Berkeley Lab database

Figure 24. 2008 Project Capacity Factors by Commercial Operation Date

Although the overall trend has generally been towards higher capacity factors, the project-level spread shown in Figure 24 is enormous, with capacity factors ranging from $16 \%$ to $54 \%$ among projects built in the same year, 2007. Some of this spread is attributable to regional variations in wind resource quality. Figure 25 shows the regional variation in 2008 capacity factors, based on a sub-sample of wind projects built from 2004 through 2007 (i.e., a period of relative stability in capacity factors, as shown in Figure 24). For this sample of projects, weighted-average capacity factors are the highest in Hawaii (above 40\% on average) and the Mountain region (around 40\% on average), and lowest in the East (below $30 \%$ on average). All other regions feature weighted- 
average capacity factors in the mid-30\% range, which is similar to the national average among the sample over this period. Given the small sample size in some regions, however, as well as the possibility that certain regions may have experienced a particularly good or bad wind resource year in 2008 or experienced different levels of wind curtailment, care should be taken in extrapolating these results.

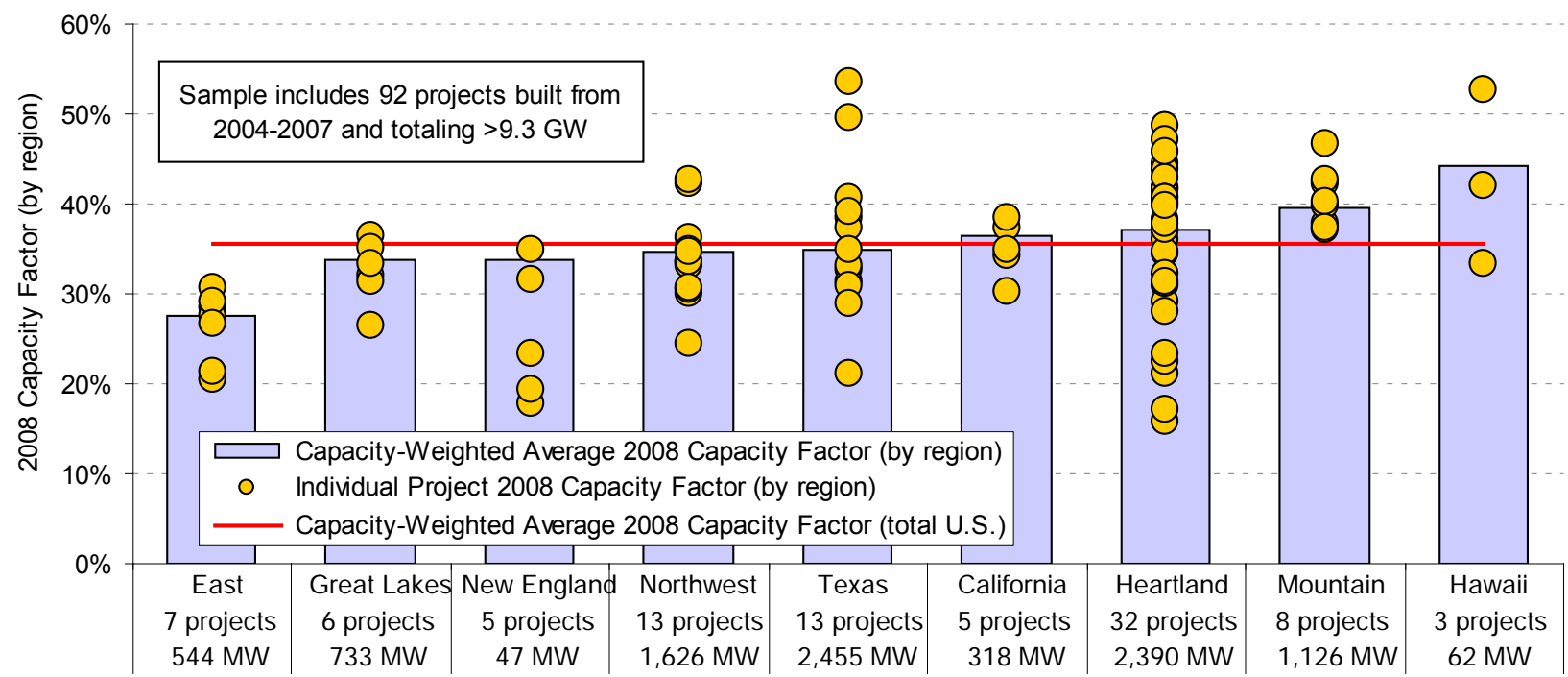

Source: Berkeley Lab database

Figure 25. 2008 Project Capacity Factors by Region: 2004-2007 Projects Only

Though limited sample size is again a problem for many regions, Table 7 illustrates trends in 2008 capacity factors for projects with different commercial operation dates, by region.

Table 7. Capacity-Weighted Average 2008 Capacity Factors by Region and COD

\begin{tabular}{|c|c|c|c|c|c|c|c|c|c|c|c|c|c|c|c|c|c|c|}
\hline $\begin{array}{c}\text { Capacity } \\
\text { Factor }\end{array}$ & \multicolumn{2}{|c|}{ East } & \multicolumn{2}{|c|}{$\begin{array}{l}\text { Great } \\
\text { Lakes }\end{array}$} & \multicolumn{2}{|c|}{$\begin{array}{c}\text { New } \\
\text { England }\end{array}$} & \multicolumn{2}{|c|}{ Northwest } & \multicolumn{2}{|c|}{ Texas } & \multicolumn{2}{|c|}{ California } & \multicolumn{2}{|c|}{ Heartland } & \multicolumn{2}{|c|}{ Mountain } & \multicolumn{2}{|c|}{ Hawaii } \\
\hline Pre-1998 & \multicolumn{2}{|c|}{-} & \multicolumn{2}{|c|}{-} & \multicolumn{2}{|c|}{$19.3 \%$} & & \multicolumn{2}{|c|}{-} & \multicolumn{2}{|c|}{$22.1 \%$} & & & \\
\hline 1998-99 & \multicolumn{2}{|r|}{-} & \multicolumn{2}{|c|}{$20.5 \%$} & \multicolumn{2}{|c|}{-} & \multicolumn{2}{|c|}{$35.7 \%$} & \multicolumn{2}{|r|}{ 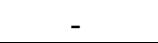 } & \multicolumn{2}{|c|}{$30.3 \%$} & \multicolumn{2}{|c|}{$29.2 \%$} & \multicolumn{2}{|c|}{$38.3 \%$} & \\
\hline $2000-01$ & \multicolumn{2}{|c|}{$22.6 \%$} & \multicolumn{2}{|c|}{$22.3 \%$} & \multicolumn{2}{|c|}{$25.5 \%$} & \multicolumn{2}{|c|}{$27.7 \%$} & & $1 \%$ & & $.9 \%$ & & $.8 \%$ & & $.9 \%$ & & - \\
\hline $2002-03$ & & $.7 \%$ & & $7 \%$ & & - & & $.3 \%$ & & $.1 \%$ & & $\%$ & & $5.7 \%$ & & $3 \%$ & & - \\
\hline 2004-05 & & $.8 \%$ & & $0 \%$ & & - & & $.0 \%$ & & $.2 \%$ & & $9 \%$ & & $9.1 \%$ & & $.0 \%$ & & - \\
\hline 2006 & & $.7 \%$ & & - & & $3 \%$ & & $.0 \%$ & & $.5 \%$ & & $8 \%$ & & $4 \%$ & & $.7 \%$ & & $.7 \%$ \\
\hline 2007 & & $.0 \%$ & & $8 \%$ & & $8 \%$ & & $.7 \%$ & & $.8 \%$ & & - & & $.2 \%$ & & $3.2 \%$ & & $.7 \%$ \\
\hline Total & & $.1 \%$ & & $5 \%$ & & $1 \%$ & & $.8 \%$ & & $4 \%$ & & $.1 \%$ & & $.7 \%$ & & $.2 \%$ & & $.1 \%$ \\
\hline Sample & \# & MW & \# & MW & \# & MW & \# & MW & $\#$ & MW & \# & MW & \# & MW & \# & MW & \# & MW \\
\hline Pre-1998 & - & - & - & - & 1 & 6 & - & - & - & - & 8 & 642 & - & - & - & - & - & - \\
\hline 1998-99 & - & - & 2 & 20 & - & - & 1 & 25 & - & - & 7 & 215 & 9 & 481 & 2 & 27 & - & - \\
\hline $2000-01$ & 7 & 85 & 1 & 30 & 1 & 1 & 3 & 373 & 4 & 669 & 1 & 67 & 8 & 226 & 4 & 123 & - & - \\
\hline $2002-03$ & 3 & 161 & 1 & 50 & - & - & 2 & 105 & 1 & 160 & 4 & 287 & 18 & 592 & 3 & 510 & - & - \\
\hline 2004-05 & 2 & 349 & 1 & 54 & - & - & 5 & 434 & 4 & 461 & 3 & 130 & 15 & 1,062 & 2 & 200 & - & - \\
\hline 2006 & 1 & 26 & - & - & 3 & 3 & 4 & 538 & 2 & 860 & 2 & 188 & \begin{tabular}{|l|}
7 \\
\end{tabular} & 279 & 2 & 150 & 2 & 41 \\
\hline 2007 & 4 & 169 & 5 & 679 & 2 & 44 & 4 & 654 & 7 & 1,135 & - & - & 10 & 1,049 & 4 & 776 & 1 & 21 \\
\hline Total & 17 & 789 & 10 & 834 & 7 & 53 & 19 & 2,130 & 18 & 3,284 & 25 & 1,529 & 67 & 3,689 & 17 & 1,785 & 3 & 62 \\
\hline
\end{tabular}




\section{Operations and Maintenance Costs Are Affected by the Age and Size of the Project, Among Other Factors}

Operations and maintenance (O\&M) costs are a significant component of the overall cost of wind projects, but can vary widely among projects. Market data on actual project-level O\&M costs for wind plants are not readily available. Even where these data are available, care must be taken in extrapolating historical O\&M costs given the dramatic changes in wind turbine technology that have occurred over the last two decades, not least of which has been the upscaling of turbine size (see Figure 9, earlier). Anecdotal evidence suggests that O\&M costs and premature component replacements continue to be key challenges to the wind industry.

Berkeley Lab has compiled O\&M cost data for 99 installed wind plants in the United States, totaling 4,751 MW of capacity, with commercial operation dates of 1982 through 2007 . These data cover facilities owned by both independent power producers and utilities, though data since 2004 is exclusively from utility-owned plants. A full time series of O\&M cost data, by year, is available for only a small number of projects; in all other cases, O\&M cost data are available for just a subset of years of project operations. Although the data sources do not all clearly define what items are included in O\&M costs, in most cases the reported values appear to include the costs of wages and materials associated with operating and maintaining the facility, as well as rent (i.e., land lease payments). Other ongoing expenses, including taxes, property insurance, and workers' compensation insurance, are generally not included. Given the scarcity, limited content, and varying quality of the data, the results that follow do not fully depict the industry's challenges with O\&M issues and expenditures; instead, these results should only be taken as illustrative of overall trends. Note also that the available data are presented in $\$ / \mathrm{MWh}$ terms, as if O\&M represents a variable cost; in fact, O\&M costs are in part variable and in part fixed. Although not presented here, expressing O\&M costs in units of $\$ / \mathrm{kW}$-year was found to yield qualitatively similar results to those presented in this section.

Figure 26 shows project-level O\&M costs by year of project installation (i.e., the most recent year that original equipment was installed, or the most recent year of project repowering). Here, O\&M costs represent an average of annual project-level data available for the years 2000 through 2008. For example, for projects that reached commercial operations in 2007, only year 2008 data are available, and that is what is shown in the figure. ${ }^{41}$ Many other projects only have data for a subset of years during the 2000-2008 period, either because they were installed after 2000 or because a full time series is not available, so each data point in the chart may represent a different averaging period over the 2000-08 timeframe. The chart highlights the 15 projects, totaling 1,887 MW, for which 2008 O\&M cost data were available.

\footnotetext{
${ }^{41}$ Projects installed in 2008 are not shown because only data from the first full year of project operations (and afterwards) are used, which in the case of projects installed in 2008 would be year 2009 (for which data are not yet available).
} 


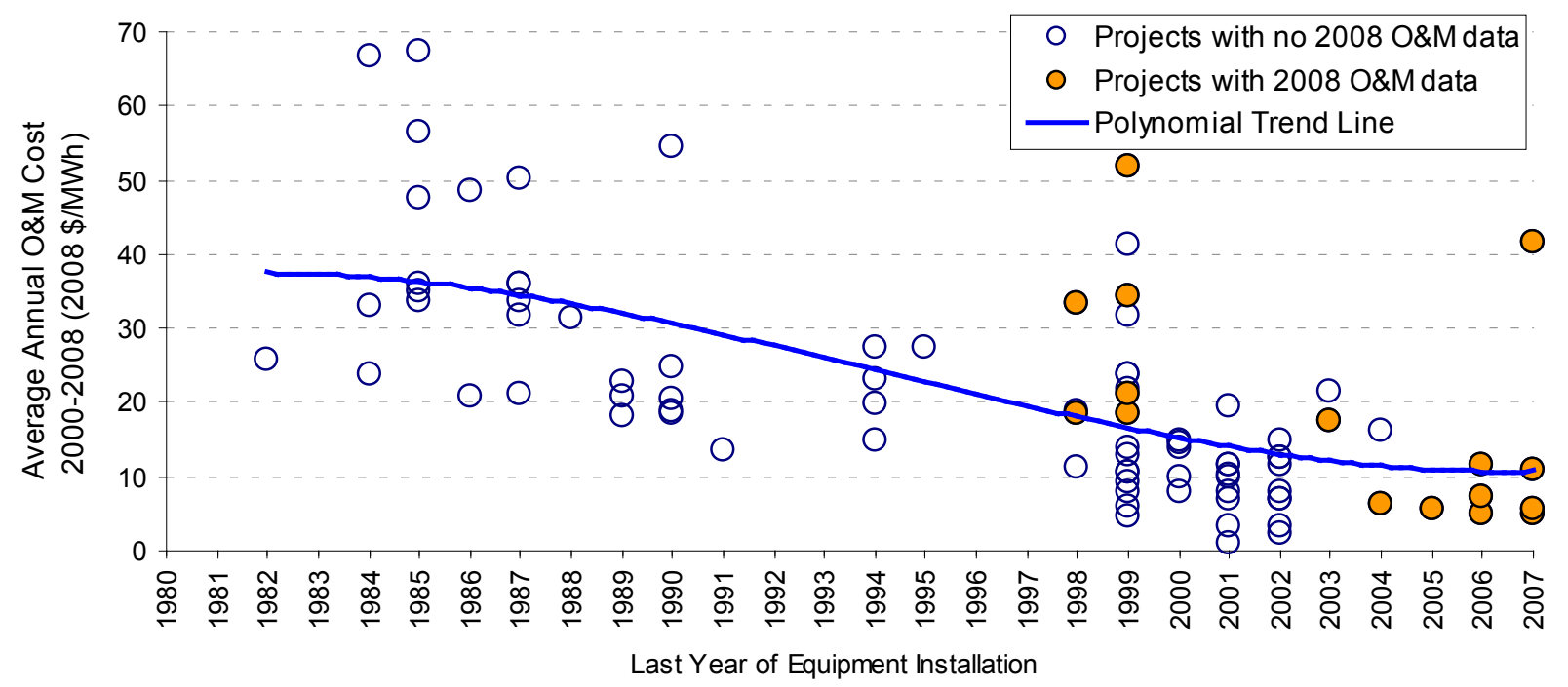

Source: Berkeley Lab database; seven data points suppressed to protect confidentiality

Figure 26. Average O\&M Costs for Available Data Years from 2000-2008, by Last Year of Equipment Installation

The data exhibit considerable spread, demonstrating that O\&M costs are far from uniform across projects. However, Figure 26 suggests that projects installed more recently have, on average, incurred lower O\&M costs. Specifically, capacity-weighted average 2000-2008 O\&M costs for projects in the sample constructed in the 1980s equal \$32/MWh, dropping to \$22/MWh for projects installed in the $1990 \mathrm{~s}$, and to $\$ 8 / \mathrm{MWh}$ for projects installed in the 2000s. This drop in O\&M costs may be due to a combination of at least two factors: (1) O\&M costs generally increase as turbines age, component failures become more common, and manufacturer warranties expire ${ }^{42}$; and (2) projects installed more recently, with larger turbines and more sophisticated designs, may experience lower overall O\&M costs on a per-MWh basis.

To help illustrate the possible influence of these two factors, Figure 27 shows annual O\&M costs over time, based on the number of years since the last year of equipment installation. Annual data for projects of similar vintages are averaged together, and data for projects under $5 \mathrm{MW}$ in size are excluded (to help control for the confounding influence of economies of scale). Note that, for each group, the number of projects used to compute the average annual values shown in the figure is limited, and varies substantially (from 4 to 17 data points per project-year for projects installed prior to 2000; from 6 to 15 data points per project-year for projects installed in 2000 through 2002; from 3 to 4 data points per project-year for projects installed in 2003 through 2005, and from 3 to 6 data points per project-year for projects installed in 2006 through 2007). With this limitation in mind, the figure appears to show that projects installed more recently have had, at least during their first three years of operation, lower O\&M costs than those installed in earlier years. In addition, the data for pre-2000 projects show an upward trend in project-level

\footnotetext{
${ }^{42}$ Many of the projects installed more-recently may still be within their turbine manufacturer warranty period, in which case the O\&M costs reported here may or may not include the costs of the turbine warranty, depending on whether the warranty is paid up-front as part of the turbine purchase, or is paid over time.
} 
O\&M costs after the third year of project operation, though the sample size after year four is quite limited.

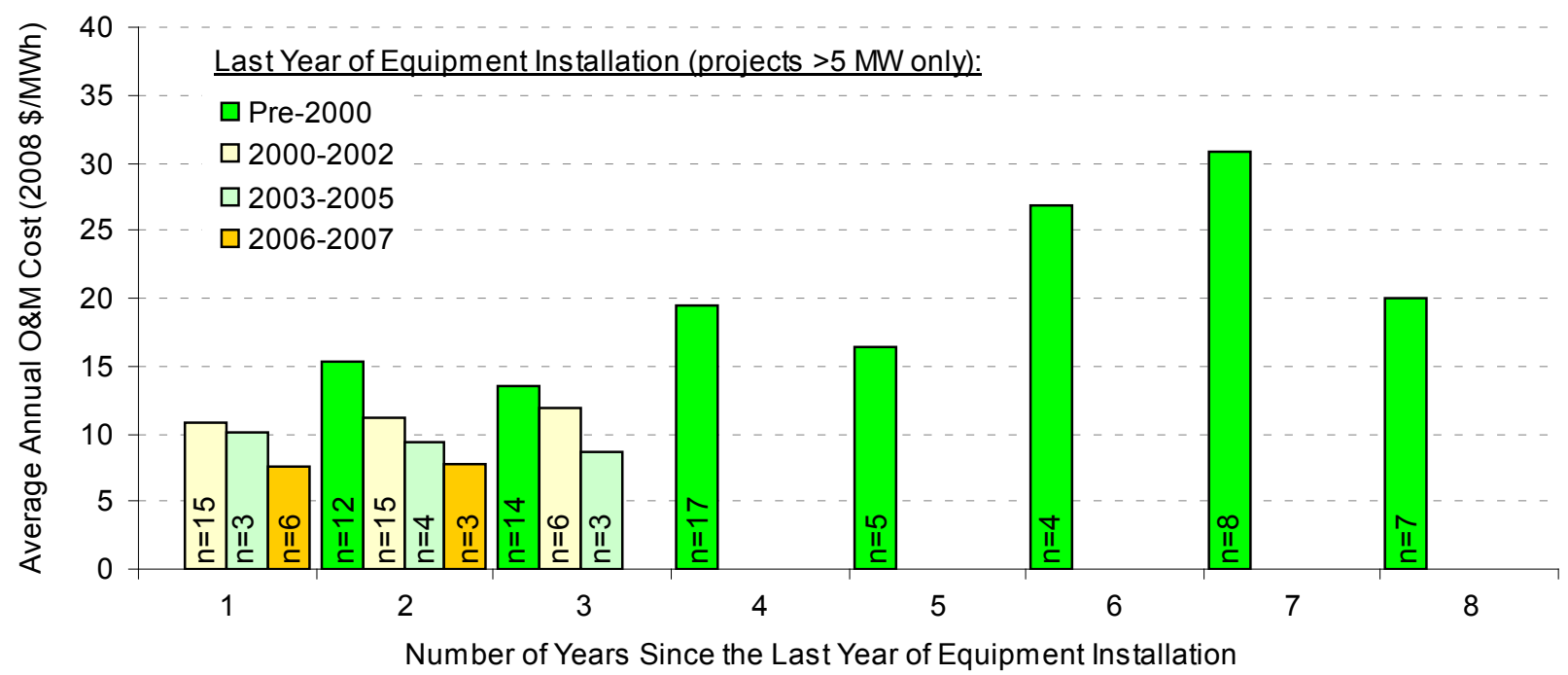

Source: Berkeley Lab database; averages shown only for groups of two or more projects

\section{Figure 27. Annual Average O\&M Costs, by Project Age and Last Year of Equipment Installation}

Another variable that may impact O\&M costs is project size. Figure 28 presents average O\&M costs for 2000 through 2008 (as in Figure 26) relative to project size. Though the sample is too small for definite conclusions, project size does appear to have some impact on average O\&M costs, with higher costs typically experienced by smaller projects. More data would be needed to confirm this inference.

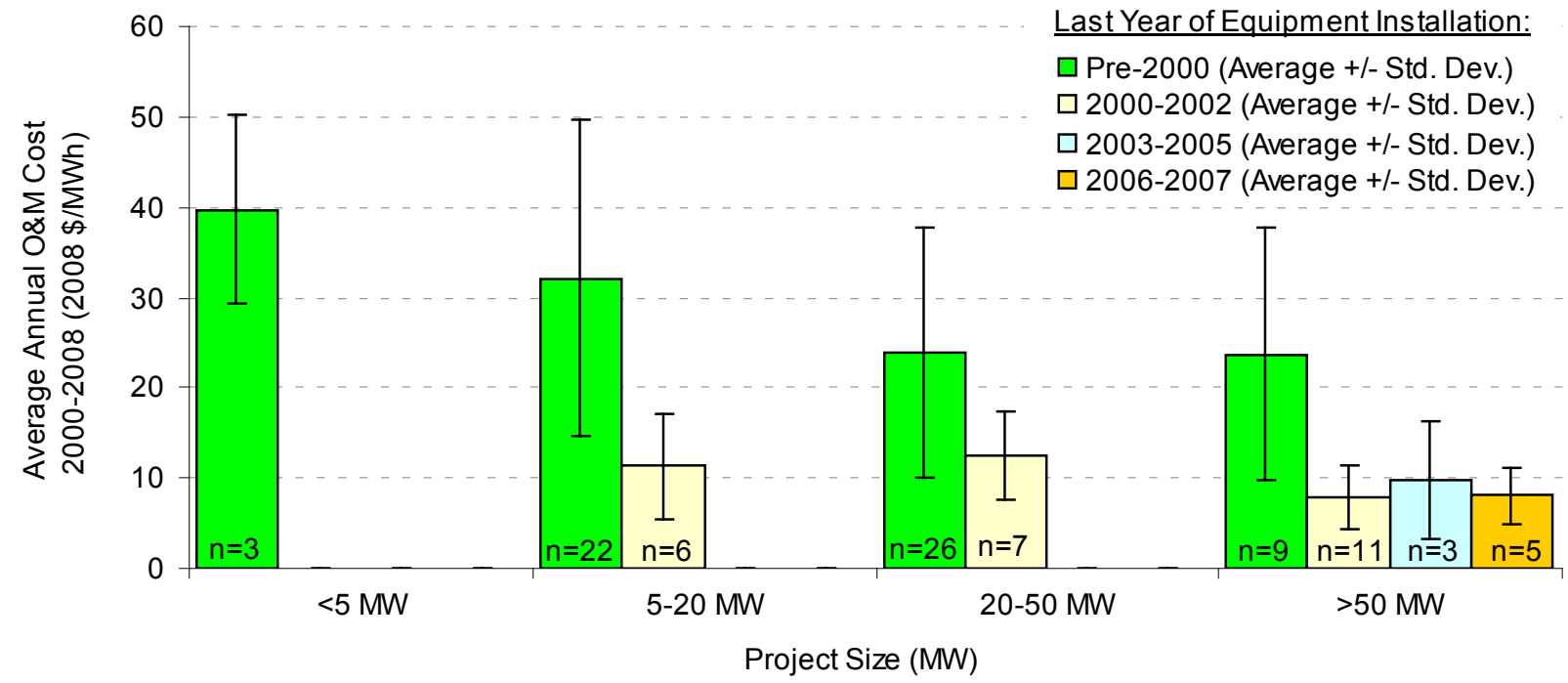

Source: Berkeley Lab database; averages shown only for groups of two or more projects

Figure 28. Average O\&M Costs for Available Data Years from 2000-2008, by Project Size 


\section{Policy and Market Drivers}

\section{The Policy Landscape Is Now More Favorable to Wind Than At Any Other Time in the Past Decade}

A variety of policy drivers have been important to the expansion of the wind power market in the U.S. Most obviously, the continued availability of the federal PTC has sustained industry growth. First established by the Energy Policy Act of 1992, the PTC provides a 10-year credit at a level that equaled $2.1 \notin / \mathrm{kWh}$ in 2008 (adjusted annually for inflation). The importance of the PTC to the U.S. wind industry is illustrated by the pronounced lulls in wind capacity additions in the three years $(2000,2002$, and 2004) in which the PTC lapsed, as well as the increased development activity often seen during the year in which the PTC is otherwise scheduled to expire - one of the reasons for the enormous capacity expansion witnessed in 2008 (see Figure 1).

A number of other federal policies have also helped support the wind industry in recent years. Wind power property, for example, may be depreciated for tax purposes over an accelerated 5year period, with bonus depreciation allowed for certain projects, in certain years. Because taxexempt entities are unable to take direct advantage of tax incentives, the Energy Policy Act of 2005 created the Clean Renewable Energy Bond (CREB) program, effectively offering interestfree debt to eligible renewable projects (though not without certain additional transaction costs). ${ }^{43}$ In February 2008, for example, the IRS announced the distribution of roughly $\$ 400$ million in CREBs, based on applications received in 2007, including more than $\$ 170$ million for 102 wind power projects. Finally, the USDA has provided grants and loan guarantees to certain renewable energy and energy efficiency projects; in 2008, for example, the USDA announced $\$ 44$ million in grants and loan guarantees, including a number for wind projects. Under the 2008 Farm Bill, USDA funding for such projects is expected to increase in future years.

As a reflection of growing interest in renewable energy, and in recognition of the negative impacts of the financial crisis on renewable energy investments, late 2008 and early 2009 brought substantial federal policy changes to the wind power landscape, increasing dramatically the role of the federal government in spurring industry growth. Most prominently, the PTC for wind projects was initially extended for one year (through 2009) in October 2008 (through the Emergency Economic Stabilization Act of 2008, EESA 2008). Then, in February 2009 (through The American Recovery and Reinvestment Act of 2009, ARRA 2009), the PTC for wind was extended for another three years (through December 2012). As a result, the wind industry has stronger and more-durable federal tax support than at any time over the last decade.

In addition to the extension of the PTC, major federal policy changes established through ARRA 2009 (and, to a lesser extent, EESA 2008) include:

\footnotetext{
${ }^{43}$ Such entities have also been eligible to receive the Renewable Energy Production Incentive (REPI), which offers a 10-year cash payment equal in face value to the PTC, but the need for annual appropriations and insufficient funding have limited the effectiveness of the REPI.
} 
- Option to Elect ITC / Cash Grant: ARRA 2009 allows renewable energy projects otherwise eligible for the PTC to forego the PTC for a $30 \%$ investment tax credit (ITC) and, for a limited time (e.g., wind projects placed in service by the end of 2010, or if construction commences by the end of 2010, placed in service by the end of 2012), allows such projects to instead receive a cash grant of equivalent value through the Treasury. Bolinger et al. (2009) find that many wind projects will likely elect the $30 \%$ grant option. ${ }^{44}$

- Removal of Double Dipping Penalty: For projects that take either the ITC or the cash grant, ARRA 2009 removes the "double dipping" penalty that formerly reduced the value of the ITC for projects that otherwise received "subsidized energy financing."

- Extension of Bonus Depreciation: ARRA 2009 extends the 50\% bonus depreciation schedule, under which projects can depreciate $50 \%$ of their depreciable basis in the first year, to qualified renewable projects completed in 2009.

- Expansion of Loan Guarantee Program: ARRA 2009 expands an existing DOE loan guarantee program to cover commercial projects, and transmission, and appropriates $\$ 6$ billion to implement the program.

- Increased Funding for CREBs: ARRA 2009 adds \$1.6 billion in new CREB funding for projects owned by governmental or tribal entities, as well as municipal utilities and cooperatives, adding to the $\$ 800$ million of new CREB funding provided in EESA 2008.

- New Transmission Encouragement: ARRA 2009 includes targeted provisions to encourage new transmission, including increased borrowing capacity for WAPA and BPA for new transmission, increased support for transmission R\&D and analysis at DOE, and expansion of the loan guarantee program to include transmission investments.

- State Grants Program: ARRA 2009 directs the DOE to provide \$3.1 billion to support an expansion of existing state energy efficiency and renewable energy programs, some of which will ultimately benefit wind.

- Small Wind ITC: EESA 2008 established a 30\% ITC for wind turbines under $100 \mathrm{~kW}$ in size, but capped the dollar value of that credit. ARRA 2009 removes the dollar cap, significantly expanding the value of the ITC for distributed wind.

- Manufacturing Tax Credit: ARRA 2009 creates a new 30\% ITC for manufacturers of qualified renewable energy and energy efficiency technologies, with an aggregate spending cap of $\$ 2.3$ billion.

- Increased R\&D Funding: ARRA 2009 provides significant new spending for renewable energy-related research and development (R\&D).

State policies also continue to play a substantial role in directing the location and amount of wind development. From 1999 through 2008, for example, 67\% of the wind power capacity built in the U.S. was located in states with RPS policies; in 2008, this proportion was $70 \%$. Three new states established mandatory RPS programs in 2008 (Michigan, Missouri, and Ohio), and Kansas did so in May 2009, bringing the total to 29 states and Washington D.C. (see Figure 29); a number of additional states strengthened previously established RPS programs in 2008.

\footnotetext{
${ }^{44}$ Reasons include the shortage of tax equity in the market, the general appeal for cash-based over tax-based returns, the reduction in resource and performance risk that comes from an investment- rather than production-based incentive, the removal of the subsidized energy financing double-dipping penalty for the ITC (and equivalent cash grant) but not the PTC, and the ability to use several different financing structures that are not viable with the PTC.
} 


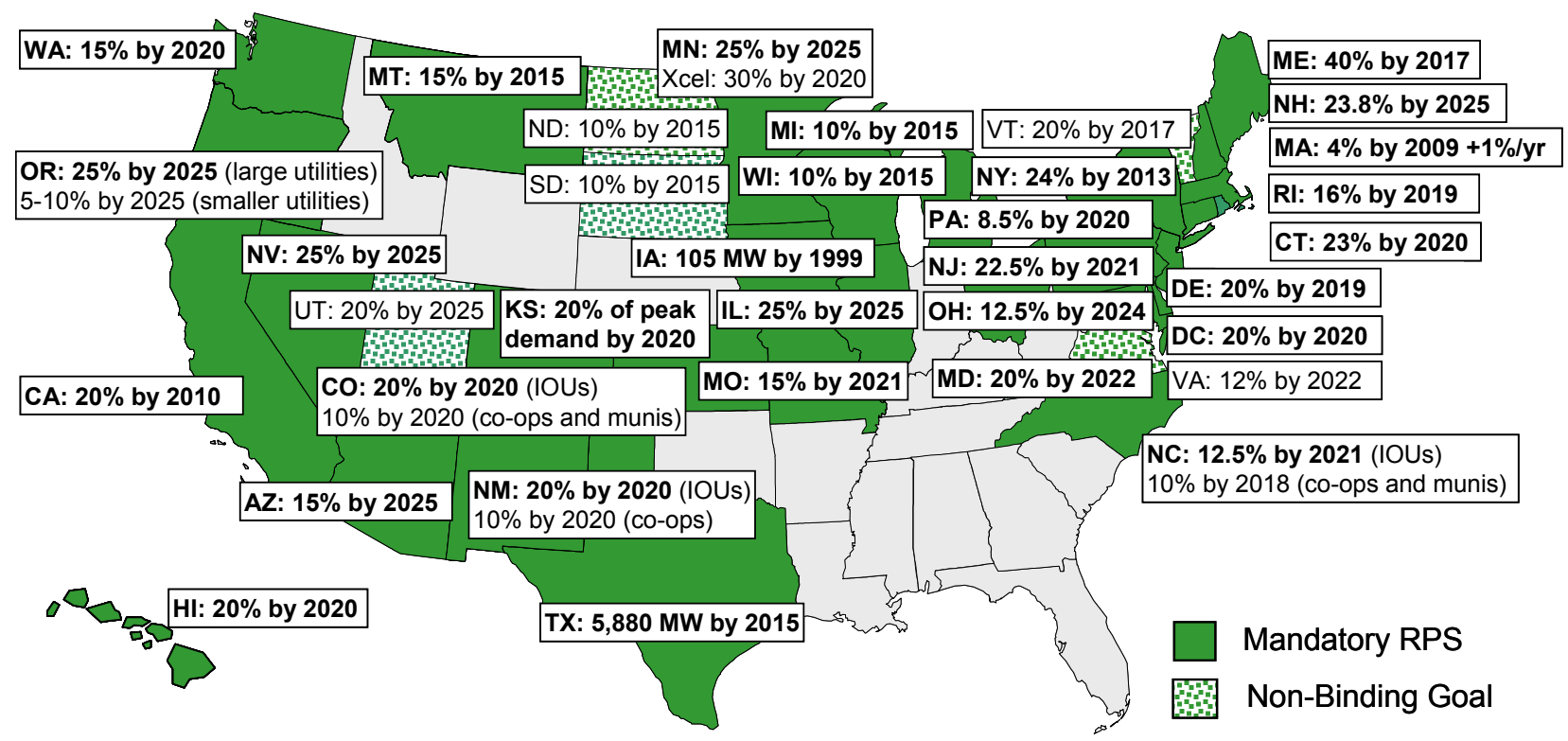

Source: Berkeley Lab

Figure 29. State RPS Policies and Non-Binding Renewable Energy Goals (as of June 2009)

Utility resource planning requirements in Western and Midwestern states have also helped spur wind additions in recent years (especially as the prospect of future carbon regulations has been included as a variable in resource selection), as has growing voluntary customer demand for "green" power, especially among commercial customers. State renewable energy funds provide support for wind projects, as do a variety of state tax incentives. Finally, concerns about the possible impacts of global climate change are fueling interest by states, regions, and the federal government to implement carbon reduction policies, a trend that is likely to increasingly underpin wind power expansion in the years ahead. The first compliance period for the Northeast's Regional Greenhouse Gas Initiative cap-and-trade policy began on January 1, 2009, with allowance auctions beginning in 2008. Regional carbon policies are also under discussion in the Western and Midwestern U.S., as well as a number of individual states, while federal carbon policy (including a federal RPS) is under active discussion in the U.S. Congress.

\section{Despite Progress on Overcoming Transmission Barriers, Constraints Remain}

After a prolonged period of relatively little transmission investment, development of new transmission appears to be on the rise in the U.S. The North American Electric Reliability Corporation's (NERC) annual reliability survey, for example, projects that the total number of transmission miles in the U.S. will increase by 15,700 circuit-miles, or $9.5 \%$, by 2017 (NERC 2008). Nonetheless, lack of transmission availability remains a primary barrier to wind development (NERC 2009). New transmission is particularly important for wind power because wind projects are constrained to areas with adequate wind speeds, which are often located at a distance from load centers. In addition, there is a mismatch between the short lead time needed 
to develop a wind project and the lengthier time often needed to develop new transmission lines. The allocation of costs for new transmission investment is also of critical importance for wind development, as are issues of transmission rate "pancaking" when power is wheeled across multiple utility systems and interconnection queuing procedures.

A number of federal, state, and regional developments may help ease the transmission barrier for wind over time. At the federal level, the U.S. Congress is considering transferring some transmission planning, cost allocation, and siting authority from states to FERC, either wholly or under certain conditions. Elsewhere, FERC approved the first "anchor customer" proposal by allowing TransCanada to negotiate transmission rates for half of the capacity on two $500-\mathrm{kV}$ transmission lines that would run through Montana and Wyoming, respectively, to southern Nevada. FERC has also continued to press for modifications to interconnection queuing procedures, and changes have been made to those procedures in a number of regions to reduce speculative queuing and to streamline the interconnection process (Porter et al. 2009).

States, grid operators, and regional entities also continue to take proactive steps to encourage transmission investment to access remote renewable resources. Numerous examples of these initiatives are presented below:

- Texas Competitive Renewable Energy Zones: The Public Utility Commission of Texas granted preliminary approval for transmission projects with an estimated cost of $\$ 4.93$ billion to access Texas' competitive renewable energy zones. This new transmission could enable $10,000 \mathrm{MW}$ of new wind power capacity in Texas.

- Colorado Renewable Energy Resource Zones: In November 2008, Xcel Energy identified five energy resource zones encompassing high-quality wind and solar resources. Xcel Energy also filed a long-term transmission expansion proposal that could access up to 3,600 MW of renewable energy from the five zones. In May 2009, Xcel Energy and Tri-State Generation and Transmission filed a transmission proposal at the Colorado public utilities commission for a series of $230-\mathrm{kV}$ and $345-\mathrm{kV}$ lines in southern Colorado.

- California Renewable Energy Transmission Initiative: The California Renewable Energy Transmission Initiative (RETI) is intended to identify competitive renewable energy zones in California and neighboring states that can provide significant renewable generation to California consumers. In its Phase I assessment, RETI identified 29 potential renewable energy zones in California capable of producing 200,000 GWh annually. Six of these zones that represent the best combination of economic cost-effectiveness and reduced environmental impact have the potential to produce 74,300 GWh annually.

- Western Renewable Energy Zones: The Western Renewable Energy Zones initiative is a collaborative between the Western Governors' Association and the U.S. Department of Energy, and is intended to identify regions with high renewable resource potential and develop conceptual transmission plans to deliver the renewable energy to Western load centers. In 2009, renewable resource areas will be identified and a model to estimate the delivered cost of power from these areas will be made available.

- Southwest Power Pool's Balanced Portfolio Initiative: In October 2008, FERC approved the Southwest Power Pool's Balanced Portfolio initiative, whereby SPP will create portfolios of economic transmission projects and will allocate the cost of the upgrades to all SPP zones on a postage-stamp basis. These portfolios will need to be both 'cost beneficial' (the overall 
benefit/cost ratio must be greater than one) and 'balanced' (the benefit/cost ratio in each zone must also be greater than one) over a ten-year timeframe. On April 29, 2009 the SPP

Regional State Committee and Board of Directors/Members Committee approved the first Balanced Portfolio. The portfolio, consisting of five new 345-kV transmission lines, a 345$\mathrm{kV}$ transformer, and a new connection between two existing $345-\mathrm{kV}$ lines, is projected to cost over $\$ 700$ million.

- Wyoming-Colorado Intertie: The Wyoming Infrastructure Authority is co-developing the $345-\mathrm{kV}$ Wyoming-Colorado Intertie project with the Western Area Power Administration and Trans-Elect. The Authority held an open season in 2008 to subscribe capacity to the line, and two wind companies committed to $585 \mathrm{MW}$ of the $850 \mathrm{MW}$ of available transmission capacity. LS Power purchased the project in April 2009.

- Bonneville Power Administration Network Open Season: Faced with a burgeoning transmission service queue, BPA introduced a network open season whereby requestors of transmission service were offered service contingent on the cost of transmission upgrades being below the BPA rolled-in rate. Requestors that accepted service were required to pay a deposit and sign a service agreement to keep their request active. The first open season ran from May to June 2008 and resulted in 153 projects representing 6,410 MW, of which wind projects accounted for 4,716 MW (74\%). BPA plans to proceed with five transmission projects to support 3,700 MW of generation, including 2,790 MW of renewable energy.

- Other Renewable Energy Zone Initiatives: Several other states have also made progress on state renewable energy zone initiatives. The Utah Renewable Energy Zone Task Force issued a Phase 1 report in early 2009 identifying the potential for solar, wind, and geothermal REZs. The Nevada Renewable Energy Transmission Access Advisory Committee identified 26 potential zones for geothermal, solar, wind, and biomass energy in January 2008. In October 2008, the Michigan Legislature approved Public Act 295, which (among other things) established the Wind Energy Resources Zone Board to identify wind energy resource zones in Michigan. Finally, the Arizona Renewable Resource and Transmission Identification Subcommittee under WestConnect was formed in late 2008 to identify renewable generation development areas in Arizona and potential transmission corridors from these areas to load centers in the state.

Progress was also made in 2008 on a number of additional transmission projects that are designed, in part, to support wind power. Nearly twenty large transmission projects in the central and western U.S. that may carry significant amounts of wind generation are in various stages of development. Though not all of these transmission projects will proceed to commercial operation, those that do may provide development opportunities for thousands of megawatts of new wind projects from 2013 onward.

\section{Integrating Wind into Power Systems Is Manageable, but Not Costless, and Market Operators Are Developing Methods to Accommodate Increased Penetration}

During the past several years, there has been a considerable amount of attention placed on the potential impacts of wind energy on power systems. Concerns about, and solutions to, these issues have affected, and continue to impact, the pace of wind power deployment in the U.S. 
Studies that have evaluated the operational impacts of wind generation have become increasingly sophisticated in recent years, resulting in a better accounting of wind's impacts and costs. Key trends among some of the more-recent studies include evaluating even higher levels of wind penetration, evaluating the integration of wind within larger electricity market areas, and identifying approaches to mitigate integration concerns.

Table 8 provides a selective listing of results from major wind integration cost studies ${ }^{45}$ completed from 2003 through 2008. ${ }^{46}$ Similar information is presented in Figure 30 at various levels of wind capacity penetration. ${ }^{47}$ Because methods vary and a consistent set of operational impacts has not been included in each study, results from the different analyses are not fully comparable. Nonetheless, key conclusions that continue to emerge from the growing body of integration literature include the following:

- Wind integration costs rise with higher levels of wind penetration, but are below $\$ 10 / \mathrm{MWh}-$ and often below $\$ 5 / \mathrm{MWh}$ - for wind capacity penetrations of as much as $30 \%$ of the peak load of the system in which the wind power is delivered. ${ }^{48}$

- Regulation impacts are often found to be relatively small, whereas the impacts of wind on load-following and unit commitment are typically found to be more significant.

\footnotetext{
${ }^{45}$ The integration costs considered in these studies typically refer to the costs associated with accommodating the variability and uncertainty associated with wind energy. Generally, these costs are associated with three different time frames: regulation - from seconds to a few minutes; load-following - tens of minutes to a few hours; and unit commitment - out to the next day or two. Studies often estimate these costs as the difference in overall electric system production costs between a scenario that captures the variability and unpredictability of wind and a scenario with an energy-equivalent block of power having no variability or uncertainty.

${ }^{46}$ Some of the studies included in the table also address capacity valuation for resource adequacy purposes; those results are not presented here. Several other studies focus on the operational impacts of wind energy and/or on the overall production-cost reduction value of wind energy, without an explicit comparison to an energy-equivalent block of power having no variability or uncertainty. These studies are not included in the table because they do not seek to explicitly calculate integration costs. Examples of such studies include a major integration study on the ancillary service implications of high wind penetration in ERCOT, which was completed in 2008 (GE Energy Consulting 2008). Two such integration studies for California were completed in 2007: one conducted by the California ISO (CAISO 2007) and another by the California Energy Commission's Intermittency Analysis Project (Porter et al. 2007). A similar study was completed for New York in 2005 (GE Energy Consulting 2005).

${ }^{47}$ Wind penetration on a capacity basis (defined as nameplate wind capacity serving a region divided by that region's peak electricity demand) is frequently used in integration studies. For a given amount of wind capacity, penetration on a capacity basis is typically higher than the comparable wind penetration in energy terms (because over the course of a year, wind projects generally operate at a lower percentage of their rated capacity, on average, than do most other resources).

${ }^{48}$ The relatively low cost estimate in the 2006 Minnesota study, despite an aggressive level of wind penetration, is partly a result of relying on the overall Midwest ISO market to accommodate certain elements of integrating wind into system operations. The low costs found in the 2006 California study arise because of the large electrical market in which wind power is integrated, the relatively low penetration level analyzed, and California's use of a sub-hourly energy market, rather than reserves, to provide load following. Conversely, the higher integration costs found by Avista and Idaho Power are, in part, caused by the relatively smaller markets in which the wind is being absorbed and, in part, by those utilities' operating practices. Specifically, the Northwest currently uses hourly scheduling intervals rather than the sub-hourly markets common in ISOs and RTOs. A sensitivity case in the Avista Utilities study demonstrates that the use of a 10-minute transaction scheduling interval would decrease the cost of integrating wind by $40-60 \%$. Note also that the rigor with which the various studies have been conducted varies, as does the degree of peer review.
} 
- Larger balancing areas, such as those found in RTOs and ISOs, make it possible to integrate wind more easily and at lower cost than is the case in smaller balancing areas.

- The successful use of regional wind power forecasts by system operators can significantly reduce integration challenges and costs. Wind forecasts are most accurate and effective when aggregated across large, electrically interconnected areas.

- Intra-hour scheduling (e.g., 5-10 minute schedules) provides access to flexibility in conventional power plants that lowers the costs of integrating wind.

- Wind integration costs tend to rise with increasing natural gas prices, though the economic value of wind energy similarly increases with higher gas prices.

Table 8. Key Results from Major Wind Integration Cost Studies

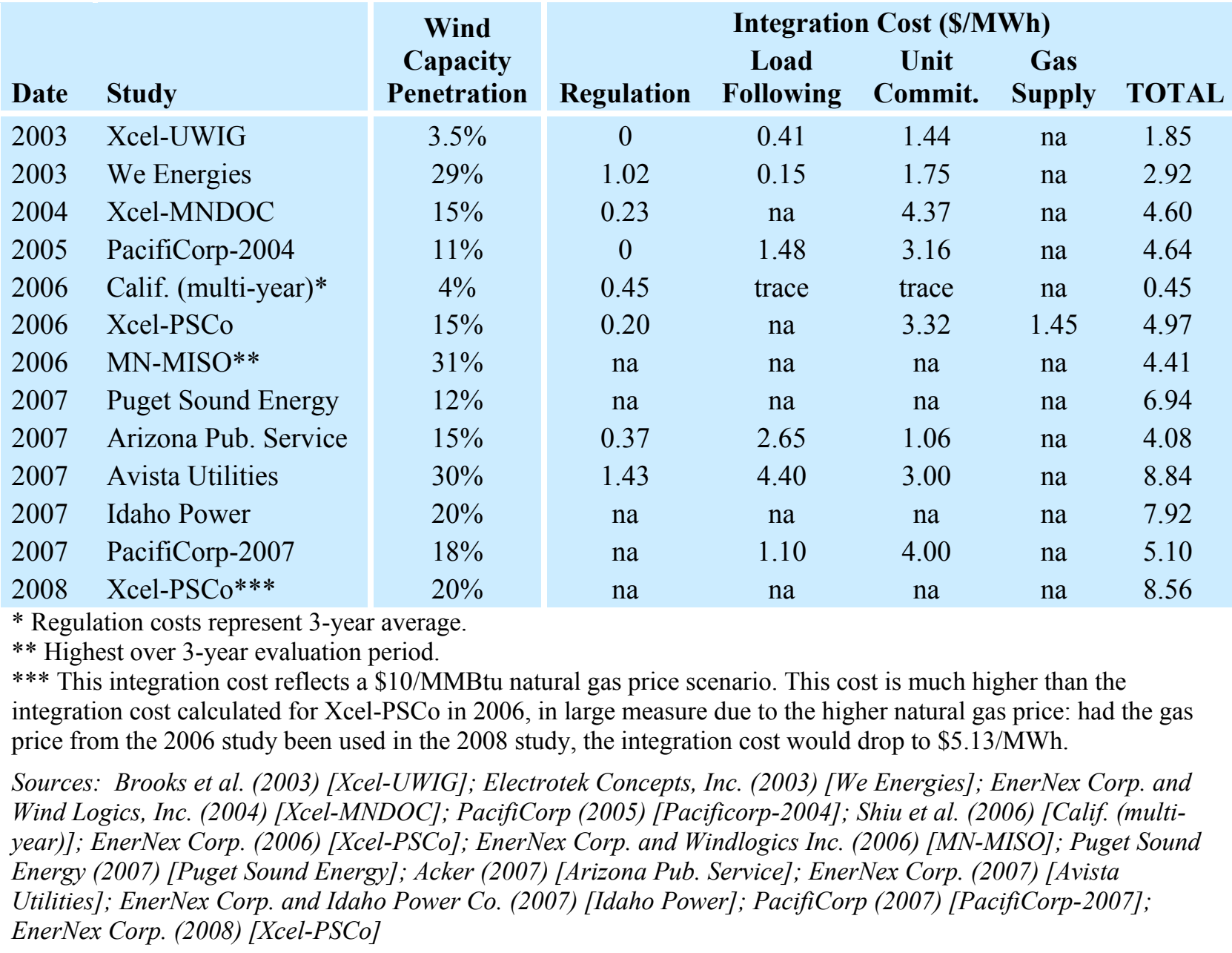




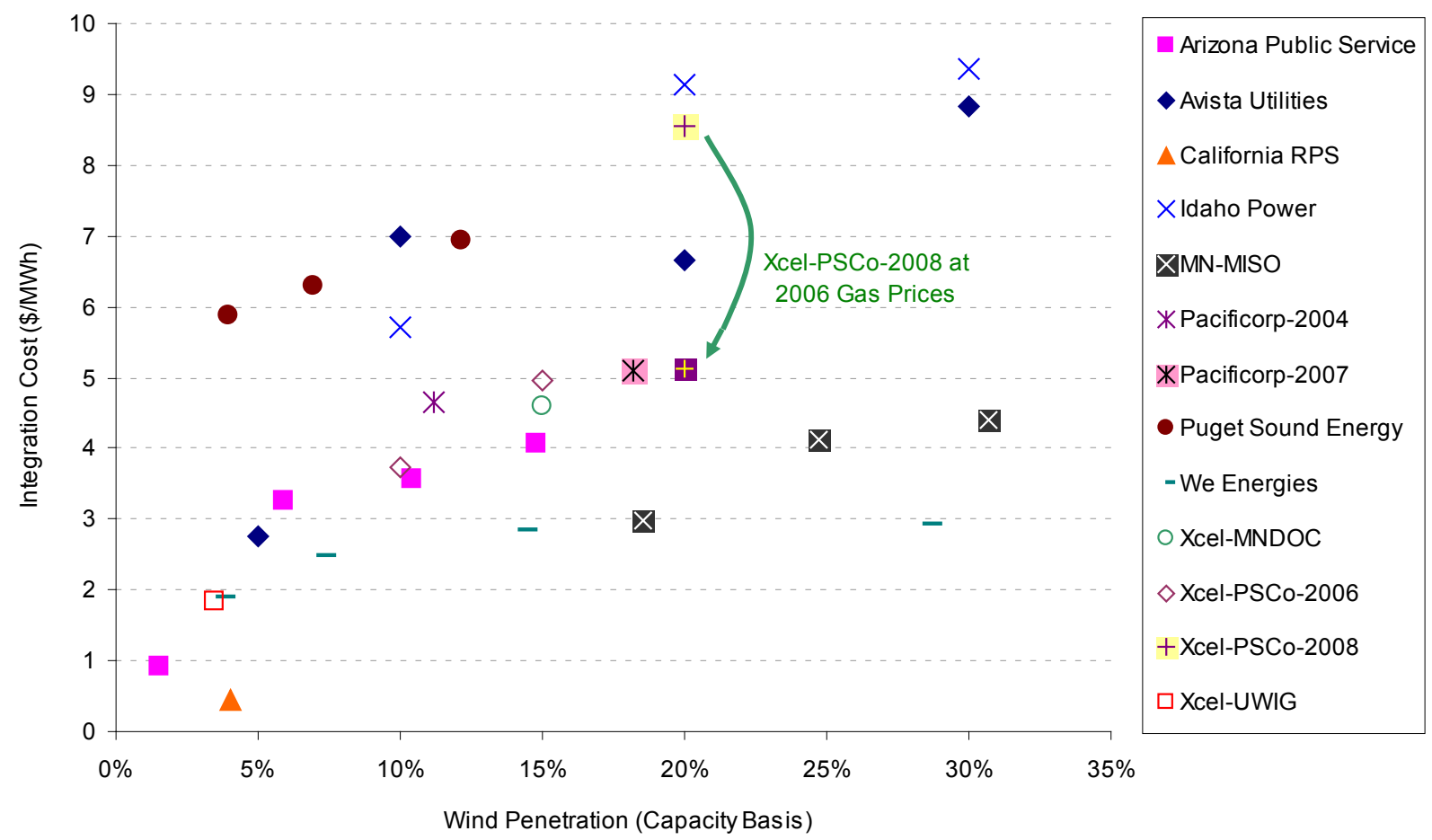

Source: See Table 8

Figure 30. Wind Integration Costs at Various Levels of Wind Capacity Penetration

Additional wind integration research is planned for 2009. The National Renewable Energy Laboratory, for example, in collaboration with others, is in the process of examining higher levels of wind penetration in larger electrical footprints, both in the interior West and in the East. The Nebraska Power Association will also be performing a study for Nebraska to determine the integration cost for up to a $20 \%$ wind on an energy basis (with one sensitivity run at $40 \%$ ). The Southwest Power Pool is expecting to complete a wind integration study that includes a 30-40\% wind penetration case on an energy basis, while the New England ISO and the New York ISO are similarly expected to release integration studies before the end of 2009. Though not a wind integration cost study per se, the California ISO is evaluating the ability of that state's generation fleet to meet the integration needs associated with increased renewable energy. A number of additional studies, led by electric utilities, national laboratories, and others, are also planned.

Many ISOs and utilities are also beginning to take important steps to mitigate the challenges faced with integrating larger quantities of wind power. For instance, at the start of 2009, the Midwest ISO began functioning as the region's overall balancing authority and initiated an ancillary services market. Large balancing areas and robust markets for ancillary services are two steps that will reduce the costs of wind integration, while also providing other benefits to customers. $^{49}$ In 2008, the New York ISO and Midwest ISO established centralized wind power forecasting systems, while ERCOT approved a procedure for supplying wind forecasts to

\footnotetext{
${ }^{49}$ Even outside of ISOs and RTOs, there is increasing interest in collaborative system control actions among balancing areas to address market operations inefficiencies, including helping to mitigate the impact of wind variability on systems operations and costs. In the West, for example, the Area Control Error (ACE) Diversity Interchange project has sought to pilot the pooling of individual ACEs to take advantage of control error diversity.
} 
scheduling entities following the lead of the California ISO's wind forecasting system. A similar wind forecasting program was launched in 2009 for PJM. The New York ISO received FERC approval to require wind generators to provide economic bids as a dispatchable resource, meaning that plant output can be curtailed on an economic basis. PJM has instituted similar requirements. Northern Tier Transmission Group, Columbia Grid, and WestConnect, meanwhile, are jointly investigating projects that will increase power system flexibility, including the creation of a dynamic scheduling communications infrastructure, and intra-hour scheduling and balancing. Though these initiatives have broad benefits, they will also provide increased flexibility to integrate wind. Finally, in 2008, BPA established a within-hour wind balancing service that charges wind generators for intra-hour balancing. In early 2009, BPA proposed a substantial increase in the cost of this service for fiscal year 2010-11 rates. 


\section{Future Outlook}

Despite enormous growth in installed capacity in 2008, the financial crisis has taken a toll on the wind power industry. By the end of 2008, financing for new projects and orders for new turbines had slowed, while turbine and component manufacturers began to announce layoffs. Portions of EESA 2008 and ARRA 2009 are intended to alleviate the current scarcity of project financing, and to lay the groundwork for near- and medium-term expansion of the wind sector.

Nonetheless, expectations of a slower year in 2009 remain, in part because implementing the 2009 stimulus policies will take time. As shown in Table 9, the latest prediction from AWEA shows more than 5,000 MW of U.S. wind additions as likely in 2009 (AWEA 2009a). BTM Consult, meanwhile, expects 6,000 MW of wind to be installed in the U.S. in 2009 (BTM 2008), while Emerging Energy Research (EER) forecasts a base-case of 6,500 MW (Hays 2009) and New Energy Finance (NEF) predicts 4,900 - 6,800 MW (NEF 2009). The EIA offers the most conservative forecast of 4,400 MW of new wind in the U.S. in 2009 (EIA 2009).

After a slower year in 2009, predictions show market resurgence in 2010 and continuing for the immediate future, as the policies established in the 2009 economic stimulus package come into full swing, and as financing constraints are relieved. From 2010 through 2012, forecasts show annual wind capacity additions that exceed the total additions in 2008 , with cumulative wind additions from 2009-2012 predicted to exceed 35,000 MW. With these wind additions from 2009 through 2012, more than $60 \%$ of EIA's projected growth in total U.S. electricity supply over this period would come from new wind plants. Moreover, if predictions hold, the United States and China are likely to vie for top-market status in terms of annual capacity additions from 2009-2012.

Table 9. Forecasts for Annual U.S. Wind Capacity Additions (MW)

\begin{tabular}{|l|c|c|c|c|c|}
\hline Source & $\mathbf{2 0 0 9}$ & $\mathbf{2 0 1 0}$ & $\mathbf{2 0 1 1}$ & $\mathbf{2 0 1 2}$ & $\begin{array}{c}\text { Cumulative Additions } \\
\mathbf{2 0 0 9 - 2 0 1 2}\end{array}$ \\
\hline EIA & 4,400 & 10,400 & 11,900 & 13,700 & 40,400 \\
\hline BTM & 6,000 & 8,500 & 10,000 & 13,000 & 37,500 \\
\hline EER & 6,500 & 9,000 & 11,000 & 10,000 & 36,500 \\
\hline NEF & $4,900-6,800$ & na & na & na & na \\
\hline AWEA & $>5,000$ & na & na & na & na \\
\hline
\end{tabular}

Source: EIA (2009), BTM (2009), Hays (2009), NEF (2009), AWEA (2009a)

Notwithstanding the slowdown in 2009, U.S. manufacturing of turbines and components is also anticipated to continue to grow, as already-announced manufacturing facilities come on line, as existing facilities reach full capacity and expand, and as new announcements and investments are made. In part as a result, and in a continuation of recent trends, the historically-dominant wind turbine suppliers in the U.S. market are likely to face growing competition from new entrants over this timeframe.

Uncertainties about market performance in the near- to medium-term reflect a balance among countering trends. On the positive side, the wind industry now has stronger federal policy support than at any time in the last decade, and state policies have become more aggressive. 
Additionally, there are reasonable prospects for further policy support through some combination of federal RPS legislation, climate legislation, and policies intended to spur new transmission investments, as well as continued state renewable energy and climate policy initiatives. With wind turbine prices now dropping, the trend of increasing project-level costs and prices experienced over the last several years may also be slowing or even reversing, which may improve the comparative economic position of wind.

At the same time, the duration of the financial crisis remains uncertain, and the degree to which the stimulus bills (and their implementation) will alleviate the impacts of that crisis on the wind sector is similarly uncertain. Natural gas prices and near-term price expectations have plummeted, making wind's primary competitor seemingly more economically attractive than in recent years past. And, with the much-lower wholesale market prices witnessed in the last months of 2008 and the first months of 2009, merchant wind development - which has grown dramatically in recent years - is likely to slow for the near future. Moreover, wind additions are increasingly constrained by inadequate transmission infrastructure, and while progress is being made to alleviate those constraints, the build-out of transmission infrastructure will take time. Finally, with the extension and expansion of federal policy support for other renewable energy sources, wind may face increased competition from other renewable generation options such as solar, geothermal, and biomass.

Notwithstanding these uncertainties, wind capacity additions over the past several years, and projected in the near- to medium-term, puts the U.S. on an early track to meet $20 \%$ of the nation's electricity demand with wind power by 2030. In May 2008, the U.S. Department of Energy, in collaboration with its national laboratories, the wind industry, and others, published a report that analyzed the technical and economic feasibility of achieving $20 \%$ wind penetration by 2030 (U.S. DOE 2008). In addition to finding no insurmountable barriers to reaching $20 \%$ wind penetration, the report also established a wind deployment path that started at $3.3 \mathrm{GW} /$ year in 2007, increasing to $4.2 \mathrm{GW} /$ year by $2009,6.4 \mathrm{GW} /$ year by $2011,9.6 \mathrm{GW} /$ year by $2013,13.4$ $\mathrm{GW} /$ year by 2015 , and roughly $16 \mathrm{GW} /$ year by 2017 and thereafter, yielding a cumulative wind capacity of $305 \mathrm{GW}$ by 2030 . Historical growth over the last three years puts the U.S. ahead of schedule vis-à-vis this deployment path, and projected growth from EER (Hays 2009) over the next four years would ensure that the U.S. remains in that position through 2012 (Figure 31). 


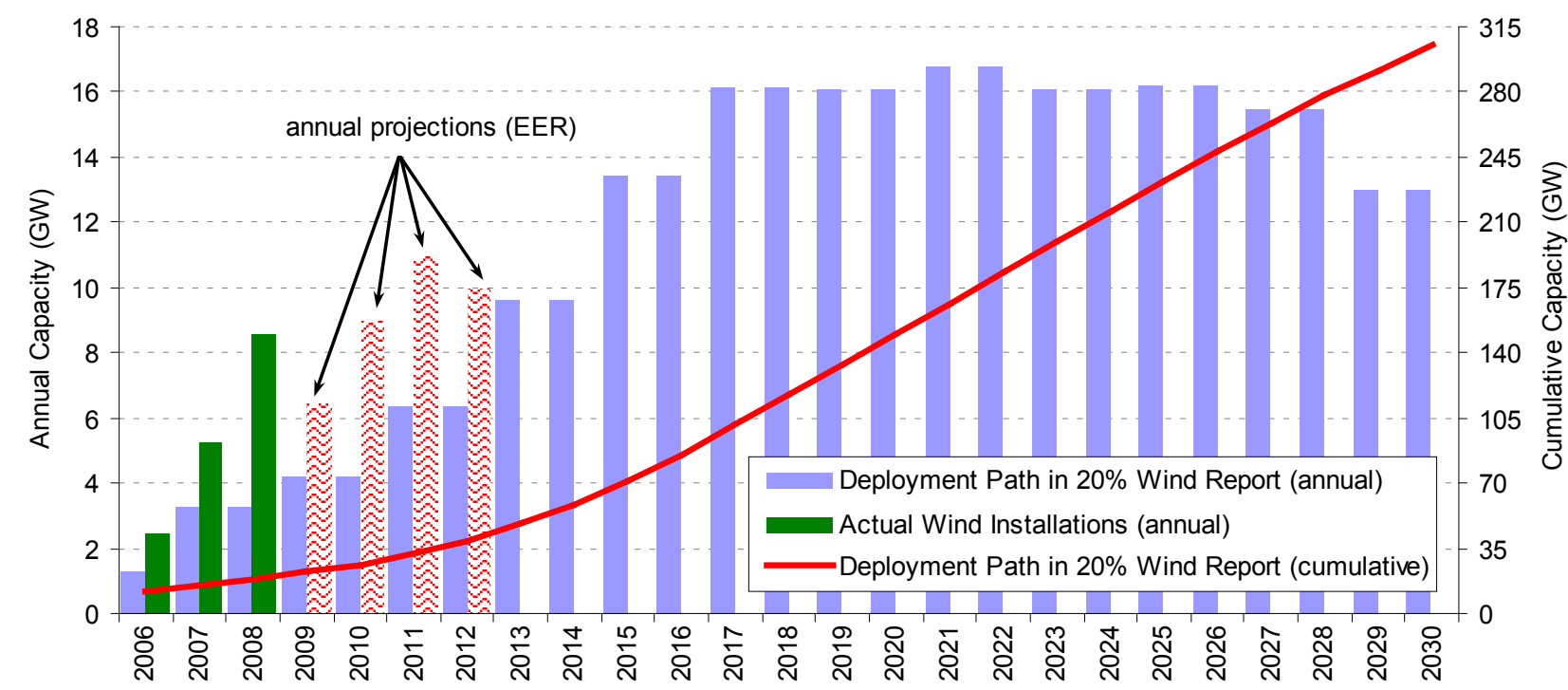

Source: U.S. DOE (20\% wind scenario); AWEA (historical additions); EER (forecasted additions)

Figure 31. Wind Capacity Growth: $20 \%$ Wind Report, Actual Installations, Forecasted Growth

Ramping up to an annual installation rate of $16 \mathrm{GW}$ per year by 2017, and maintaining that rate for the following decade, is, however, far from pre-determined. The record $8.5 \mathrm{GW}$ installation pace in 2008 was achieved, in part, because of the then-pending expiration of the PTC, and it remains to be seen whether the wind market can support the sustained $16 \mathrm{GW} /$ year pace needed for wind to contribute $20 \%$ of the nation's electricity by 2030 . In addition to stable, long-term promotional policies, the U.S. DOE (2008) report suggests four other areas where supportive actions are likely to be needed. First, the nation will need to invest in significant amounts of new transmission infrastructure designed to access remote wind resources. Second, to moreeffectively integrate wind into electricity markets, larger power control regions, better wind forecasting, and increased investment in fast-responding generating plants will be required. Third, streamlined siting and permitting procedures will need to be established to allow wind developers to identify appropriate project locations and move from wind resource prospecting to construction quickly. Finally, enhanced research and development efforts in both the public and private sector will be required to lower the cost of offshore wind power, and incrementally improve conventional onshore wind technology. 


\section{Appendix: Sources of Data Presented in this Report}

\section{Wind Installation Trends}

Data on wind power additions in the United States come from AWEA. Annual wind capital investment estimates derive from multiplying these wind capacity data by weighted-average capital cost data, provided elsewhere in the report. Data on non-wind electric capacity additions come primarily from the EIA (for years prior to 2008) and Ventyx's Energy Velocity database (for 2008), except that solar data come from the Interstate Renewable Energy Council (IREC) and Berkeley Lab. Data on the distributed wind segment come from AWEA (2009b). Information on offshore wind development activity in the U.S. was compiled by NREL.

Global cumulative (and 2008 annual) wind capacity data come from BTM (2009), but are revised to include the most recent AWEA data on U.S. wind capacity. Historical cumulative and annual worldwide capacity data come from BTM Consult and the Earth Policy Institute. Wind as a percentage of country-specific electricity consumption is based on end-of-2008 (and end-of2006/07) wind capacity data and country-specific assumed capacity factors that primarily come from BTM (2009). For the United States, the performance data presented in this report are used to estimate wind production. Country-specific projected wind generation is then divided by projected electricity consumption in 2009 (and 2007/08), based on actual 2006 consumption and a country-specific growth rate assumed to be the same as the rate of growth from 2001 through 2006 (these data come from the EIA (2008)).

The wind project installation map of the United States was created by NREL, based in part on AWEA's database of wind power projects and in part on data from Platts on the location of individual wind power plants. Effort was taken to reconcile the AWEA project database and the Platts-provided project locations, though some discrepancies remain. Wind as a percentage contribution to statewide electricity generation is based on AWEA installed capacity data for the end of 2008 and the underlying wind project performance data presented in this report. Where necessary, judgment was used to estimate state-specific capacity factors. The resulting state wind generation is then divided by in-state total electricity generation in 2008, based on EIA data.

Data on wind capacity in various interconnection queues come from a review of publicly available data provided by each ISO, RTO, or utility. Only projects that were active in the queue at the end of 2008, but that had not yet been built, are included. Suspended projects are not included in these listings.

\section{Wind Capacity Serving Electric Utilities}

The listing of wind capacity serving specific electric utilities comes from AWEA's Annual Wind Industry Report (AWEA 2009a). To translate this capacity to projected utility-specific annual electricity generation, regionally appropriate wind capacity factors are used. The resulting utility-specific projected wind generation is then divided by the aggregate national retail sales of each utility in 2007 (based on EIA Form-861 data). Only utilities with 100 MW or more of wind capacity are included in these calculations. In the case of G\&T cooperatives and power authorities that provide power to other cooperatives and municipal utilities (but do not directly serve load themselves), this report uses 2007 retail sales from the electric utilities served by those 
G\&T cooperatives and power authorities. In some cases, these individual utilities may be buying additional wind directly from other projects, or may be served by other G\&T cooperatives or power authorities that supply wind. In these cases, the penetration percentages shown in the report may be somewhat misleading. Finally, some of the entities shown in Table 3 are wholesale power marketing companies that are affiliated with electric utilities. In these cases, estimated wind generation is divided by the retail sales of the power marketing company and any affiliated electric utilities.

\section{Turbine Manufacturing, Turbine Size, and Project Size}

Turbine manufacturer market share, average turbine size, and average project size are derived from the AWEA wind project database. Information on wind turbine and component manufacturing come from NREL, AWEA, and Berkeley Lab, based on a review of press reports, personal communications, and other sources. The listings of manufacturing and supply chain facilities are not intended to be exhaustive. Information on wind developer consolidation and financing trends were compiled by Berkeley Lab. Wind project ownership and power purchaser trends are based on a Berkeley Lab analysis of the AWEA project database.

\section{Wind Power Prices and Wholesale Market Prices}

Wind power price data are based on multiple sources, including prices reported in FERC's Electronic Quarterly Reports, FERC Form 1, avoided cost data filed by utilities, pre-offering research conducted by bond rating agencies, and a Berkeley Lab collection of power purchase agreements.

Wholesale power price data were compiled by Berkeley Lab from the IntercontinentalExchange (ICE) as well as Ventyx's Energy Velocity database (which itself derives wholesale price data from the ICE and the various ISOs). Earlier years' wholesale power price data come from FERC (2007, 2005).

REC price data were compiled by Berkeley Lab based on information provided by Evolution Markets and Spectron, and represent the mid-point between REC price "bids" and "offers."

\section{Installed Project and Turbine Costs}

Berkeley Lab used a variety of public and some private sources of data to compile capital cost data for a large number of U.S. wind power projects. Data sources range from pre-installation corporate press releases to verified post-construction cost data. Specific sources of data include: EIA Form 412, FERC Form 1, various Securities and Exchange Commission filings, various filings with state public utilities commissions, Windpower Monthly magazine, AWEA's Wind Energy Weekly, DOE/EPRI's Turbine Verification Program, Project Finance magazine, various analytic case studies, and general web searches for news stories, presentations, or information from project developers. Some data points are suppressed in the figures to protect data confidentiality. Because the data sources are not equally credible, little emphasis should be placed on individual project-level data; instead, it is the trends in those underlying data that offer insight. Only wind power cost data from the contiguous lower-48 states are included.

Wind turbine transaction prices were compiled by Berkeley Lab. Sources of transaction price data vary, but most derive from press releases and press reports. In part because wind turbine 
transactions vary in the services offered, a good deal of intra-year variability in the cost data is apparent. Additionally, the data do not adequately capture the rumored softening of the wind turbine market in late 2008, as few publicly reported wind turbine sales transactions were identified during this period.

\section{Wind Project Performance}

Wind project performance data are compiled overwhelmingly from two main sources: FERC's Electronic Quarterly Reports and EIA Form 923. Additional data come from FERC Form 1 filings and, in several instances, other sources. Where discrepancies exist among the data sources, those discrepancies are handled based on the judgment and experience of Berkeley Lab staff.

\section{Wind Project Operations and Maintenance Costs}

Wind project operations and maintenance costs come primarily from two sources: EIA Form 412 data from 2001-2003 for private power projects and projects owned by POUs, and FERC Form 1 data for IOU-owned projects. Some data points are suppressed in the figures to protect data confidentiality.

\section{Wind Integration, Transmission, and Policy}

The wind integration, transmission, and policy sections were written by staff at Berkeley Lab, NREL, and Exeter Associates, based on publicly available information. 


\section{References}

Acker, T. 2007. Arizona Public Service Wind Integration Cost Impact Study. Prepared for Arizona Public Service Company. Flagstaff, Arizona: Northern Arizona University.

American Wind Energy Association (AWEA). 2009a. Annual Wind Industry Report: Year Ending 2008. Washington, DC: American Wind Energy Association.

American Wind Energy Association (AWEA). 2009b. AWEA Small Wind Turbine Global Market Study: Year Ending 2008. Washington, DC: American Wind Energy Association.

Bolinger, M., R. Wiser, K. Cory, T. James. 2009. PTC, ITC, or Cash Grant? An Analysis of the Choice Facing Renewable Power Projects in the United States. LBNL-1642E. Berkeley, California: Lawrence Berkeley National Laboratory.

Brooks, D., E. Lo, R. Zavadil, S. Santoso, J. Smith. 2003. Characterizing the Impact of Significant Wind Generation Facilities on Bulk Power System Operations Planning: Xcel Energy - North Case Study. Prepared for the Utility Wind Integration Group. Arlington, Virginia: Electrotek Concepts.

BTM. 2009. International Wind Energy Development: World Market Update 2008. Ringkobing, Denmark: BTM Consult ApS.

California ISO (CAISO). 2007. Integration of Renewable Resources. Folsom, California: California Independent System Operator.

Chadbourne \& Parke. 2009. "Trends in Tax Equity for Renewable Energy." Project Finance Newswire. January 2009, pp. 27-34.

Chadbourne \& Parke. 2008. "State of the Tax Equity Market." Project Finance Newswire. November 2008, pp. 22-36.

Chupka, M. and G. Basheda. 2007. Rising Utility Construction Costs: Sources and Impacts. Washington, DC: The Edison Foundation.

Eber, J. 2009. Presentation at WINDPOWER 2009, Chicago, Illinois, May 6, 2009.

Electrotek Concepts, Inc. 2003. Systems Operations Impacts of Wind Generation Integration Study. Prepared for We Energies. Knoxville, Tennessee: Electrotek Concepts.

Energy Information Administration (EIA). 2009. Annual Energy Outlook 2009 (Updated Reference Case Service Report, April 2009). DOE/EIA-0383(2009). Washington D.C.: Energy Information Administration.

Energy Information Administration (EIA). 2008. International Energy Annual 2006.

Washington D.C.: Energy Information Administration.

EnerNex Corp. and Wind Logics, Inc. 2004. Wind Integration Study-Final Report. Prepared for Xcel Energy and Minnesota Department of Commerce. Knoxville, Tennessee: EnerNex Corporation.

EnerNex Corp. 2006. Wind Integration Study for Public Service Company of Colorado. Prepared for Xcel Energy. Denver, Colorado. 
EnerNex Corp. and Windlogics Inc. 2006. Final Report-2006 Minnesota Wind Integration Study, Volume I. Prepared for the Minnesota Public Utilities Commission. Knoxville, Tennessee: EnerNex Corporation.

EnerNex Corp. 2007. Final Report Avista Corporation Wind Integration Study. Knoxville, Tennessee: EnerNex Corporation.

EnerNex Corp. and Idaho Power Co. 2007. Operational Impacts of Integrating Wind Generation into Idaho Power's Existing Resource Portfolio: Report Addendum. Boise, Idaho: Idaho Power Company.

EnerNex Corp. 2008. Wind Integration Study for Public Service of Colorado, Addendum, Detailed Analysis of 20\% Wind Penetration. Prepared for Xcel Energy. Denver, Colorado: Xcel Energy.

European Wind Energy Association (EWEA). 2009. "Wind Now Leads EU Power Sector." EWEA Press Release, February 2, 2009.

Federal Energy Regulatory Commission (FERC). 2007. 2006 State of the Markets Report. Washington, DC: Federal Energy Regulatory Commission.

Federal Energy Regulatory Commission (FERC). 2005. 2004 State of the Markets Report. Washington, DC: Federal Energy Regulatory Commission.

Forsyth, T., I. Baring-Gould. 2007. Distributed Wind Market Applications. NREL/TP-50039871. Golden, Colorado: National Renewable Energy Laboratory.

GE Energy Consulting. 2008. Analysis of Wind Generation Impact on ERCOT Ancillary Services Requirements. Prepared for the Electricity Reliability Council of Texas. Schenectady, New York: GE Energy.

GE Energy Consulting. 2005. The Effects of Integrating Wind Power on Transmission System Planning, Reliability, and Operations: Report on Phase 2. Prepared for the New York State Energy Research \& Development Authority. Schenectady, New York: GE Energy.

Goodwin, M. 2009. “Turbine and EPC Price Trends.” WINDPOWER 2009, Chicago, Illinois, May 5, 2009.

Hays, K. 2009. "Wind in the Mix: Staying Competitive in the Downturn." WINDPOWER 2009, Chicago, Illinois, May 5, 2009.

IHS CERA. 2008. "IHS CERA Power Capital Costs Index Shows Power Plant Construction Costs Decreasing Slightly." CERA Press Release. December 17, 2008.

New Energy Finance (NEF). 2009. Q1 Wind Industry Outlook. April 2009. London, UK: New Energy Finance.

North American Electric Reliability Corporation (NERC). 2008. 2008 Long-Term Reliability Assessment, 2008-2017. Princeton, New Jersey: North American Electric Reliability Corporation.

North American Electric Reliability Corporation (NERC). 2009. Accommodating High Levels of Variable Generation. Princeton, New Jersey: North American Electric Reliability Corporation. 
PacifiCorp. 2005. Technical Appendix for the 2004 Integrated Resource Plan. Portland, Oregon: PacifiCorp.

PacifiCorp. 2007. Technical Appendix for the 2007 Integrated Resource Plan. Portland, Oregon: Pacificorp.

Porter, K., S. Fink, C. Mudd, J. DeCesaro. 2009. Generation Interconnection Policies and Wind Power: A Discussion of Issues, Problems, and Potential Solutions. NREL/SR-550-44508. Denver, Colorado: National Renewable Energy Laboratory.

Porter, K. and Intermittency Analysis Project Team. 2007. Intermittency Analysis Project: Summary of Final Results. Sacramento, California: California Energy Commission, PIER Research Development \& Demonstration Program.

Puget Sound Energy. 2007. 2007 Integrated Resource Plan, Appendix G-Wind Integration Studies. Bellevue, Washington: Puget Sound Energy.

Shiu, H., M. Milligan, B. Kirby, K. Jackson. 2006. California Renewables Portfolio Standard Renewable Generation Cost Analysis: Multi-Year Analysis Results and Recommendations. Consultant report prepared by the California Wind Energy Collaborative. Sacramento, California: California Energy Commission.

U.S. Department of Energy. 2008. 20\% Wind Energy by 2030: Increasing Wind Energy's Contribution to U.S. Electricity Supply. DOE/GO-102008-2567. Washington, D.C.: U.S. Department of Energy. 


\section{Wind Energy Web Sites}

\section{U.S. Department of Energy Wind and Hydropower Technologies Program}

www.eere.energy.gov/windandhydro/

\section{American Wind Energy Association}

www.awea.org

\section{Lawrence Berkeley National Laboratory}

eetd.lbl.gov/ea/ems/re-pubs.html

\section{National Renewable Energy Laboratory National Wind Technology Center} www.nrel.gov/wind/

\section{NREL Wind Systems Integration}

www.nrel.gov/wind/systemsintegration/

\section{Sandia National Laboratories}

www.sandia.gov/wind/

\section{National Wind Coordinating Collaborative}

www.nationalwind.org/

\section{Utility Wind Integration Group}

www.uwig.org

\section{Wind Powering America}

www.eere.energy.gov/windandhydro/windpoweringamerica/

\section{Key Report Contacts}

For more information on this report, please contact:

Ryan Wiser, Lawrence Berkeley National Laboratory

510-486-5474; RHWiser@lbl.gov

Mark Bolinger, Lawrence Berkeley National Laboratory

603-795-4937; MABolinger@lbl.gov

\section{On the Cover}

Installation of wind turbines, such as these in Montana, continued to grow in 2008.

Klaus Obel/PIX 16082

U.S. DEPARTMENT OF

\section{ENERGY}

Energy Efficiency \& Renewable Energy
Prepared by the National Renewable Energy Laboratory (NREL) NREL is a national laboratory of the U.S. Department of Energy Office of Energy Efficiency and Renewable Energy Operated by the Alliance for Sustainable Energy, LLC
For more information contact: EERE Information Center 1-877-EERE-INF (1-877-337-3463) www.eere.energy.gov/informationcenter 